\title{
Allosteric Cooperativity and Template-Directed Synthesis with Stacked Ligands in Porphyrin Nanorings
}

\author{
Pernille S. Bols, Michel Rickhaus, ${ }^{\ddagger}$ Lara Tejerina, ${ }^{\ddagger}$ Henrik Gotfredsen, Kristina Eriksen, \\ Michael Jirasek and Harry L. Anderson* \\ Department of Chemistry, University of Oxford, Chemistry Research Laboratory, \\ Oxford OX1 3TA, United Kingdom
}

$\left({ }^{\ddagger}\right.$ These authors contributed equally)

Table of Contents

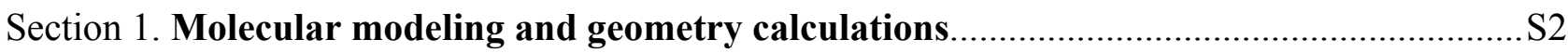

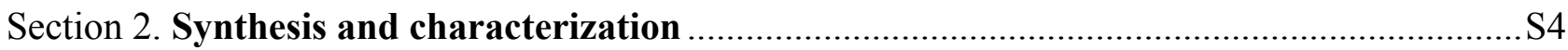

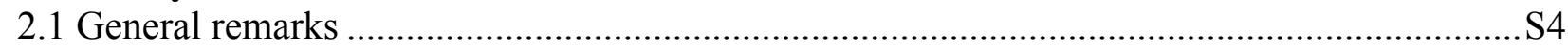

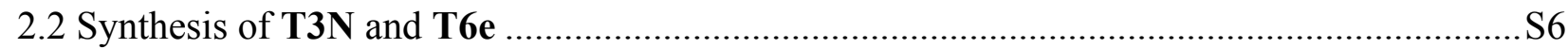

2.3 NMR and mass spectra of new compounds ...................................................................... 10

$2.4{ }^{1} \mathrm{H}$ NMR spectra of stacked nanoring-template complexes .................................................. 22

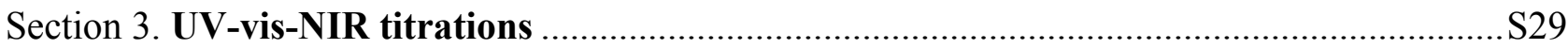

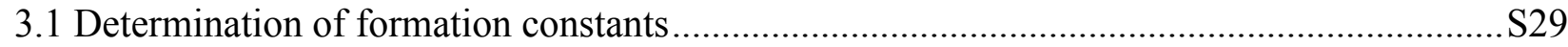

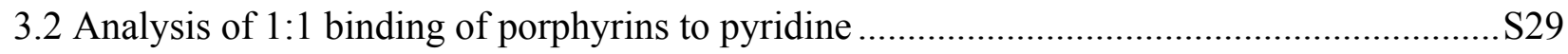

3.3 Analysis of 'all-or-nothing' denaturation of a 1:2 complex...................................................S30

3.4 Using ReactLab Equilibria to determine equilibrium constants .........................................S32

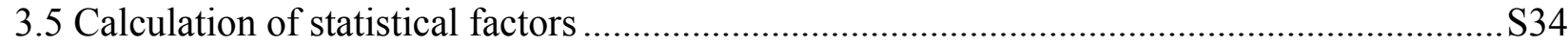

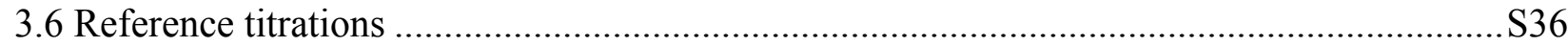

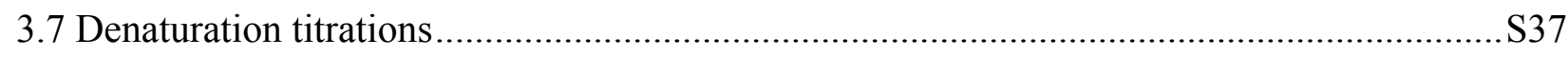

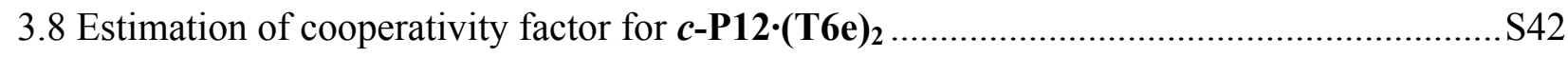

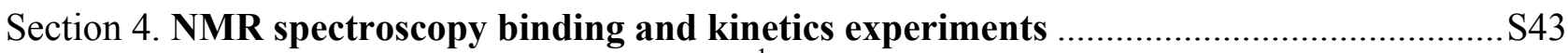

4.1 Confirmation of equilibrium constants by ${ }^{1} \mathrm{H}$ NMR spectroscopy .........................................S43

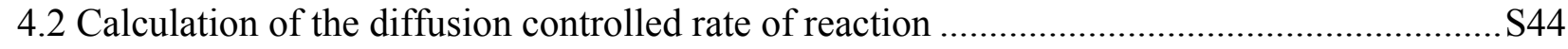

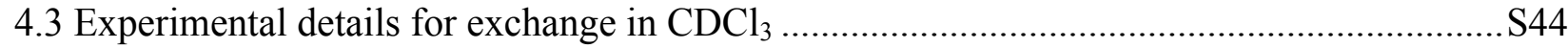

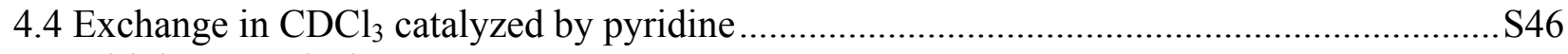

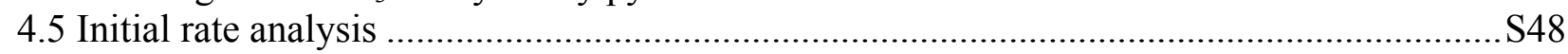

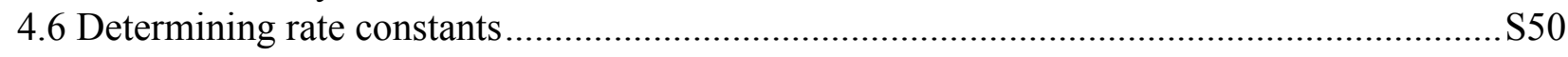

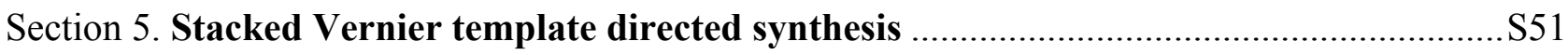

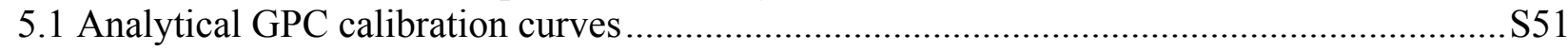

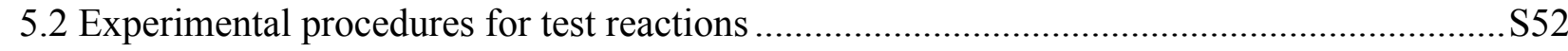

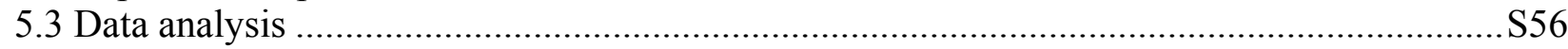

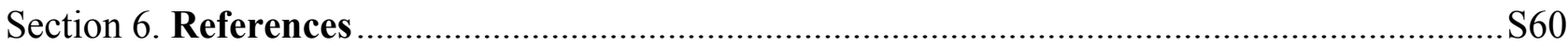




\section{Molecular modeling and geometry calculations}

Calculations of model geometries of nanorings and templates were simplified by replacing aryl and octyl solubilizing groups with hydrogen atoms. Geometries were optimized using Gaussian16/A.03 [ref. 1] and either DFT (B3LYP/3-21G functional/basis set, used for $\boldsymbol{c}$-P6·(T3),$c$-P6·(T3N) $)_{2}$, T3 and T3N) or semiempirical PM6 method (used for $c-P 12 \cdot(\text { T6e) })_{2}$ and T6e). Optimized geometries were confirmed as local minima by performing frequency calculation which showed no imaginary frequencies, with exception of T6e, for which frequency calculation revealed two imaginary frequencies of -1.6 and $-0.9 \mathrm{~cm}^{-1}$, to which is attributed no significance.

Geometry optimizations for $\boldsymbol{c}$-P12.(T6e) $)_{2}$ always converged to structures in which the $12 \mathrm{Zn}$ atoms are coplanar (maximum deviation from the plane $\pm 0.1 \AA$ ). Contrary to our expectation, the minimized geometry does not possess equivalent T6e molecules, regardless of the symmetric or anti-symmetric $\left(C_{6}\right.$ vs. $\left.S_{12}\right)$ arrangement of propellers formed by the T6e 'spokes'. One template unit is essentially within the nanoring plane, with the second template stacked on top of it in a domed shape. The centers of the templates are stacked at separation of $3.7 \AA$. The $\mathrm{Zn}-\mathrm{N}$ distance for nanoring-template interaction is $2.11 \AA$ for all 12 sites, which agrees with interaction distance observed in crystal structures $(2.15 \pm 0.02 \AA){ }^{2}$ We attempted to find a more symmetric structure with potentially $S_{12}$ symmetry, in which both templates bear equal amounts of doming. All geometry searches (e.g. optimization starting from perfect $S_{12}$ symmetric model and several times reoriented with various constrains and frequency calculations to help the search) did not converged to this $S_{12}$ symmetric structure (i.e. the criteria for maximum atom displacement and energy changes were not met using default thresholds as implemented in Gaussian 16), but rather eventually escaped to the unsymmetrical structure

To explore the potential energy surface of $c$-P12.(T6e) $)_{2}$, scan calculations were carried out to mimic the template bowl-flattening motion (Table S1 and Figure S1). During each step of the scan, the position of the midpoint of the two T6e templates was constrained relative to the plane of the whole complex and the geometry was re-optimized with loose optimization criteria (as implemented in Gaussian16). Frequency calculation performed on the $S_{12}$ symmetric conformer, which has the T6e templates midpoint in plane of the $\mathrm{Zn}$ atoms, confirmed that it represents transition state with one imaginary frequency. Electronic energy of such structure is, however, very close to the true minimum $(+2.5 \mathrm{~kJ} / \mathrm{mol})$ and it is reasonable to assume that all examined geometries are populated under ambient conditions and that the bowl-flat interchange is rapid.

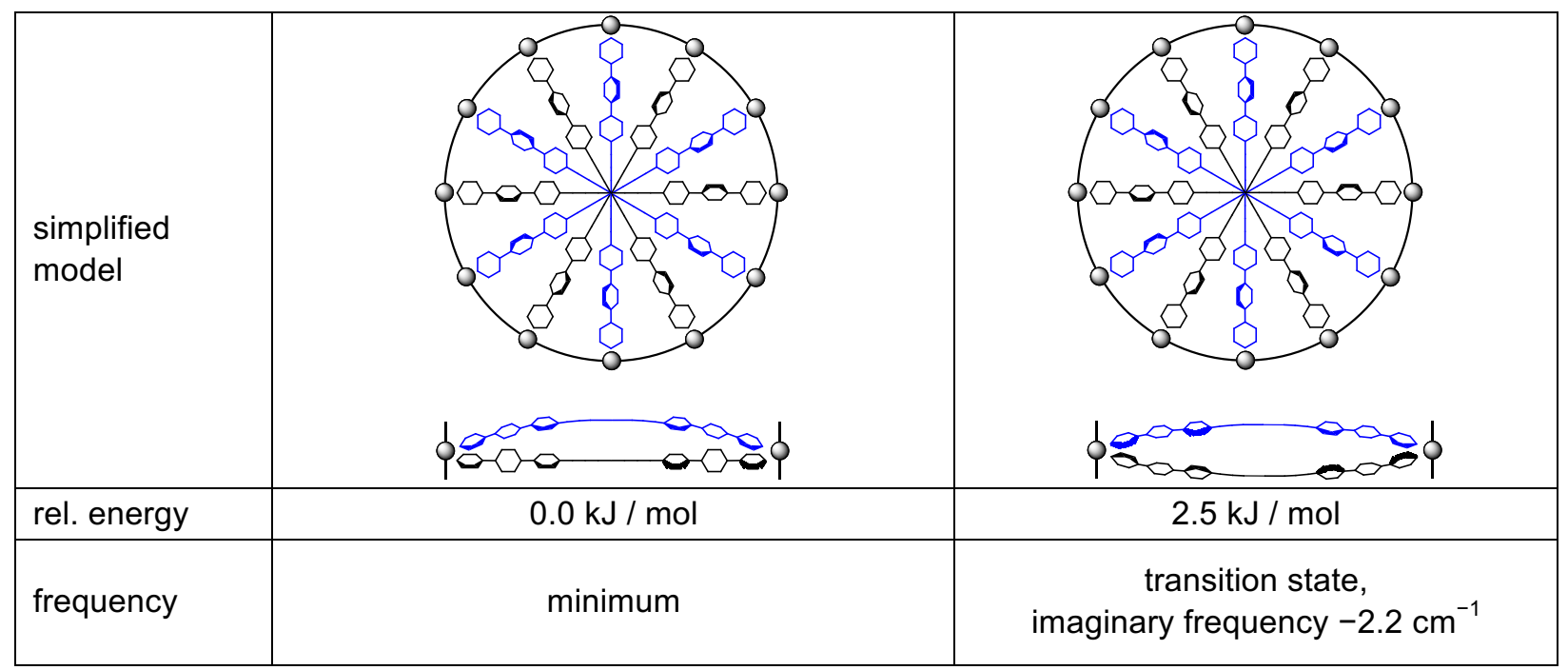

Table S1. Summary of qualitative symmetric arrangement and relative energies of important geometries of complex c-P12·(T6e) $)_{2}$. 

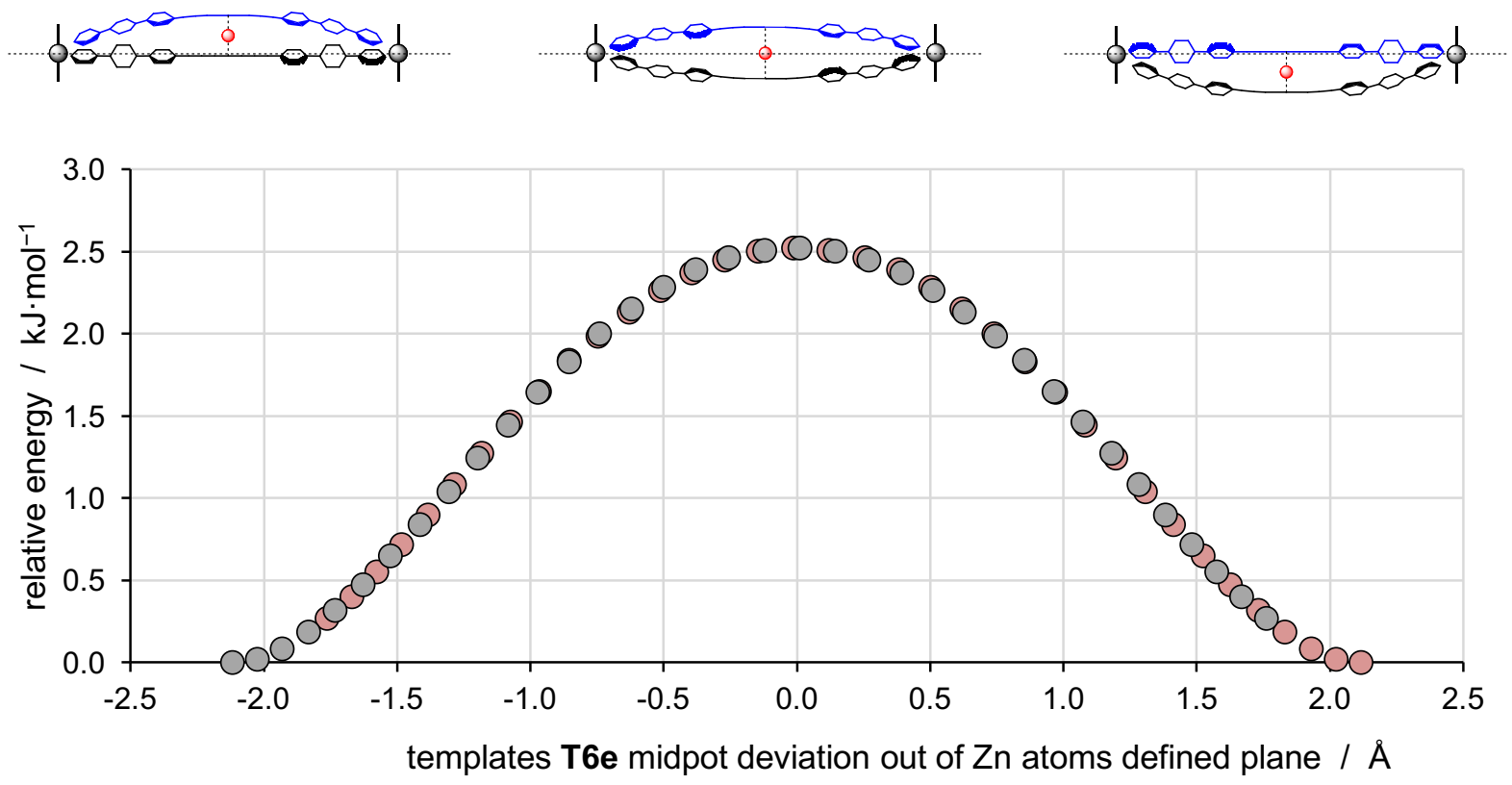

Figure S1. Relative energy of $c-P 12 \cdot(T 6 e)_{2}$ conformers as a function of T6e midpoint deviation out of the plane of the nanoring as scanned in forward (grey circles) and backward (orange circles) direction (PM6).

In contrast to the $\boldsymbol{c}$-P12 $\cdot(\mathbf{T 6 e})_{2}$ complex, the smaller nanoring $\boldsymbol{c}$-P6 adopts a saddle shape in the template complexes $\boldsymbol{c}-\mathbf{P 6} \cdot(\mathbf{T 3})_{2}$ and $\boldsymbol{c}-\mathbf{P 6} \cdot(\mathbf{T 3 N})_{2}$. This distortion can be quantified by fitting the surface function $z=f(x, y)$ to core atoms positions (butadiyne and to it connected meso carbon atoms and zinc porphyrin centers). For $\boldsymbol{c}$-P6 $(\text { T3 })_{2}$, positions of these core atoms can be well fitted with function: $z=-0.6401+0.01699 \cdot x^{2}-0.009104 \cdot y^{2}$, (where $x, y, z$ are coordinates of core atoms in $\AA$ of structure re-oriented to have allow best fit) with fit quality $R^{2}=0.97$. The centers of the T3 templates are stacked apart at distance of $4.0 \AA$. Saddle geometry of $\boldsymbol{c}$-P6 $(\mathbf{T 3 N})_{2}$ is slightly twisted diagonally relative to $\boldsymbol{c}$-P6 $(\mathbf{T 3})_{2}$. Positions of core atoms can be well fitted with function: as $z=-1.923+$ $0.02447 \cdot x^{2}-0.007992 \cdot x \cdot y$, with $R^{2}=0.97$. The centers of the $\mathbf{T 3 N}$ templates are stacked apart at distance of $3.5 \AA$. 


\section{Synthesis and Characterization}

2.1. General Remarks. All reagents (Acros, Aldrich, Fluorochem, and TCI) were purchased as reagent grade and used without further purification. Solvents for extraction or column chromatography were used in HPLC grade. Dry solvents for reactions were purified by the solvent drying system MBraun MB-SPS-5- Bench Top under nitrogen atmosphere $\left(\mathrm{H}_{2} \mathrm{O}\right.$ content $<20$ ppm as determined by Karl Fischer titration). Diisopropylamine was dried over calcium hydride and freshly distilled before use. 1,4-Diazabicyclo[2.2.2] octane (DABCO) was dried by addition and evaporation of benzene and recrystallized from diethyl ether. Flash column chromatography was performed using $\mathrm{SiO}_{2}(60 \AA$, 230-400 mesh, particle size $0.040-0.063 \mathrm{~mm}$, Merck) at $25^{\circ} \mathrm{C}$ with a head pressure of $0.4-0.8 \mathrm{bar}$. Analytical thin layer chromatography (TLC) was performed on aluminum sheets coated with silica gel 60 F254 (Merck). Visualization was achieved using UV light (254 or $366 \mathrm{~nm}$ ). Evaporation in vacuum was performed at $25-60{ }^{\circ} \mathrm{C}$ and $900-10$ mbar. Reported yields refer to spectroscopically and chromatographically pure compounds that were dried under high vacuum $(0.01-0.005$ mbar) before analytical characterization.

NMR data were recorded at $500 \mathrm{MHz}$ using a Bruker AVII500 (with DUAL cryoprobe) or DRX500, or at $400 \mathrm{MHz}$ using a Bruker AVII400 or AVIII400, or at $700 \mathrm{MHz}$ using a Bruker AVIII700 (with TCI cryoprobe). Chemical shifts are quoted as parts per million (ppm) relative to residual $\mathrm{CHCl}_{3}\left(\delta_{\mathrm{H}} 7.26 \mathrm{ppm}\right.$ for ${ }^{1} \mathrm{H} \mathrm{NMR}$ and at $\delta_{\mathrm{C}} 77.2 \mathrm{ppm}$ for $\left.{ }^{13} \mathrm{C} \mathrm{NMR}\right)$. Multiplicity $(\mathrm{s}=$ singlet, $\mathrm{d}=$ doublet, $\mathrm{t}=$ triplet, $\mathrm{q}=$ quartet, $\mathrm{m}=$ multiplet) and coupling constants were reported whenever possible.

${ }^{1} \mathrm{H}$ NMR signals were assigned based on comparison between compounds, chemical shifts, integrals and coupling constants. MALDI-TOF spectra were measured at the EPSRC National Mass Spectrometry service (Swansea) using a Bruker MicroflexTM LRF and DCTB matrix. ESI mass spectra were collected using a Waters LCT Premier (LRMS) operating in positive mode. UV-vis-NIR absorbance measurements were recorded at $25^{\circ} \mathrm{C}$ with a Perkin-Elmer Lambda 20 photospectrometer using quartz $1 \mathrm{~cm}$ cuvettes and temperature was controlled by a PTP-1 peltier unit from Perkin Elmer. Unless stated otherwise, measurements were carried out at $25^{\circ} \mathrm{C}$ under ambient conditions. Molar absorption coefficients $\varepsilon$ are quoted in units of $\mathrm{mol}^{-1} \mathrm{~L} \mathrm{~cm}^{-1}$. Size exclusion chromatography (SEC) was carried out using Bio-Beads S-X1. 

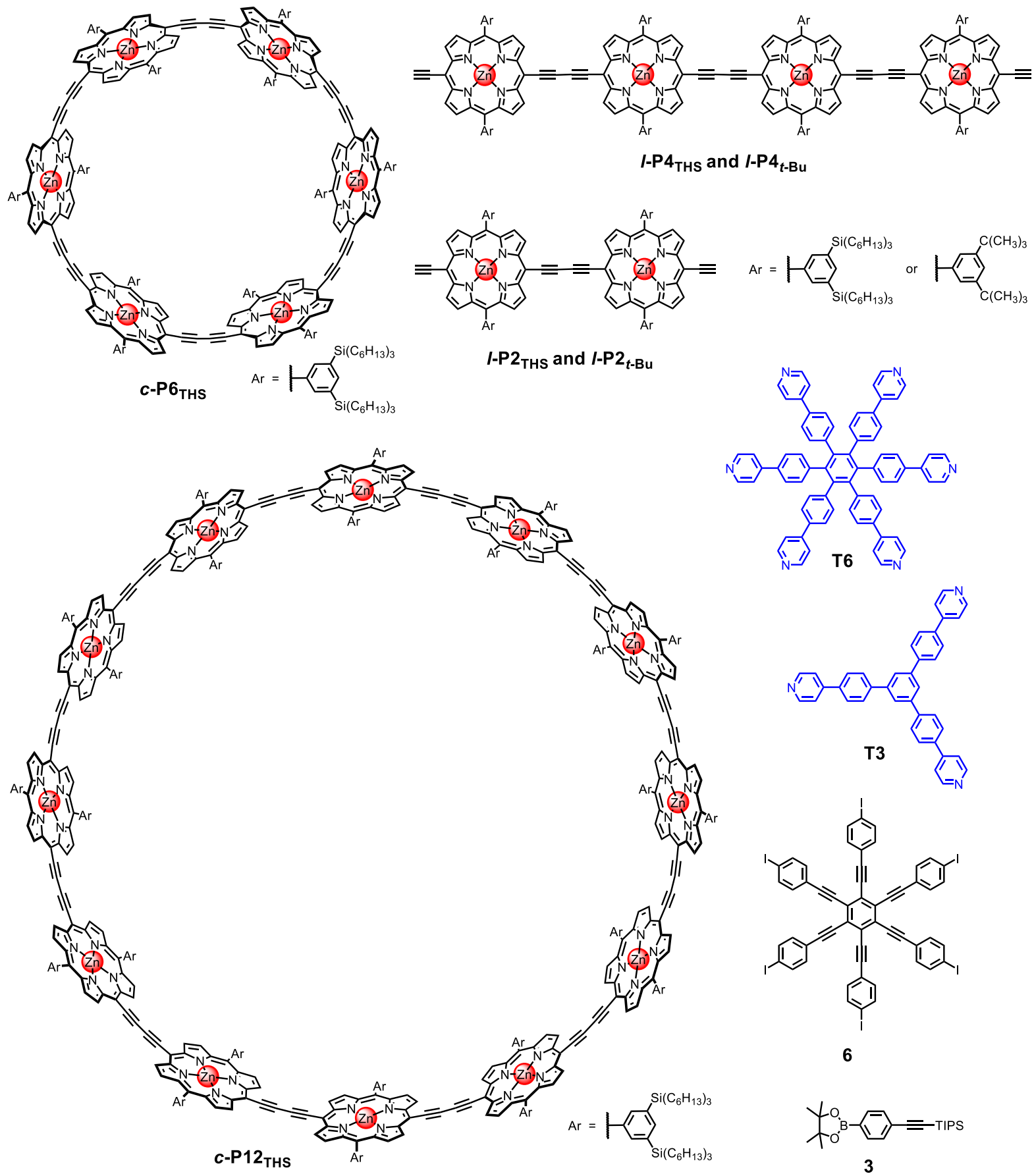

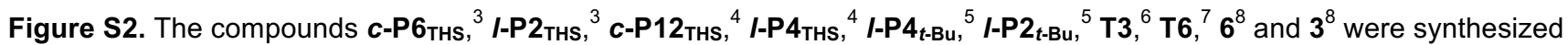
according to literature procedures. 


\subsection{Synthesis of T3N and T6e}

T3N. This known compound ${ }^{9,10}$ was prepared by a similar method to that of Fujita et al. ${ }^{10}$ A mixture of commercially available 2,4,6-tris(4-bromophenyl)-1,3,5-triazine (200 $\mathrm{mg}, 0.37 \mathrm{mmol})$,

$\mathrm{Pd}(\mathrm{dppf}) \mathrm{Cl}_{2} \cdot \mathrm{CH}_{2} \mathrm{Cl}_{2}(51 \mathrm{mg}, 69 \mu \mathrm{mol})$, 4-pyridinylboronic acid (203 $\left.\mathrm{mg}, 1.65 \mathrm{mmol}\right)$ and sodium carbonate $(233 \mathrm{mg}, 2.20 \mathrm{mmol})$ were placed in a round-bottom flask equipped with a condenser.

Dioxane $(12 \mathrm{~mL})$ and water $(6 \mathrm{~mL})$ were added under argon atmosphere and the mixture was stirred under reflux for 3 days. The solvents were then removed under reduced pressure and the residue was purified by column chromatography $\left(\mathrm{SiO}_{2}\right.$; gradient from $\mathrm{CHCl}_{3}$ to mixtures $\mathrm{CHCl}_{3} / \mathrm{MeOH} 100: 1,50: 1$ and 20:1). The product was finally recrystallized from $\mathrm{CHCl}_{3} / \mathrm{MeOH}$ to yield $\mathbf{T 3 N}$ as a white powder (148 mg, 75\%).

${ }^{1} \mathrm{H}$ NMR $\left(400 \mathrm{MHz}, \mathrm{CDCl}_{3}\right): \delta_{\mathrm{H}} 8.91(\mathrm{~d}, J=8.6 \mathrm{~Hz}, 6 \mathrm{H}), 8.74(\mathrm{~d}, J=6.4 \mathrm{~Hz}, 6 \mathrm{H}), 7.87(\mathrm{~d}, J=8.6 \mathrm{~Hz}$, $6 \mathrm{H}), 7.62(\mathrm{~d}, J=6.4 \mathrm{~Hz}, 6 \mathrm{H}) \mathrm{ppm}$.

${ }^{13} \mathrm{C}$ NMR (100 MHz, THF-d 8$): \delta_{\mathrm{C}} 171.4,150.6,147.5,142.4,136.8,129.9,127.4,121.7 \mathrm{ppm}$.

UV-vis-NIR $\left(\mathrm{CHCl}_{3}\right): \lambda_{\max }(\log \varepsilon) 305$ (4.82).

MALDI-ToF MS: $m / z 541$ (calculated for $\left[\mathrm{C}_{36} \mathrm{H}_{24} \mathrm{~N}_{6}\right]^{+}:$540.6). 


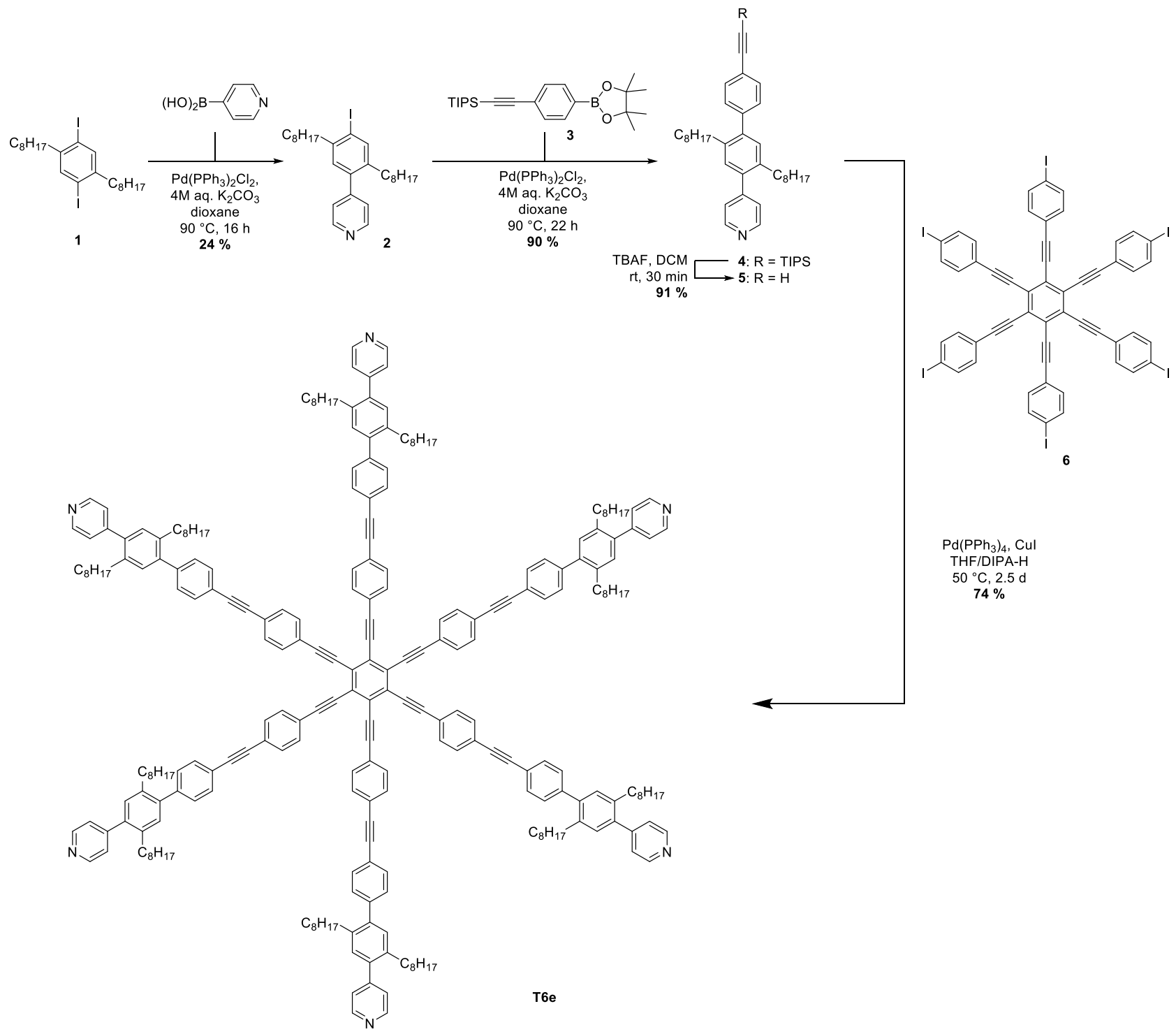

Scheme S1: Synthesis of T6e.

4-(4-Iodo-2,5-dioctylphenyl)pyridine (2). To a deoxygenated mixture of 1,4-diiodo-2,5dioctylbenzene 1 (1.49 g, $2.69 \mathrm{mmol}$ ), pyridine-4-boronic acid hydrate (379 mg, $2.69 \mathrm{mmol}), \mathrm{K}_{2} \mathrm{CO}_{3}$ $(2.23 \mathrm{~g}, 16.2 \mathrm{mmol})$ in dioxane $(25 \mathrm{~mL})$ and water $(5 \mathrm{~mL})$ was added $\mathrm{Pd}\left(\mathrm{PPh}_{3}\right)_{2} \mathrm{Cl}_{2}(94 \mathrm{mg}, 0.13 \mathrm{mmol})$ and the reaction mixture was heated to $90{ }^{\circ} \mathrm{C}$ for $16 \mathrm{~h}$, cooled to $25^{\circ} \mathrm{C}$, filtered through a short pad of $\mathrm{SiO}_{2}\left(\mathrm{EtOAc} / \mathrm{CH}_{2} \mathrm{Cl}_{2}\right.$ 1:1), and concentrated under reduced pressure. Purification by flash column chromatography $\left(\mathrm{SiO}_{2}\right.$, gradient elution: petroleum ether to 1:5 to 2:3 to 1:1 EtOAc / petroleum ether) afforded the title compound (322 mg, 24\%) as a yellow oil.

$R_{\mathrm{f}}=0.44($ EtOAc / petroleum ether 1:5).

${ }^{1} \mathrm{H}$ NMR $\left(400 \mathrm{MHz}, \mathrm{CDCl}_{3}\right) \delta_{\mathrm{H}} 8.67-8.61(\mathrm{~m}, 2 \mathrm{H}, \mathrm{Ar}-\mathrm{H}), 7.74(\mathrm{~s}, 1 \mathrm{H}, \mathrm{Ar}-\mathrm{H}), 7.23-7.19(\mathrm{~m}, 2 \mathrm{H}, \mathrm{Ar}-$ $\mathrm{H}), 6.97$ (s, 1H, Ar-H), 2.71-2.65 (m, 2H, Ar- $\mathrm{CH}_{2}$-heptyl), 2.48-2.42 (m, 2H, Ar-CH $-\mathrm{CH}_{2}$-heptyl), $1.63-$ $1.53\left(\mathrm{~m}, 2 \mathrm{H}\right.$, benzyl- $\mathrm{CH}_{2}$-hexyl), $1.47-1.12\left(\mathrm{~m}, 22 \mathrm{H}, \mathrm{CH}_{2}\right.$ aliphatic), 0.92-0.82 (m, 6H, $\mathrm{CH}_{3}$ aliphatic) ppm. 
${ }^{13} \mathrm{C}$ NMR $\left(126 \mathrm{MHz}, \mathrm{CDCl}_{3}\right) \delta_{\mathrm{C}} 149.84,149.23,143.22,140.35,139.60,139.27,130.00,124.27$, $100.84,40.46,32.20,32.02,31.94,31.45,30.48,29.55,29.54,29.49,29.39,29.33,29.25,22.82$, 22.78, $14.27,14.25 \mathrm{ppm}$.

HRMS (ESI): $m / z$ calcd for $\mathrm{C}_{27} \mathrm{H}_{41} \mathrm{IN}^{+}\left([\mathrm{M}+\mathrm{H}]^{+}\right)$506.22782, found 506.22684.

Compound 4. To a deoxygenated mixture of 4-(4-iodo-2,5-dioctylphenyl)pyridine 2 (484 mg, 0.957 $\mathrm{mmol})$, boronic acid pinacol ester 3 (465 mg, $1.21 \mathrm{mmol}), \mathrm{K}_{2} \mathrm{CO}_{3}(794 \mathrm{mg}, 5.74 \mathrm{mmol})$ in dioxane (12 $\mathrm{mL})$ and water $(4 \mathrm{~mL})$ was added $\mathrm{Pd}\left(\mathrm{PPh}_{3}\right)_{2} \mathrm{Cl}_{2}(67 \mathrm{mg}, 0.096 \mathrm{mmol})$ and the reaction mixture was heated to $90^{\circ} \mathrm{C}$ for $22 \mathrm{~h}$, cooled to $25^{\circ} \mathrm{C}$, filtered through a short pad of $\mathrm{SiO}_{2}\left(\mathrm{EtOAc} / \mathrm{CH}_{2} \mathrm{Cl}_{2} 1: 1\right)$, and concentrated under reduced pressure. Purification by flash column chromatography $\left(\mathrm{SiO}_{2}\right.$, gradient elution: $5 \%$ to $10 \% \mathrm{EtOAc} / \mathrm{CH}_{2} \mathrm{Cl}_{2}$ ) afforded the title compound (549 $\mathrm{mg}, 90 \%$ ) as a yellow oil.

$R_{\mathrm{f}}=0.46\left(\mathrm{EtOAc} / \mathrm{CH}_{2} \mathrm{Cl}_{2}\right)$.

${ }^{1} \mathrm{H}$ NMR $\left(400 \mathrm{MHz}, \mathrm{CDCl}_{3}\right) \delta_{\mathrm{H}} 8.70-8.63(\mathrm{~m}, 2 \mathrm{H}, \mathrm{Ar}-\mathrm{H}), 7.56(\mathrm{~d}, J=8.4 \mathrm{~Hz}, 2 \mathrm{H}, \mathrm{Ar}-\mathrm{H}), 7.32-7.28$ (m, 4H, Ar-H), 7.11 (s, 1H, Ar-H), 7.09 (s, 1H, Ar-H), 2.61-2.50 (m, 4H, Ar-CH2-heptyl), 1.55-1.40 (m, 4H, $\mathrm{CH}_{2}$ aliphatic), 1.32-1.11 (m, 41H, $\mathrm{CH}_{2}$ aliphatic and TIPS), $0.86\left(\mathrm{t}, J=7.0 \mathrm{~Hz}, 6 \mathrm{H}, \mathrm{CH}_{3}\right.$ aliphatic) ppm.

${ }^{13} \mathrm{C}$ NMR $\left(126 \mathrm{MHz}, \mathrm{CDCl}_{3}\right) \delta_{\mathrm{C}} 149.96,149.75,141.82,141.36,138.38,138.03,137.37,131.94$, 131.13, 130.50, 129.24, 124.52, 122.30, 107.13, 91.03, 32.69, 32.61, 31.94, 31.57, 31.51, 29.58, 29.37, $29.26,29.24,22.77,18.83,14.22,11.50 \mathrm{ppm}$ (five signals less than chemically distinct $\mathrm{C}$ atoms in the aliphatic region, presumably due to overlap).

HRMS (ESI): $m / z$ calcd for $\mathrm{C}_{44} \mathrm{H}_{66} \mathrm{NSi}^{+}\left([\mathrm{M}+\mathrm{H}]^{+}\right)$636.49590, found 636.49544 .

Compound 5. To a solution of $4(518 \mathrm{mg}, 0.814 \mathrm{mmol})$ in $\mathrm{CH}_{2} \mathrm{Cl}_{2}(15 \mathrm{~mL})$ was added a solution of tetrabutylammonium fluoride $(1.0 \mathrm{M}$ in THF, $4.1 \mathrm{~mL}, 4.1 \mathrm{mmol})$ and the reaction mixture was stirred for $30 \mathrm{~min}$, filtered through a short pad of $\mathrm{SiO}_{2}\left(\mathrm{EtOAc} / \mathrm{CH}_{2} \mathrm{Cl}_{2} 1: 1\right)$, and concentrated under reduced pressure. Purification by flash column chromatography $\left(\mathrm{SiO}_{2}\right.$, EtOAc / petroleum ether 3:7) and drying in vacuo gave the title compound (357 $\mathrm{mg}, 91 \%)$ as a white solid.

$R_{\mathrm{f}}=0.56($ EtOAc / petroleum ether $)$.

${ }^{1} \mathrm{H}$ NMR $\left(400 \mathrm{MHz}, \mathrm{CDCl}_{3}\right) \delta_{\mathrm{H}} 8.66(\mathrm{~d}, J=6.0 \mathrm{~Hz}, 2 \mathrm{H}, \mathrm{Ar}-\mathrm{H}), 7.56(\mathrm{~d}, J=8.3 \mathrm{~Hz}, 2 \mathrm{H}, \mathrm{Ar}-\mathrm{H}), 7.33-$ 7.28 (m, 4H, Ar-H), $7.11(\mathrm{~s}, 1 \mathrm{H}, \mathrm{Ar}-\mathrm{H}), 7.08(\mathrm{~s}, 1 \mathrm{H}, \mathrm{Ar}-\mathrm{H}), 3.13(\mathrm{~s}, 1 \mathrm{H}, \mathrm{C} \equiv \mathrm{C}-\mathrm{H}), 2.59-2.50(\mathrm{~m}, 4 \mathrm{H}$, Ar- $\left.\mathrm{CH}_{2}\right), 1.51-1.39\left(\mathrm{~m}, 4 \mathrm{H}\right.$, benzyl- $\left.\mathrm{CH}_{2}\right), 1.30-1.13\left(\mathrm{~m}, 20 \mathrm{H}, \mathrm{CH}_{2}\right.$ aliphatic), 0.85 (td, $J=7.0,1.2 \mathrm{~Hz}$, $6 \mathrm{H}, \mathrm{CH}_{3}$ aliphatic) ppm.

${ }^{13} \mathrm{C}$ NMR $\left(126 \mathrm{MHz}, \mathrm{CDCl}_{3}\right) \delta_{\mathrm{C}} 149.94,149.76,142.35,141.19,138.45,138.03,137.43,132.04$, $131.10,130.54,129.38,124.53,120.84,83.70,77.61,32.69,32.63,31.96,31.94,31.62,31.50,29.61$, $29.59,29.37,29.36,29.27,22.79,22.78,14.25,14.24 \mathrm{ppm}$ (one signal coincident or not observed in aliphatic region).

HRMS (ESI): $m / z$ calcd for $\mathrm{C}_{35} \mathrm{H}_{46} \mathrm{~N}^{+}\left([\mathrm{M}+\mathrm{H}]^{+}\right) 480.36248$, found 480.36270 . 
T6e. A solution of deoxygenated THF $(35 \mathrm{~mL})$ and diisopropylamine $(5 \mathrm{~mL})$ was transferred via cannula to a Schlenk flask with $5(150 \mathrm{mg}, 0.31 \mathrm{mmol})$ and $6(37 \mathrm{mg}, 0.026 \mathrm{mmol})$. The reaction mixture was subjected to freeze-pump-thaw cycles (3) and while frozen, $\mathrm{Pd}\left(\mathrm{PPh}_{3}\right)_{4}(12 \mathrm{mg}, 10 \mu \mathrm{mol})$ and $\mathrm{CuI}(2.0 \mathrm{mg}, 10 \mu \mathrm{mol})$ were added. The reaction mixture was subjected to additional freeze-pumpthaw-cycles (3) and heated to $50{ }^{\circ} \mathrm{C}$. At first, undissolved 6 was clearly visible (yellow solid) but after one day the reaction mixture was a clear orange solution. After 2.5 days, the reaction mixture was cooled to room temperature and concentrated under reduced pressure. The crude mixture was subjected to flash column chromatography $\left(\mathrm{SiO}_{2}\right.$, gradient elution: $\mathrm{CHCl}_{3}$ to $1 \%$ to $2.5 \%$ to $5 \%$ to $10 \% \mathrm{MeOH} /$ $\left.\mathrm{CHCl}_{3}\right)$ affording title compound with minor impurities. Repeated flash column chromatography $\left(\mathrm{SiO}_{2}\right.$, $5 \% \mathrm{MeOH} / \mathrm{CHCl}_{3}$ ) followed by precipitation from $\mathrm{CHCl}_{3} / \mathrm{MeOH}$ under reduced pressure. The resulting precipitate was collected on a glass sinter, washed with $\mathrm{MeOH}$, and dried to obtain the title compound (69 mg, 74\%) as a dark orange solid.

$R_{\mathrm{f}}=0.36\left(5 \% \mathrm{MeOH} / \mathrm{CHCl}_{3}\right)$.

${ }^{1} \mathrm{H}$ NMR $\left(500 \mathrm{MHz}, \mathrm{CDCl}_{3}\right) \delta_{\mathrm{H}} 8.67(\mathrm{~d}, J=5.7 \mathrm{~Hz}, 2 \mathrm{H}), 7.71-7.58(\mathrm{~m}, 6 \mathrm{H}), 7.37(\mathrm{~d}, J=8.2 \mathrm{~Hz}, 2 \mathrm{H})$, $7.30(\mathrm{~d}, J=5.7 \mathrm{~Hz}, 2 \mathrm{H}), 7.15(\mathrm{~s}, 1 \mathrm{H}), 7.10(\mathrm{~s}, 1 \mathrm{H}), 2.64-2.49(\mathrm{~m}, 4 \mathrm{H}), 1.52-1.42(\mathrm{~m}, 4 \mathrm{H}), 1.31-1.11$ $(\mathrm{m}, 20 \mathrm{H}), 0.85(\mathrm{td}, J=7.1,1.6 \mathrm{~Hz}, 6 \mathrm{H}) \mathrm{ppm}$.

${ }^{13} \mathrm{C} \mathrm{NMR}\left(126 \mathrm{MHz}, \mathrm{CDCl}_{3}\right) \delta_{\mathrm{C}} 149.93,149.77,142.18,141.24,138.48,138.08,137.48,131.97$, $131.94,131.61,130.60,129.52,127.69,124.53,124.31,122.86,121.68,99.72,92.08,89.60,89.15$, $32.75,32.66,31.98,31.95,31.66,31.52,29.62,29.61,29.38,29.37,29.28,22.81,22.78,14.28,14.24$ ppm (two signals coincident or not observed: one in the Ar-H region and one in the aliphatic-H region).

MS (MALDI, DCTB): $m / z$ calcd for $\mathrm{C}_{264} \mathrm{H}_{288} \mathrm{~N}_{6}^{+}\left(\left[\mathrm{M}^{\circ}\right]^{+}\right) 3542.3$ found 3542.4. 


\subsection{NMR and mass spectra of new compounds}
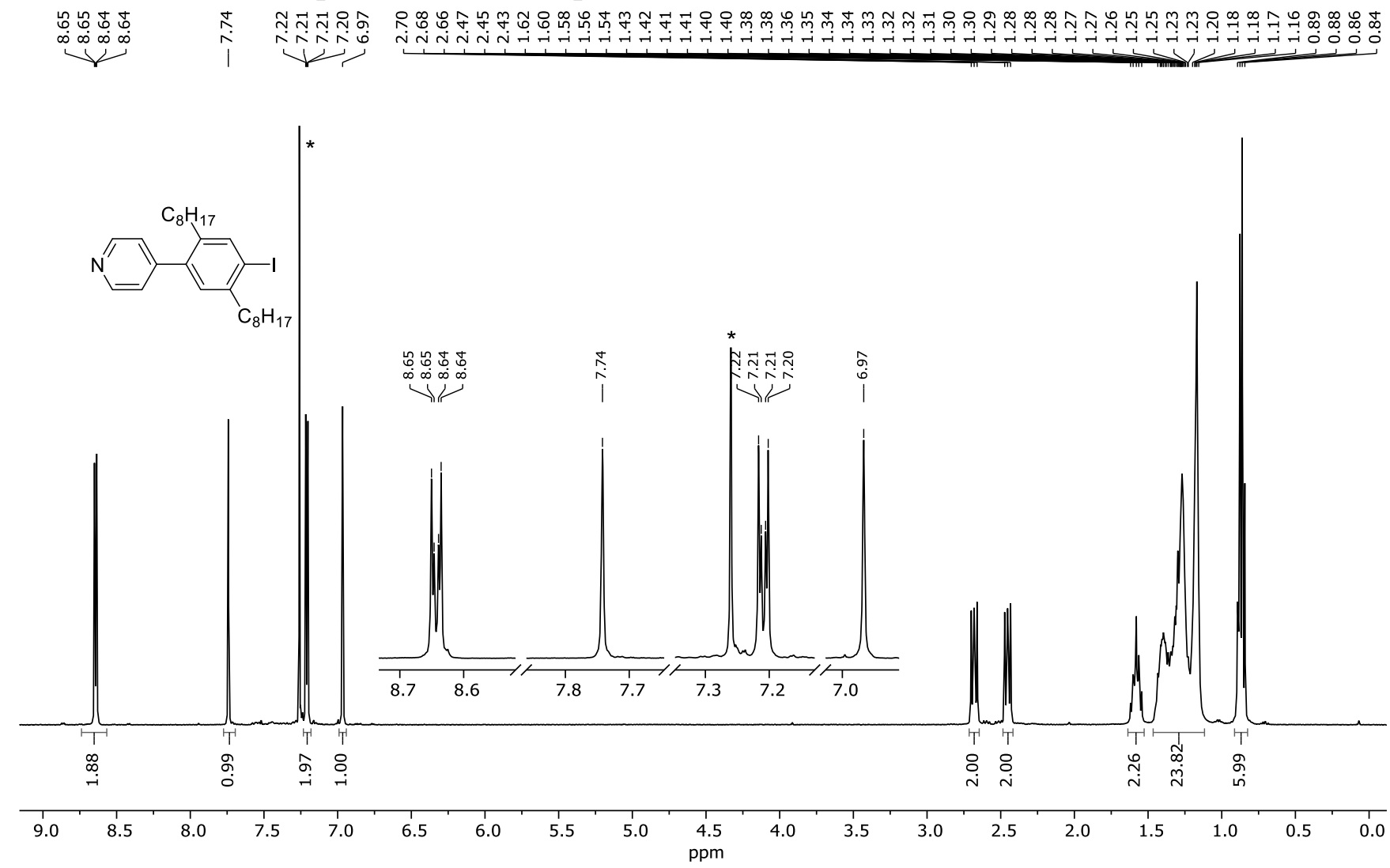

Figure S3. ${ }^{1} \mathrm{H}$ NMR $(400 \mathrm{MHz})$ spectrum of 2 recorded in $\mathrm{CDCl}_{3}$ at $298 \mathrm{~K}$. Solvent peak is marked with an asterisk $\left({ }^{*}\right)$.
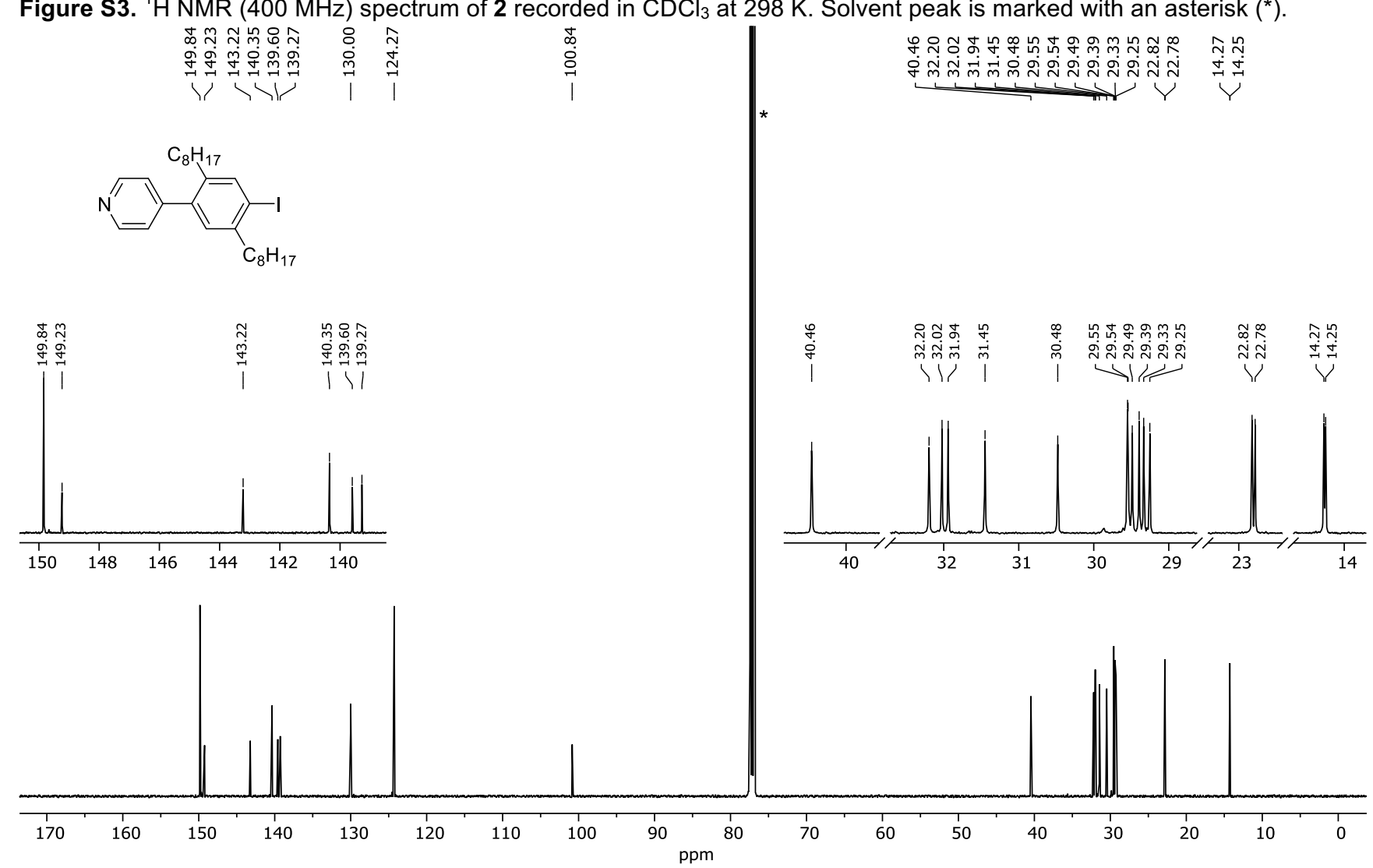

Figure S4. ${ }^{13} \mathrm{C}$ NMR (126 MHz) spectrum of 2 recorded in $\mathrm{CDCl}_{3}$ at $298 \mathrm{~K}$. Solvent peak is marked with an asterisk $\left({ }^{*}\right)$. 


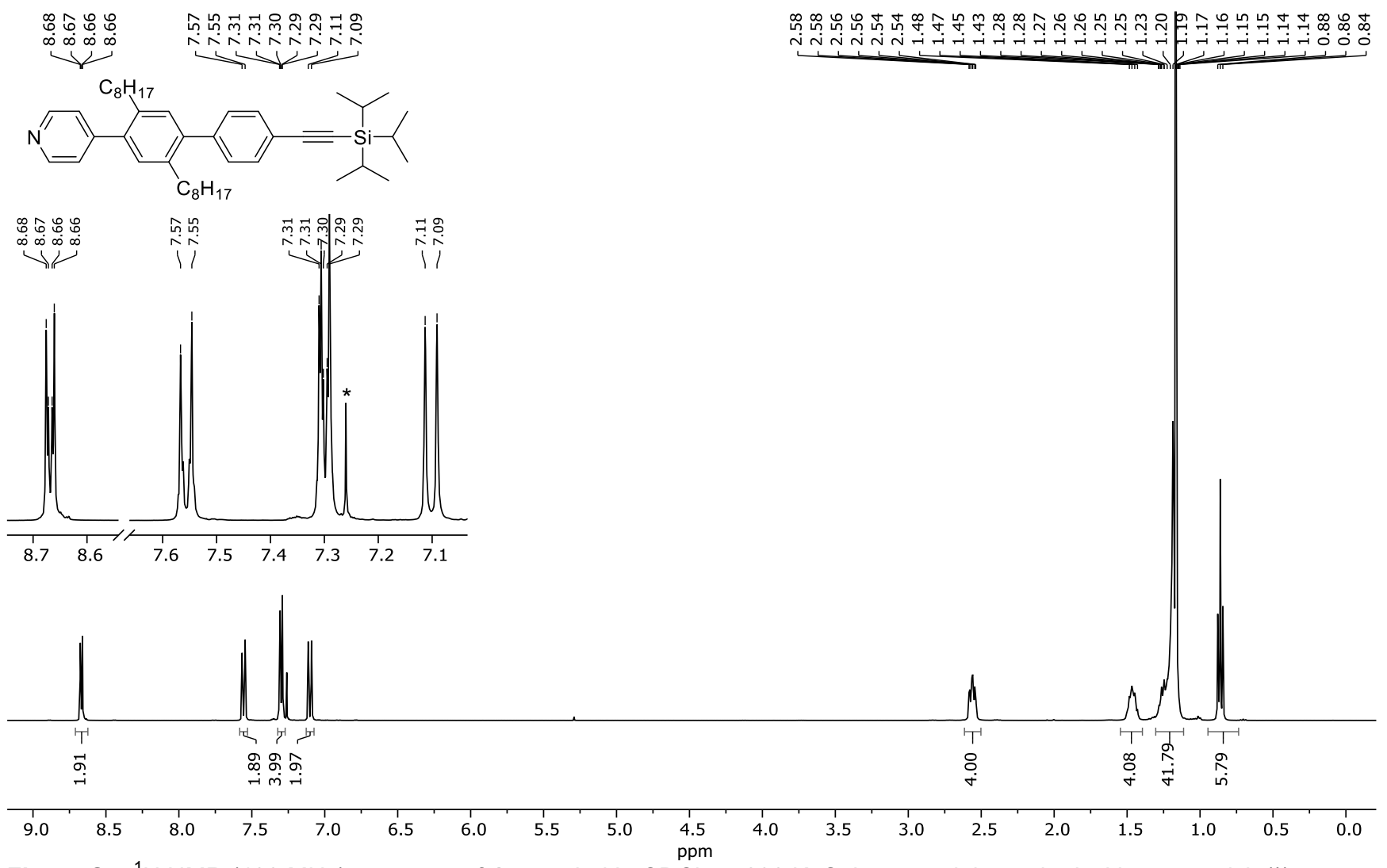

Figure S5. ${ }^{1} \mathrm{H}$ NMR $(400 \mathrm{MHz})$ spectrum of 4 recorded in $\mathrm{CDCl}_{3}$ at $298 \mathrm{~K}$. Solvent peak is marked with an asterisk (*).

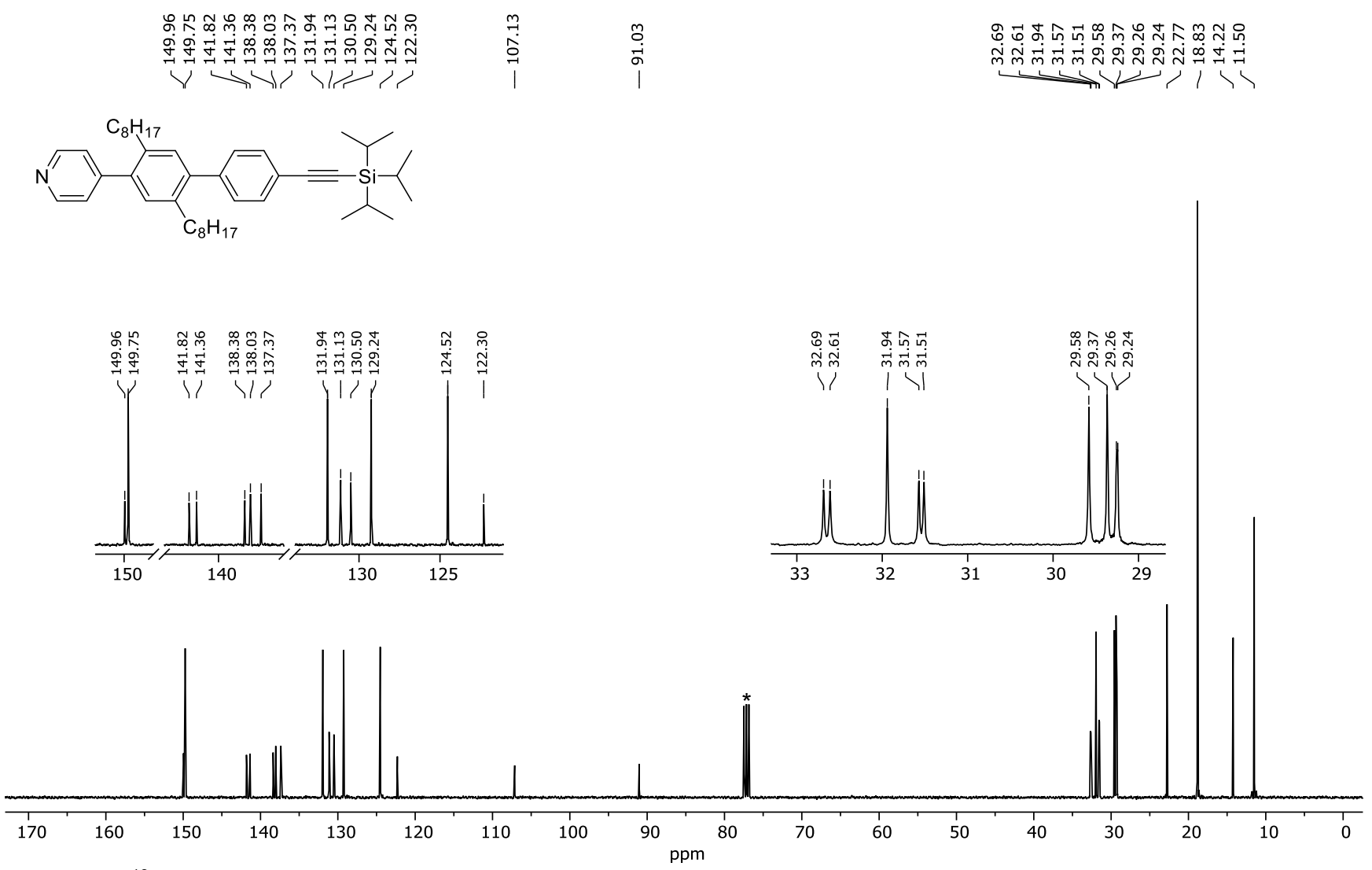

Figure S6. ${ }^{13} \mathrm{C}$ NMR (126 MHz) spectrum of 4 recorded in $\mathrm{CDCl}_{3}$ at $298 \mathrm{~K}$. Solvent peak is marked with an asterisk $\left({ }^{*}\right)$. 


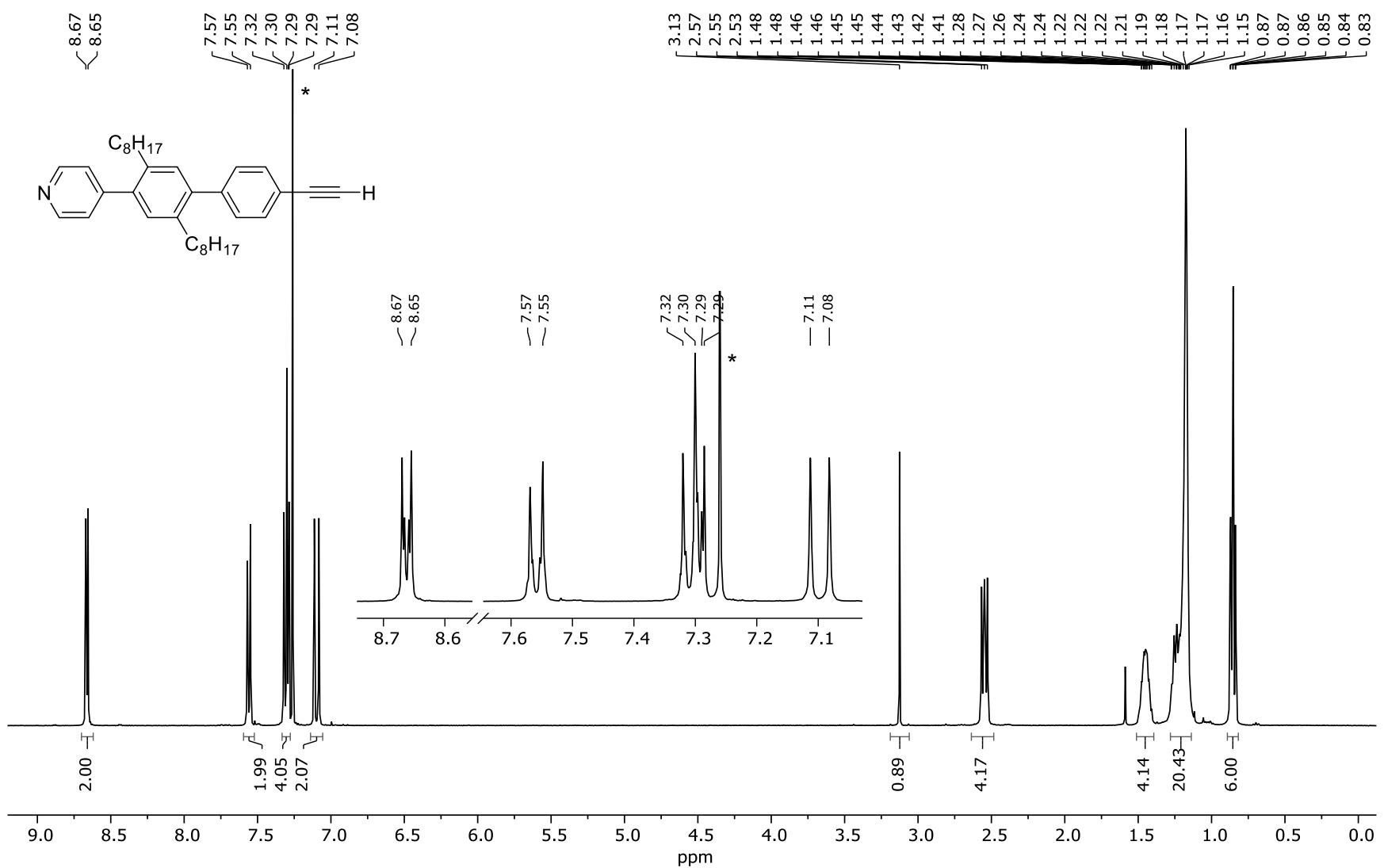

Figure S7. ${ }^{1} \mathrm{H}$ NMR $(400 \mathrm{MHz})$ spectrum of 5 recorded in $\mathrm{CDCl}_{3}$ at $298 \mathrm{~K}$. Solvent peak is marked with an asterisk $\left({ }^{*}\right)$.
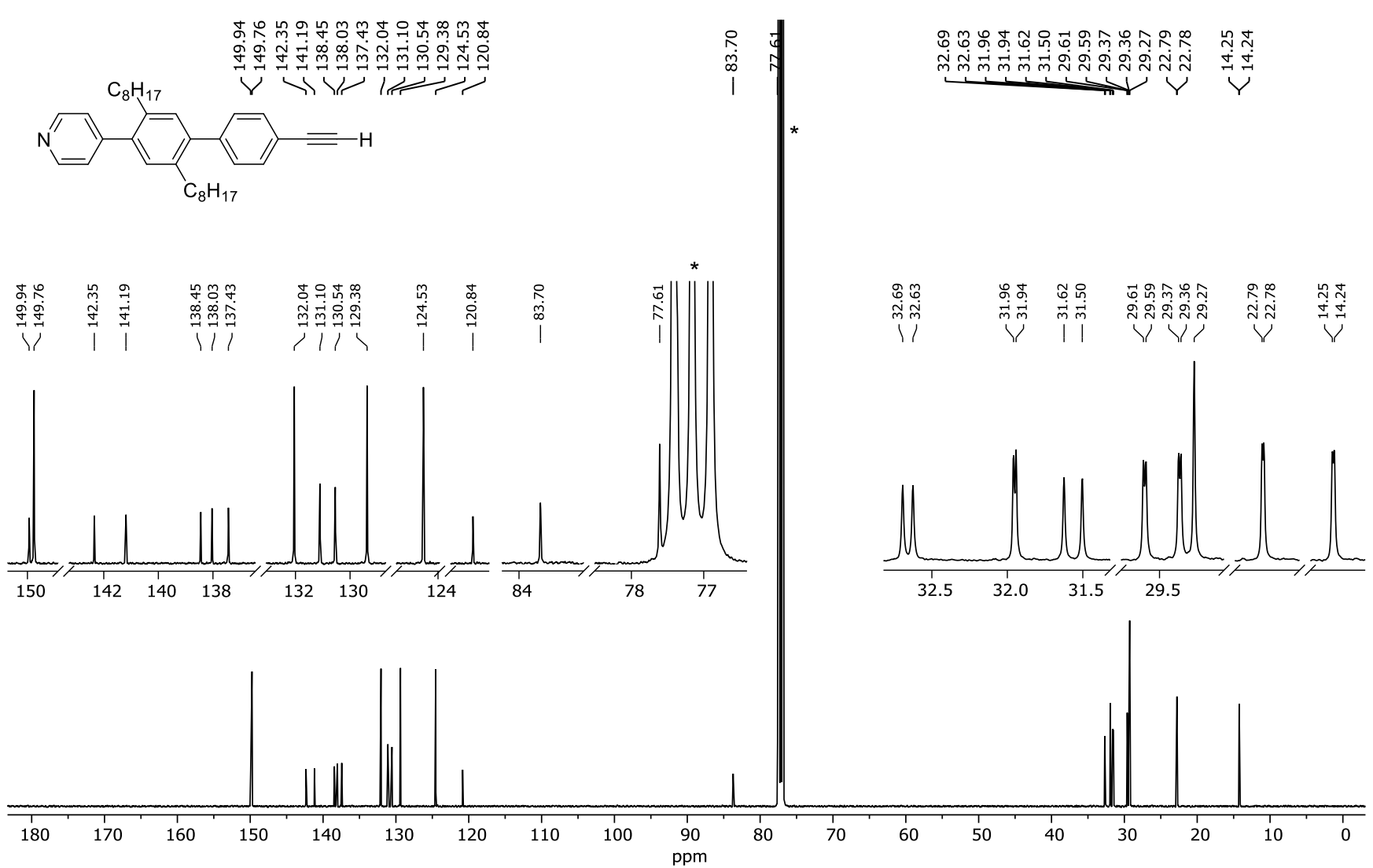

Figure S8. ${ }^{13} \mathrm{C}$ NMR $(126 \mathrm{MHz})$ spectrum of 5 recorded in $\mathrm{CDCl}_{3}$ at $298 \mathrm{~K}$. Solvent peak is marked with an asterisk (*). 
${ }^{1} \mathrm{H}$ NMR assignment of template T6e.

Figure 59. Label assignment of T6e and key HMBC correlations (red arrows).

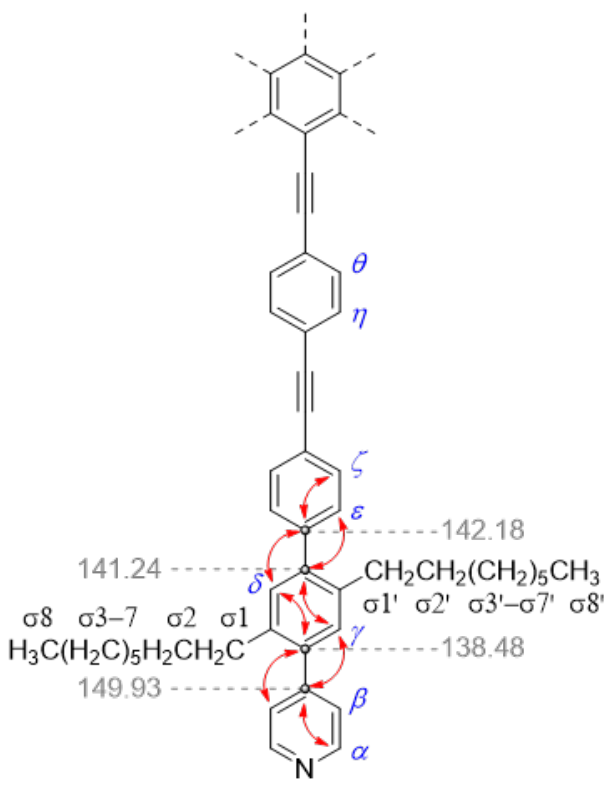

Table S2. NMR correlations for T6e.

\begin{tabular}{|c|c|c|c|c|c|c|}
\hline Label & ${ }^{1} \mathrm{H}$ & Mult. & cosy & NOESY & $\mathrm{HSQC}^{\dagger}$ & HМBC $^{\ddagger}$ \\
\hline$\alpha$ & $8.67(12 \mathrm{H})$ & $\mathrm{d}, \mathrm{J}=5.7 \mathrm{~Hz}$ & $\beta$ & $\beta$ & 149.77 & $149.93,124.53$ \\
\hline$\eta / \theta$ & $7.67(12 \mathrm{H})$ & $\mathrm{d}, J=8.4 \mathrm{~Hz}$ & $\eta / \theta$ & - & $\begin{array}{c}131.97 / 131.94 / \\
131.61\end{array}$ & $\begin{array}{c}131.97,131.94,124.31 \\
99.72\end{array}$ \\
\hline$\zeta$ & $7.64(12 \mathrm{H})$ & $\mathrm{d}, J=8.2 \mathrm{~Hz}$ & $\varepsilon$ & $\varepsilon$ & $\begin{array}{c}131.97 / 131.94 / \\
131.61\end{array}$ & $\begin{array}{c}142.18,131.61,129.52 w \\
92.08\end{array}$ \\
\hline$\eta / \theta$ & $7.62(12 \mathrm{H})$ & $\mathrm{d}, J=8.4 \mathrm{~Hz}$ & $\eta / \theta$ & - & $\begin{array}{c}131.97 / 131.94 / \\
131.61 \\
\end{array}$ & $\begin{array}{c}131.97,131.94,122.86 \\
89.60\end{array}$ \\
\hline$\varepsilon$ & $7.37(12 \mathrm{H})$ & $\mathrm{d}, J=8.2 \mathrm{~Hz}$ & $\zeta$ & $\zeta$ & 129.52 & $\begin{array}{c}\mathbf{1 4 1 . 2 4 ,} 131.61,129.52 \\
121.68\end{array}$ \\
\hline$\beta$ & $7.30(12 \mathrm{H})$ & $\mathrm{d}, J=5.7 \mathrm{~Hz}$ & $\alpha$ & $\alpha$ & 124.53 & 149.77, 138.48, 121.68 \\
\hline$\delta$ & $7.15(6 \mathrm{H})$ & $\mathrm{s}$ & - & $\sigma 1,1^{\prime}$ & 131.61 & $\begin{array}{c}\text { 149.93w, 142.18, 138.48, } \\
32.75,32.66\end{array}$ \\
\hline$Y$ & $7.10(6 \mathrm{H})$ & $\mathrm{s}$ & - & $\sigma 1,1^{\prime}$ & 130.60 & $\begin{array}{c}\text { 149.93, 141.24, } 137.48 \\
32.75,32.66\end{array}$ \\
\hline$\sigma 1,1^{\prime}$ & $2.64-2.49(24 \mathrm{H})$ & $\mathrm{m}$ & $\begin{array}{l}\sigma 3-7 \\
\sigma 3^{\prime}-7\end{array}$ & $\gamma, \delta$ & $32.75,32.66$ & $\begin{array}{c}141.24,137.48,131.13 \\
130.60,32.75,32.66\end{array}$ \\
\hline$\sigma 2,2^{\prime}$ & $1.52-1.42(24 \mathrm{H})$ & $\mathrm{m}$ & $\begin{array}{r}\sigma 3-7 \\
\sigma 3 '-7, \\
\sigma 1,1^{\prime}\end{array}$ & - & $31.66,31.52$ & $\begin{array}{c}\text { 141.24, } 138.08,137.48 \\
\text { 131.61, } 131.13,31.66 \\
31.52\end{array}$ \\
\hline $\begin{array}{l}\sigma 3-7 \\
\sigma 3-7\end{array}$ & $1.31-1.11(120 \mathrm{H})$ & $\mathrm{m}$ & $\begin{array}{c}\sigma 8 \\
\sigma 8 \\
\sigma 2,2\end{array}$ & - & $\begin{array}{c}31.98,31.95 \\
29.62,29.61 \\
29.38,29.37 \\
29.28,22.81 \\
22.78\end{array}$ & $\begin{array}{l}31.98,31.95,29.62 \\
29.61,29.38,29.37 \\
29.28,22.81,22.78\end{array}$ \\
\hline $\begin{array}{l}\sigma 8 \\
\sigma 8\end{array}$ & $0.88-0.83(36 \mathrm{H})$ & $\mathrm{m}$ & $\begin{array}{l}\sigma 3-7 \\
\sigma 3 \prime-7\end{array}$ & - & $14.28,14.24$ & $\begin{array}{l}31.98,31.95,(31.66 \\
31.52), 22.81,22.78\end{array}$ \\
\hline
\end{tabular}

\footnotetext{
${ }^{\dagger}$ When signals are separated by / this should be interpreted as 'or' since these ${ }^{13} \mathrm{C}$ signals where too close to distinguish.
}

${ }^{\ddagger}$ Key HMBC correlations highlighted in bold. 


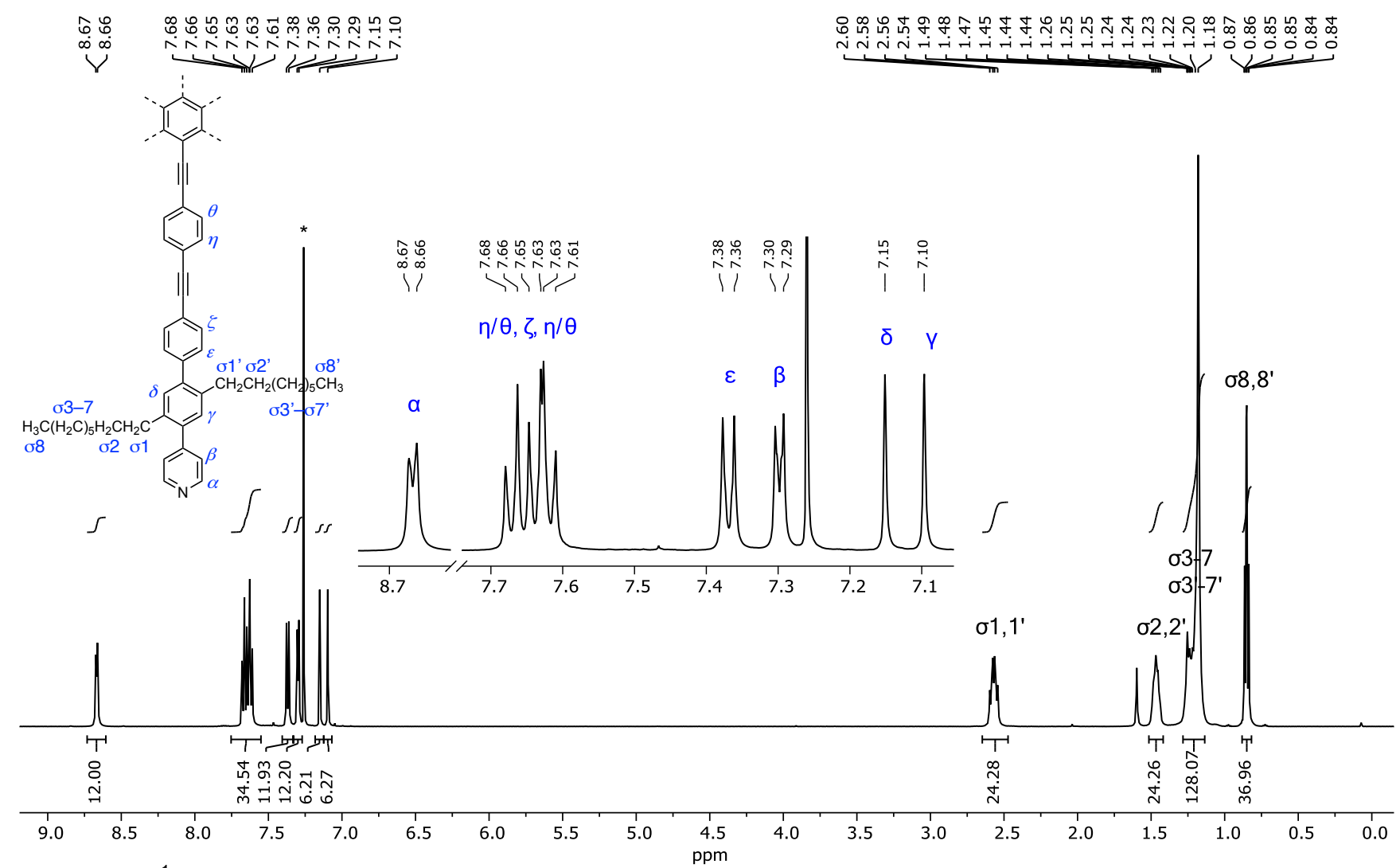

Figure S10. ${ }^{1} \mathrm{H}$ NMR $(500 \mathrm{MHz})$ spectrum of T6e recorded in $\mathrm{CDCl}_{3}$ at $298 \mathrm{~K}$. Solvent peak is marked with an asterisk $\left({ }^{*}\right)$.

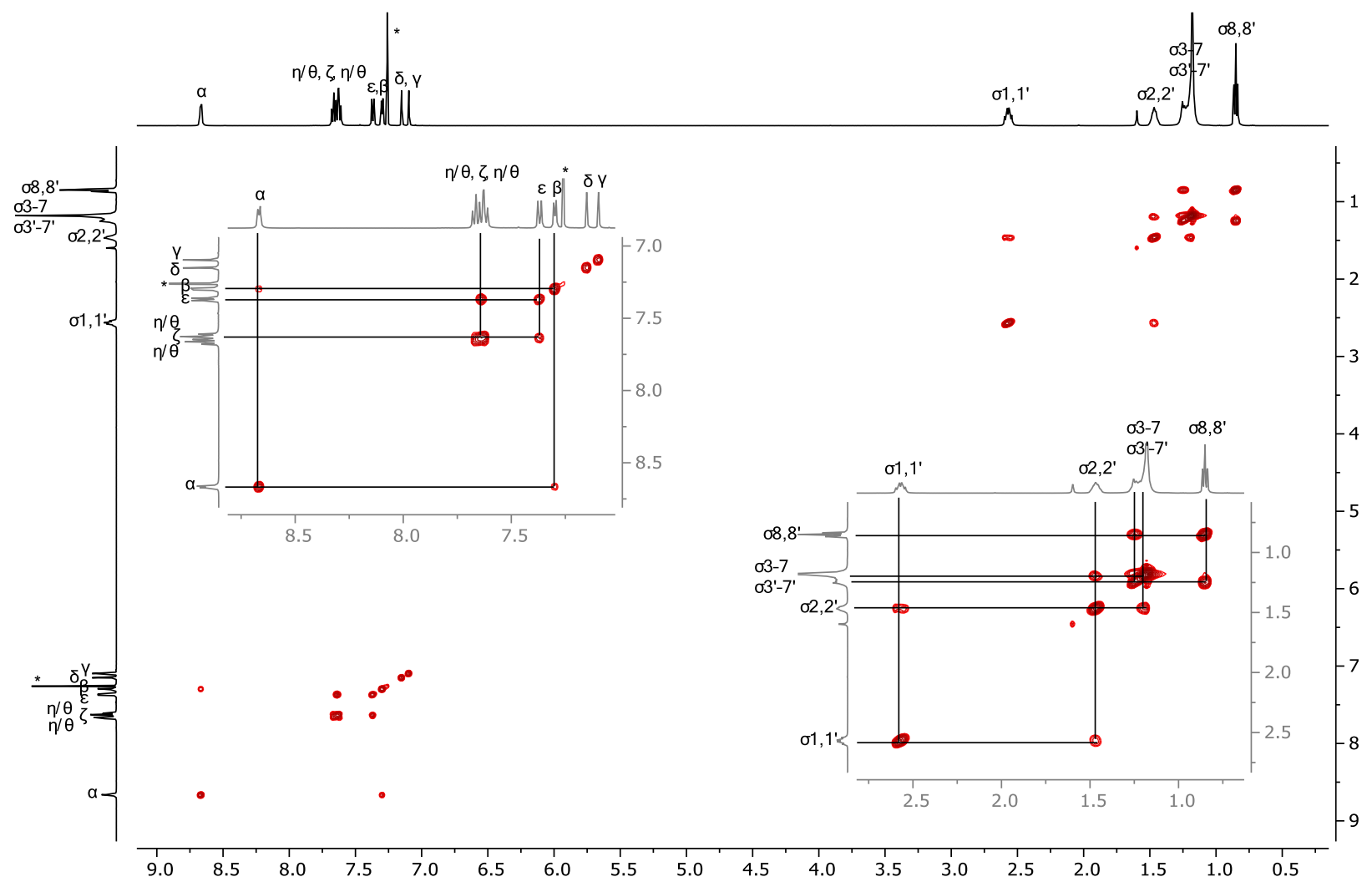

Figure S11. COSY spectrum of T6e recorded in $\mathrm{CDCl}_{3}$ at $298 \mathrm{~K}$. Solvent peak is marked with an asterisk (*). 


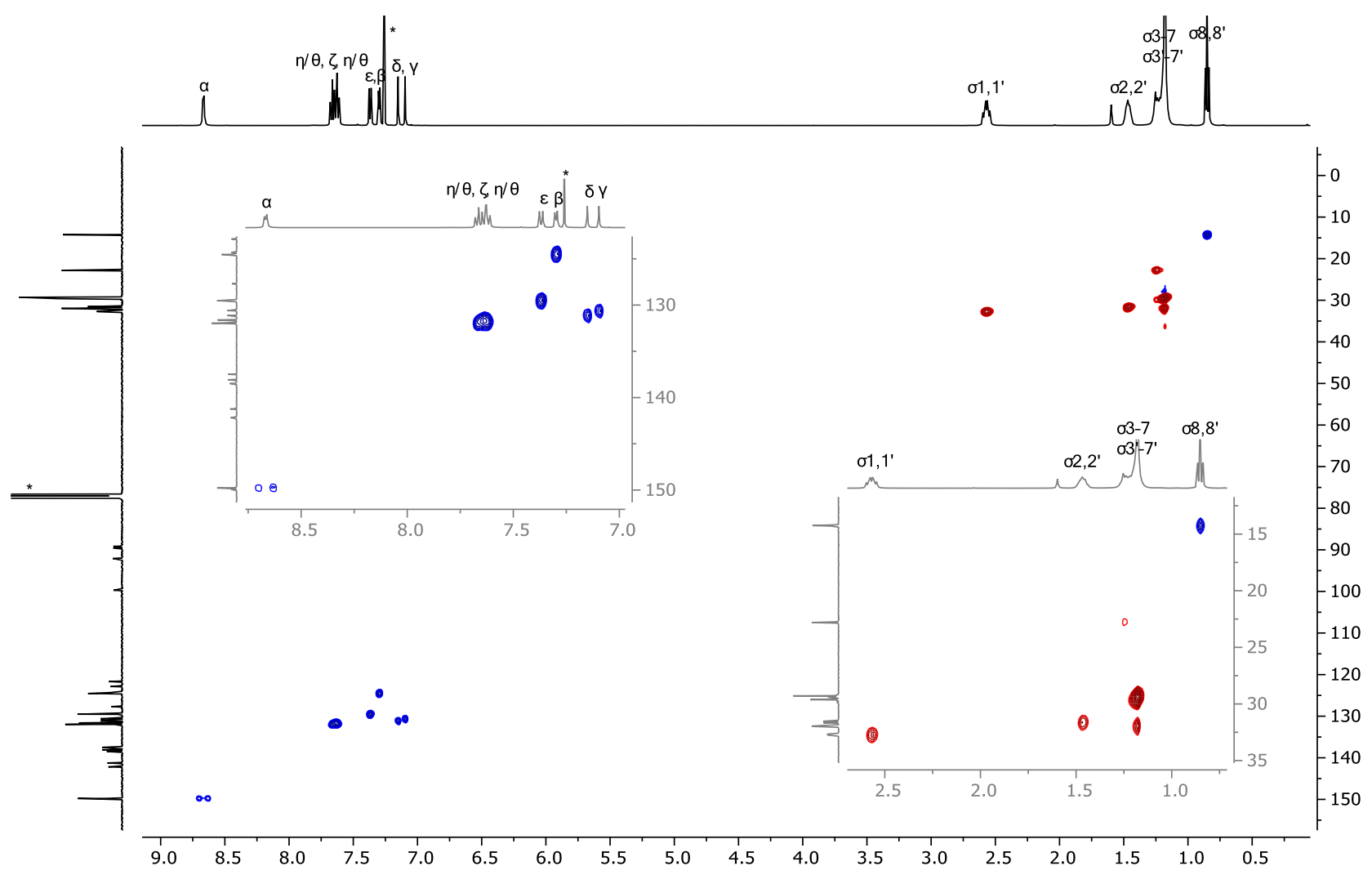

Figure S12. HSQC spectrum of T6e recorded in $\mathrm{CDCl}_{3}$ at $298 \mathrm{~K}$. Solvent peak is marked with an asterisk (*).

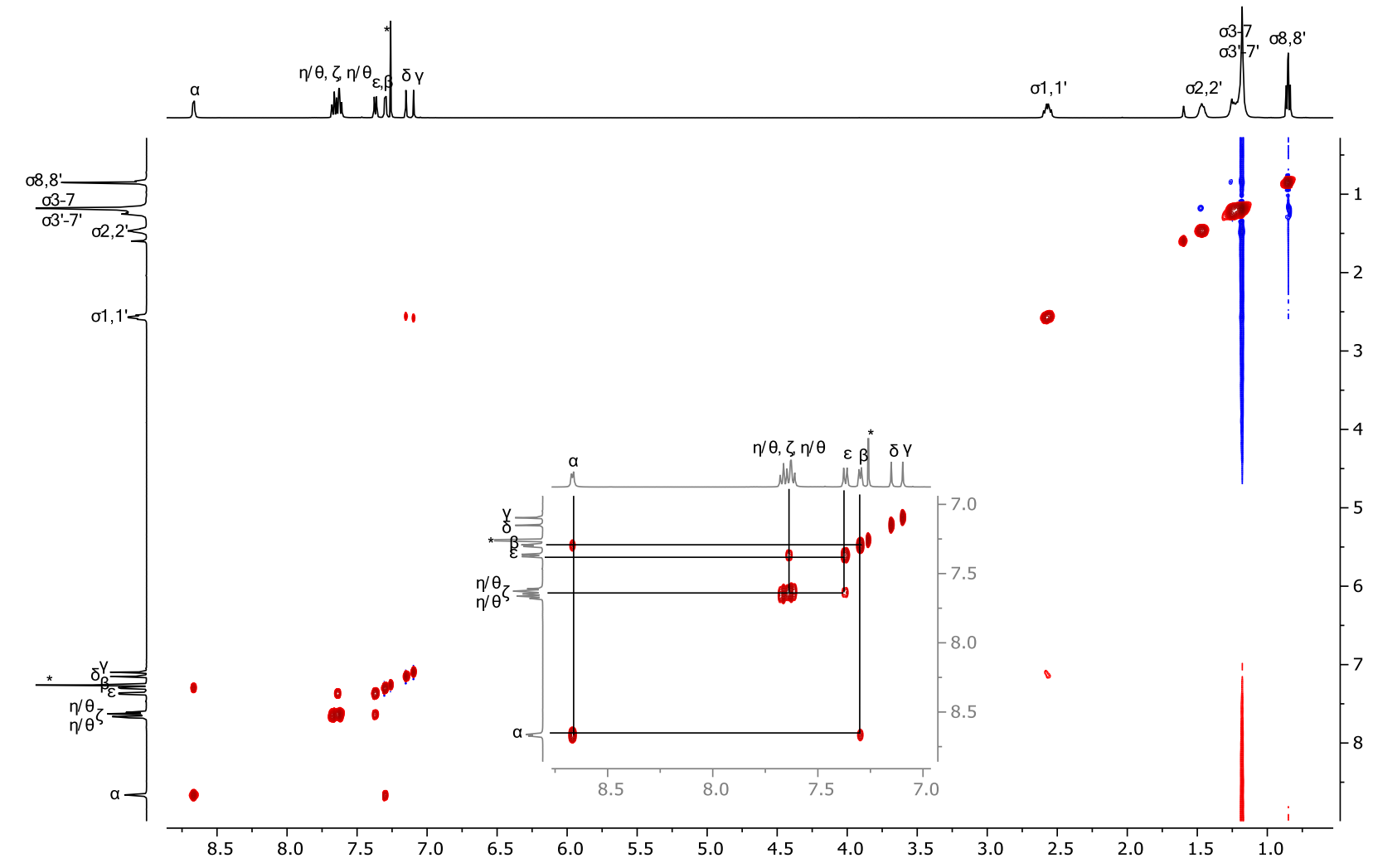

Figure S13. NOESY spectrum of T6e recorded in $\mathrm{CDCl}_{3}$ at $298 \mathrm{~K}$. Solvent peak is marked with an asterisk (*). 


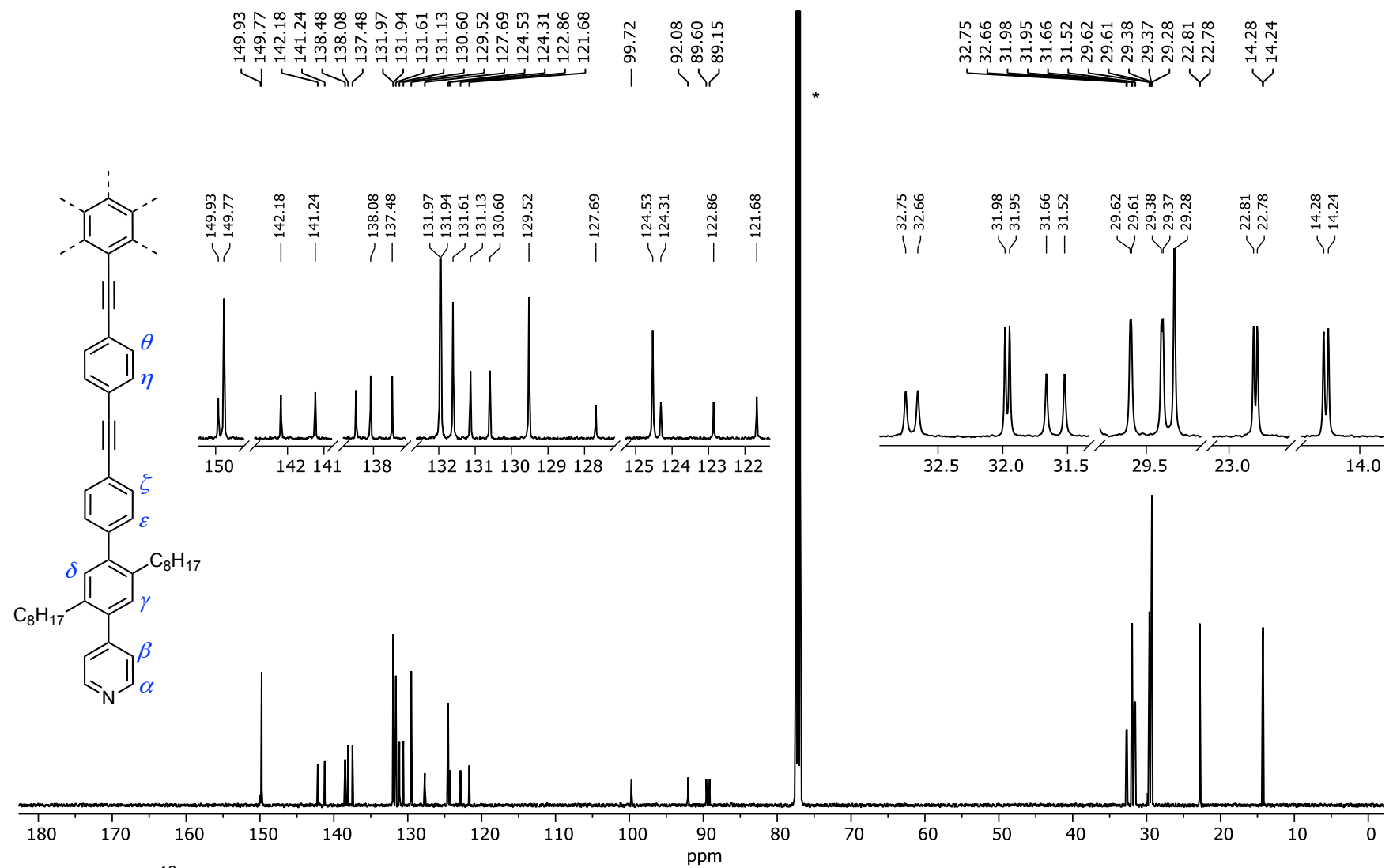

Figure S14. ${ }^{13} \mathrm{C}$ NMR (126 MHz) spectrum of T6e recorded in $\mathrm{CDCl}_{3}$ at $298 \mathrm{~K}$. Solvent peak is marked with an asterisk $\left({ }^{*}\right)$.

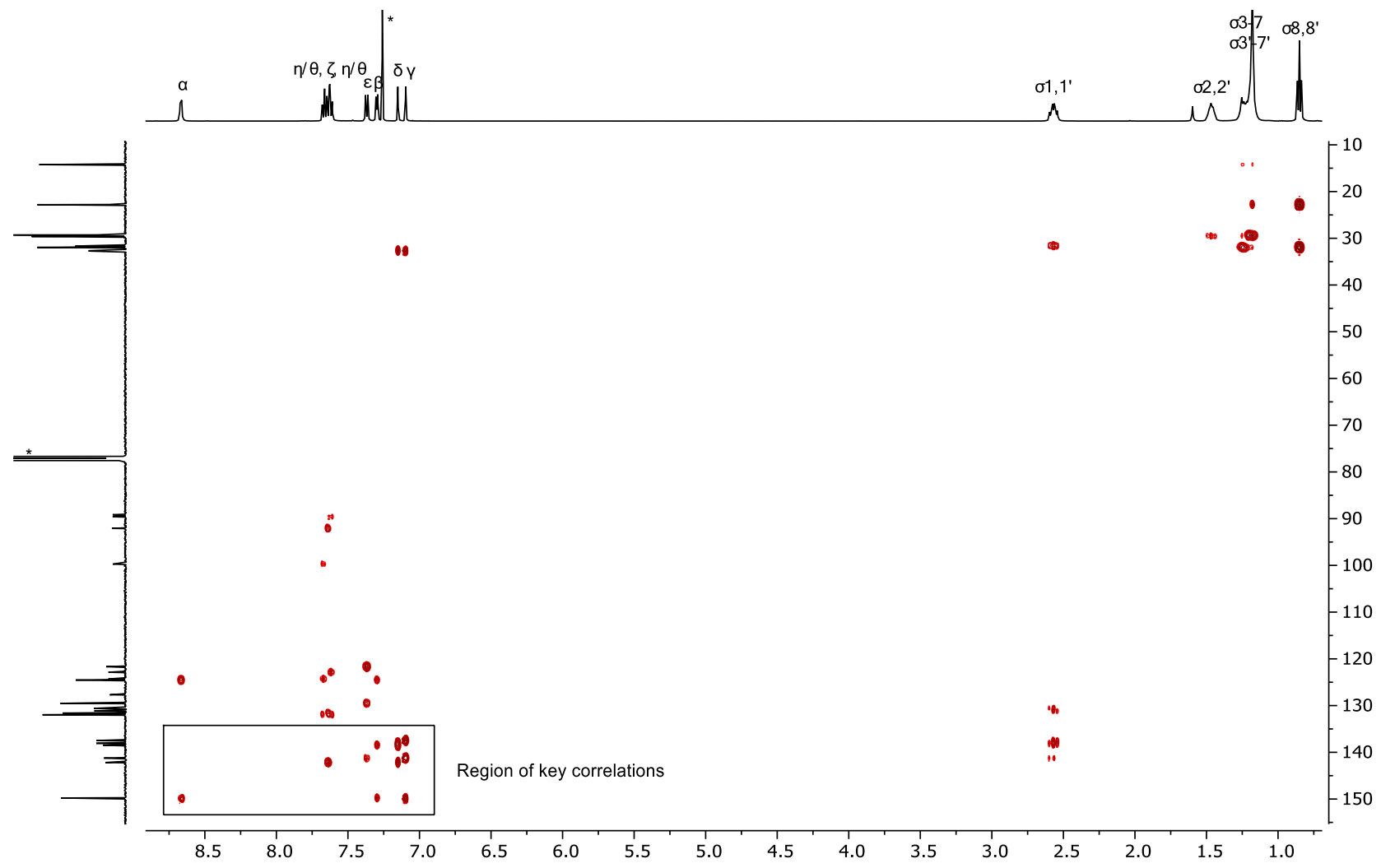

Figure S15. HMBC spectrum of T6e recorded in $\mathrm{CDCl}_{3}$ at $298 \mathrm{~K}$. Solvent peak is marked with an asterisk $\left(^{*}\right)$. 


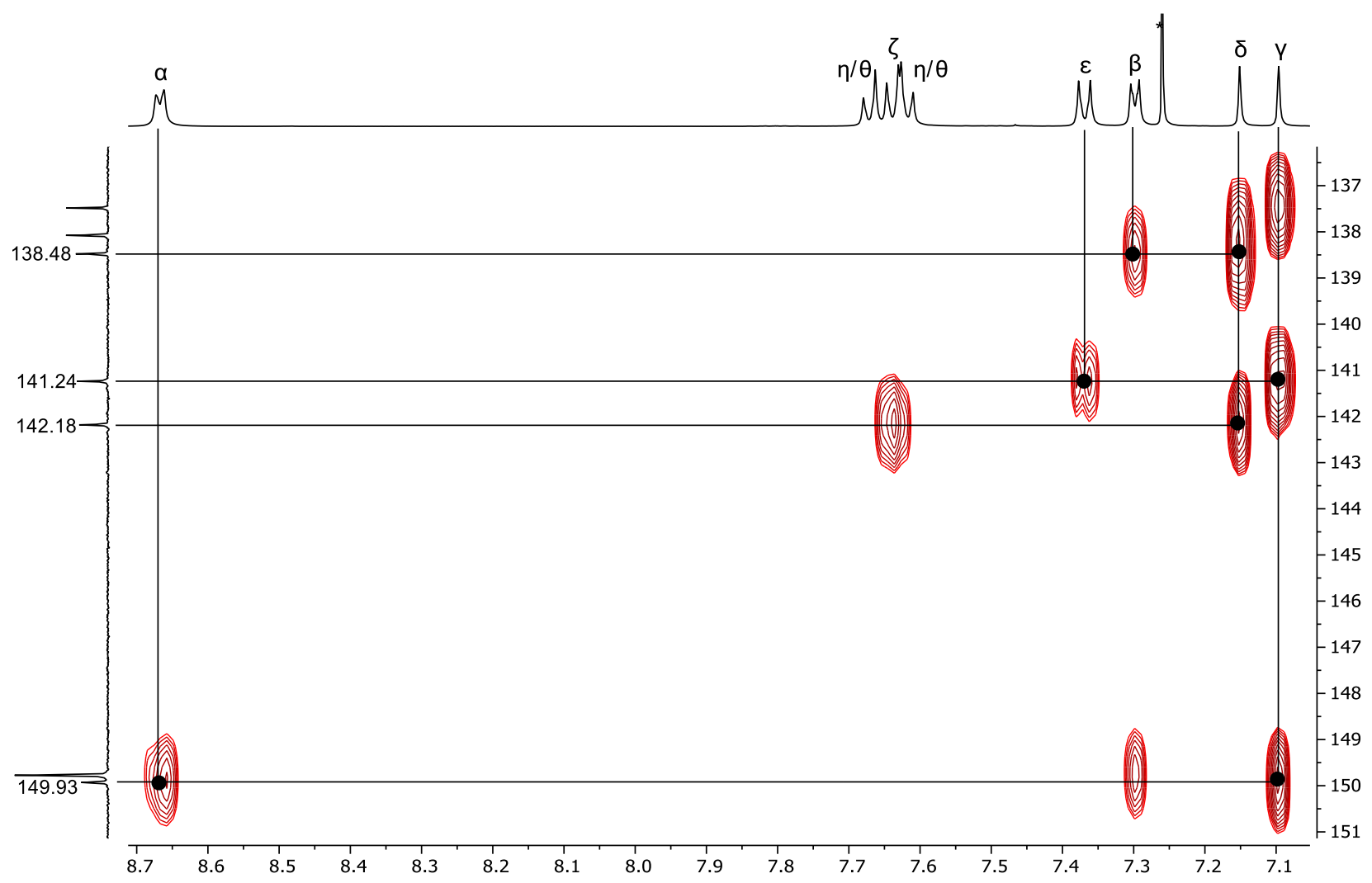

Figure S16. Region of key correlations in the $\mathrm{HMBC}$ spectrum of $\mathrm{T6e}\left(\mathrm{CDCl}_{3}, 298 \mathrm{~K}\right)$. Solvent peak is marked with an asterisk $\left(^{*}\right)$. 


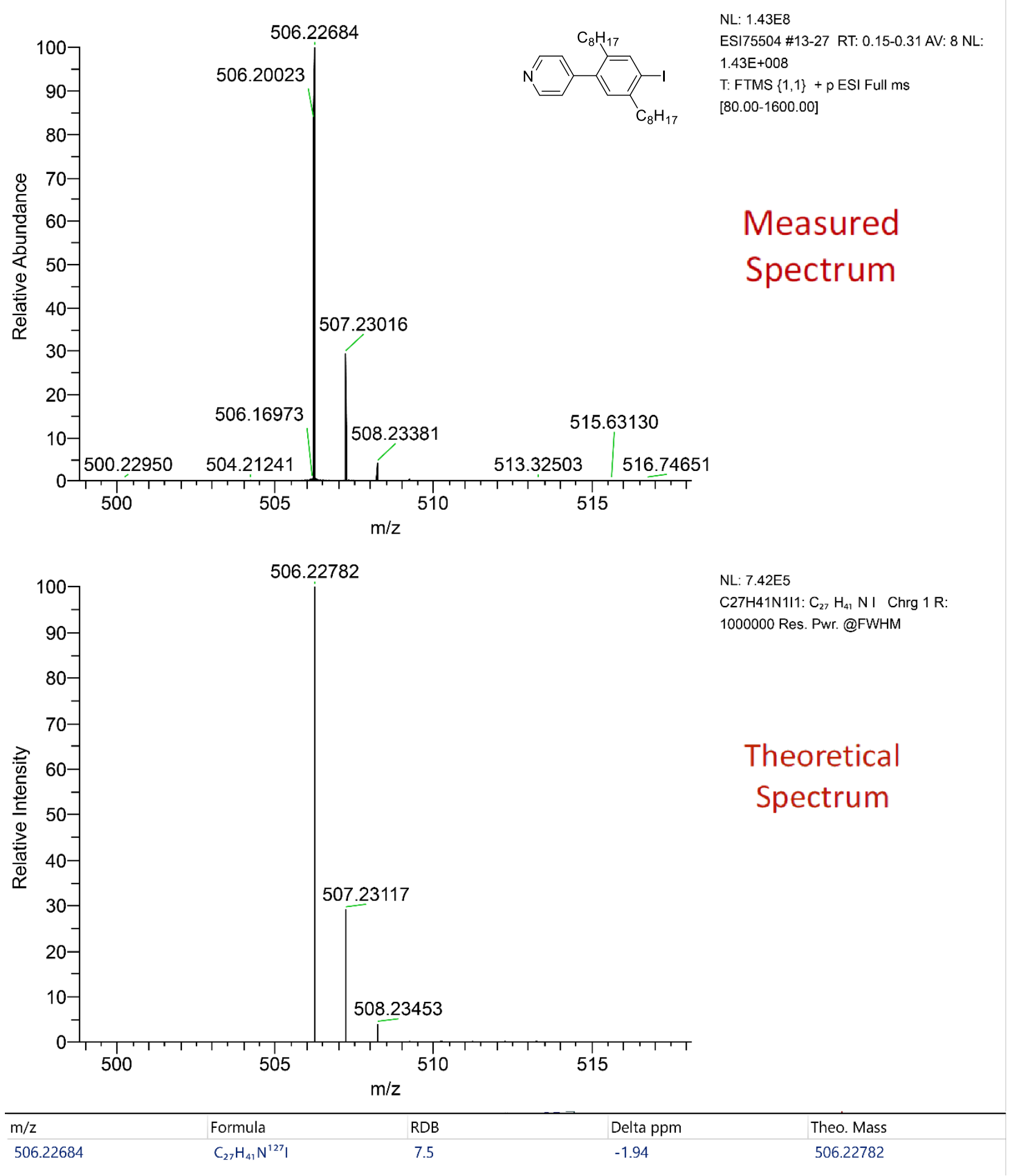

Figure S17. ESI (+) MS spectrum of compound 2. Measured spectrum (top) and theoretical spectrum (bottom). 


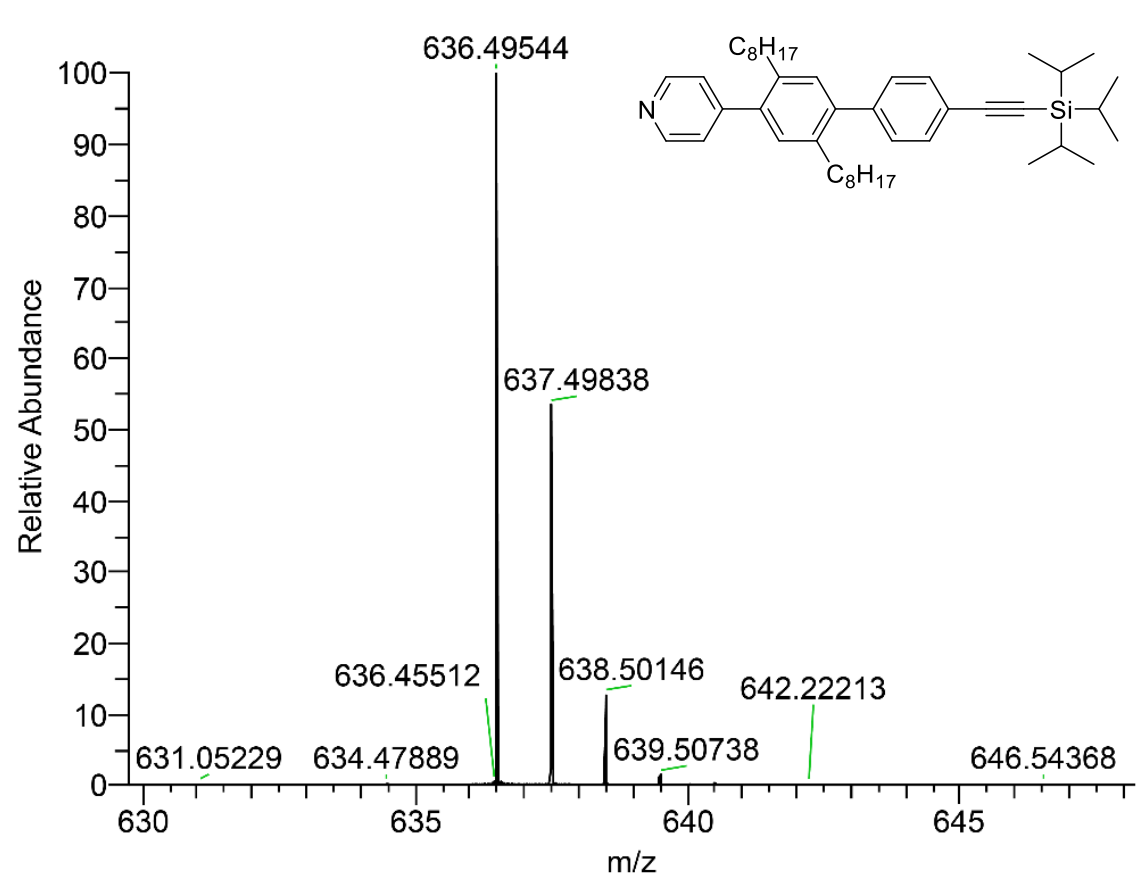

NL: 4.31E7

ESI75540 \#13-26 RT: 0.15-0.29 AV: 7 NL: $4.31 \mathrm{E}+007$

T: FTMS $\{1,1\}+p$ ESI Full ms [80.00-1600.00]

\section{Measured Spectrum}

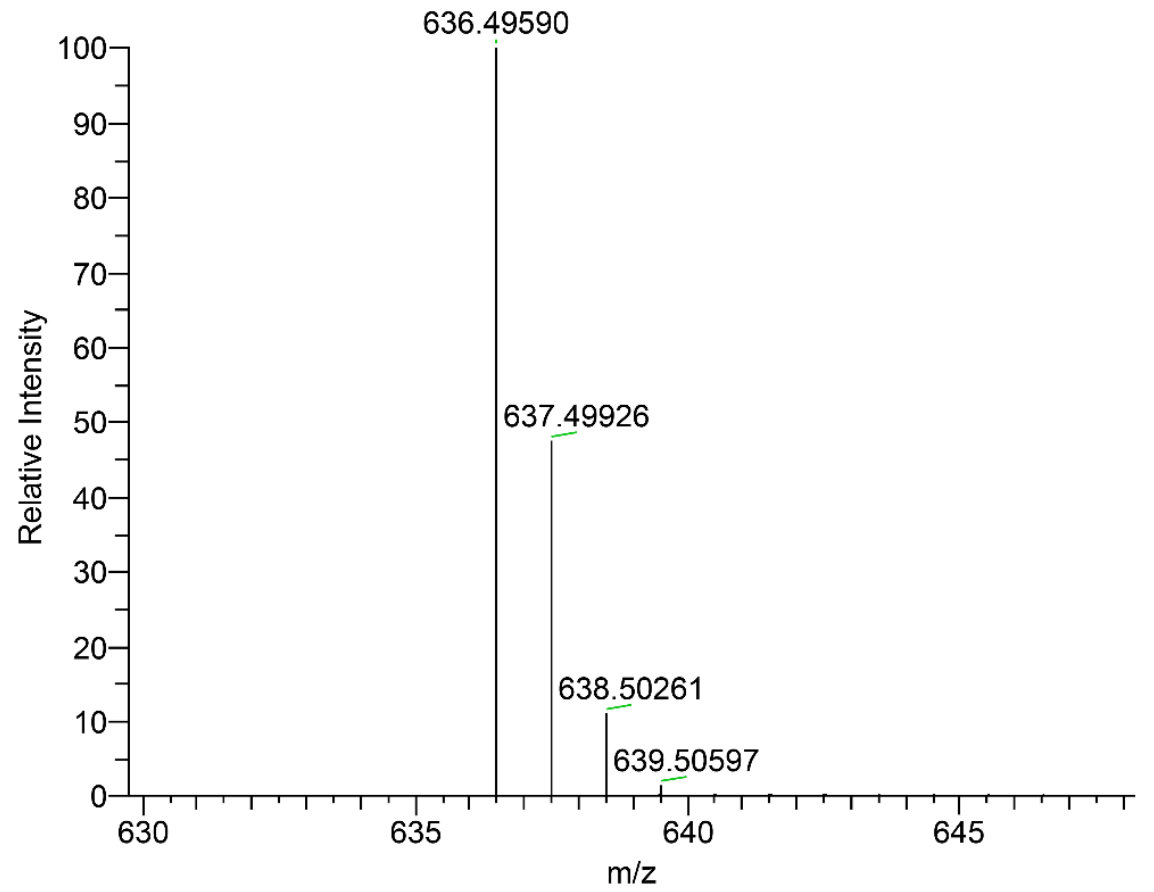

$\mathrm{NL}: 5.68 \mathrm{E} 5$

C44H66N1Si1: $\mathrm{C}_{44} \mathrm{H}_{66} \mathrm{~N}$ Si Chrg 1 R: 1000000 Res. Pwr. @FWHM

\section{Theoretical Spectrum}

\begin{tabular}{llcll}
\hline $\mathrm{m} / \mathrm{z}$ & Formula & RDB & Delta ppm & Theo. Mass \\
\hline 636.49542 & $\mathrm{C}_{44} \mathrm{H}_{66} \mathrm{~N}^{28} \mathrm{Si}$ & 13.5 & -0.76 & 636.49590
\end{tabular}

Figure S18. ESI (+) MS spectrum of compound 4. Measured spectrum (top) and theoretical spectrum (bottom). 


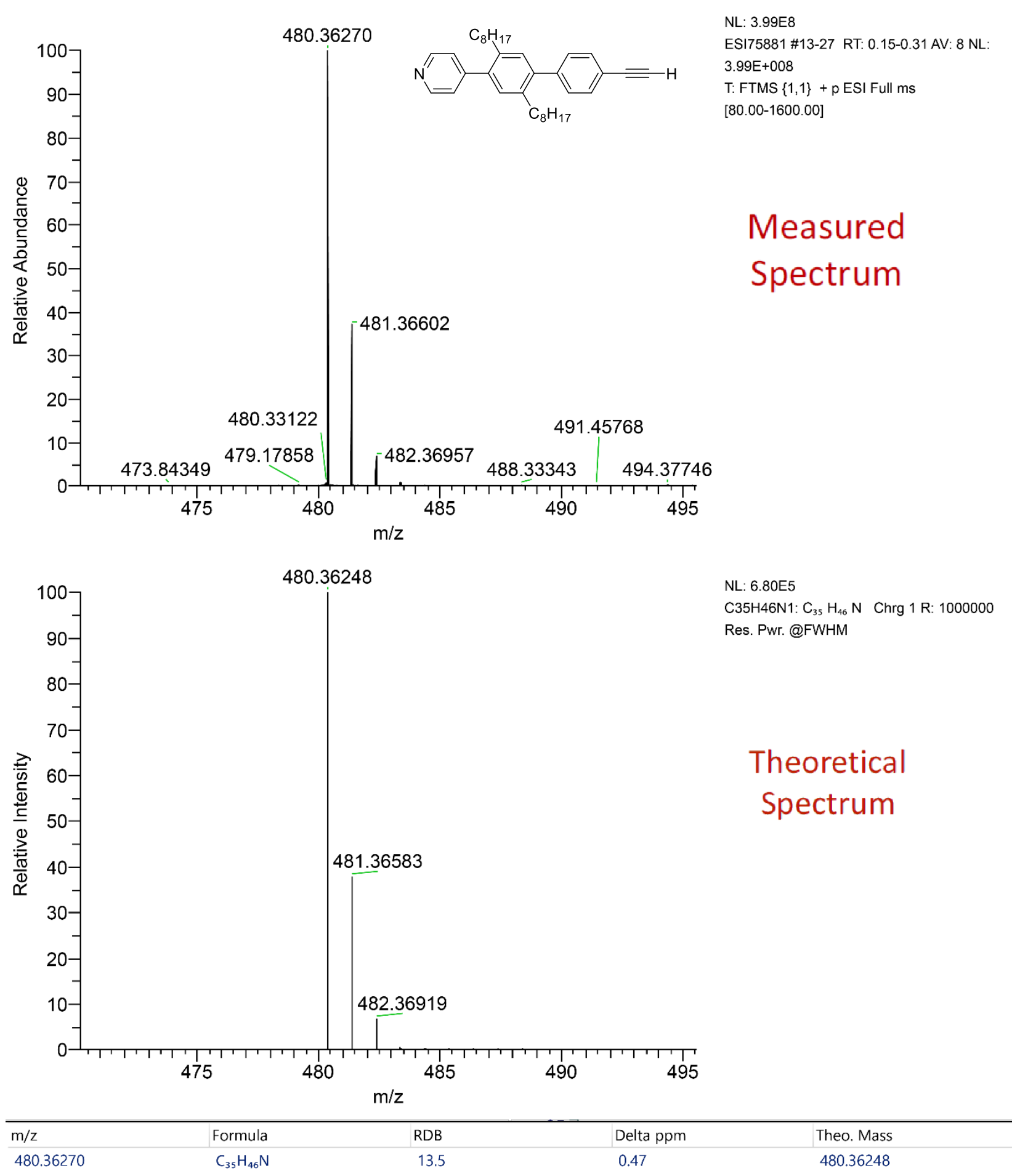

Figure S19. ESI (+) MS spectrum of compound 5. Measured spectrum (top) and theoretical spectrum (bottom). 


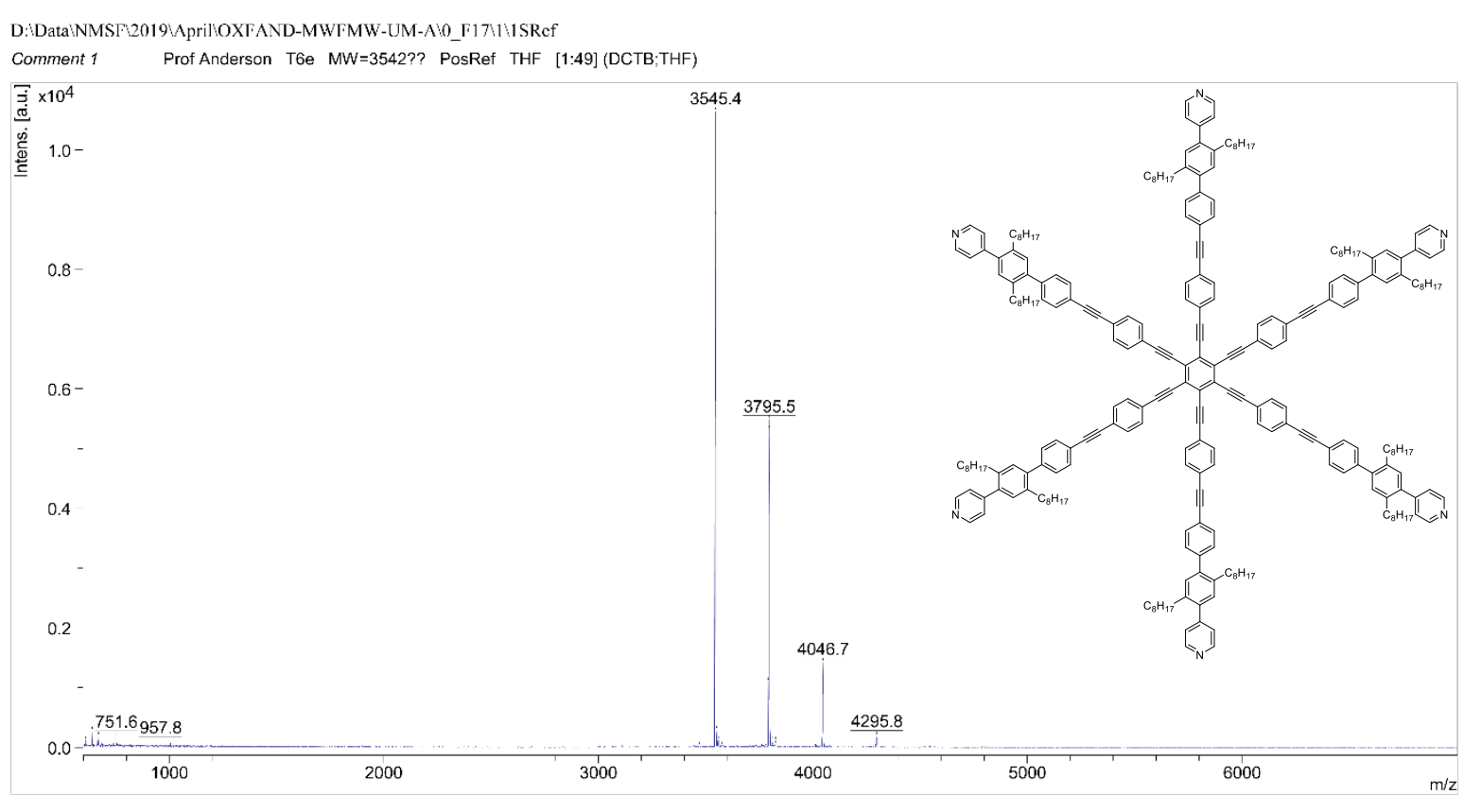

\begin{tabular}{lllll} 
& & \\
\hline ultrafleXtreme MALDI & Date of Acquisition & 2019-04-08T13:00:18.393+01:00 & Pr/04/2019 & 13:04:50
\end{tabular}

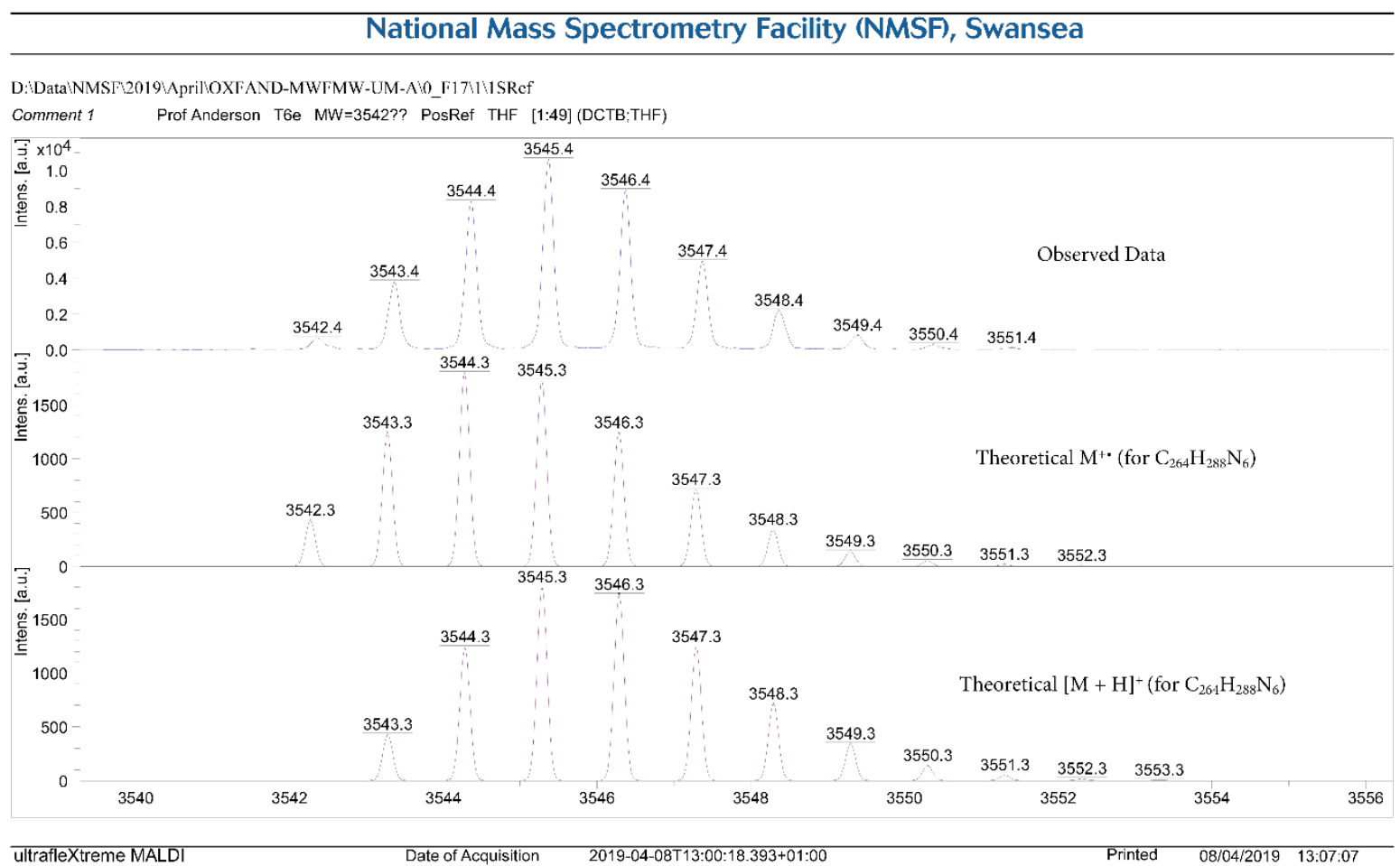

Figure S20. MALDI MS spectrum of T6e. Full spectrum (top) and zoom on the molecular ion peak (bottom) including theoretical isotope patterns. Matrix used was DCTB. 


\section{4. ${ }^{1} \mathrm{H}$ NMR spectra of stacked nanoring-template complexes}

\section{$c-\mathrm{P} 12 \cdot(\mathrm{T} 6 \mathrm{e})_{2}$}

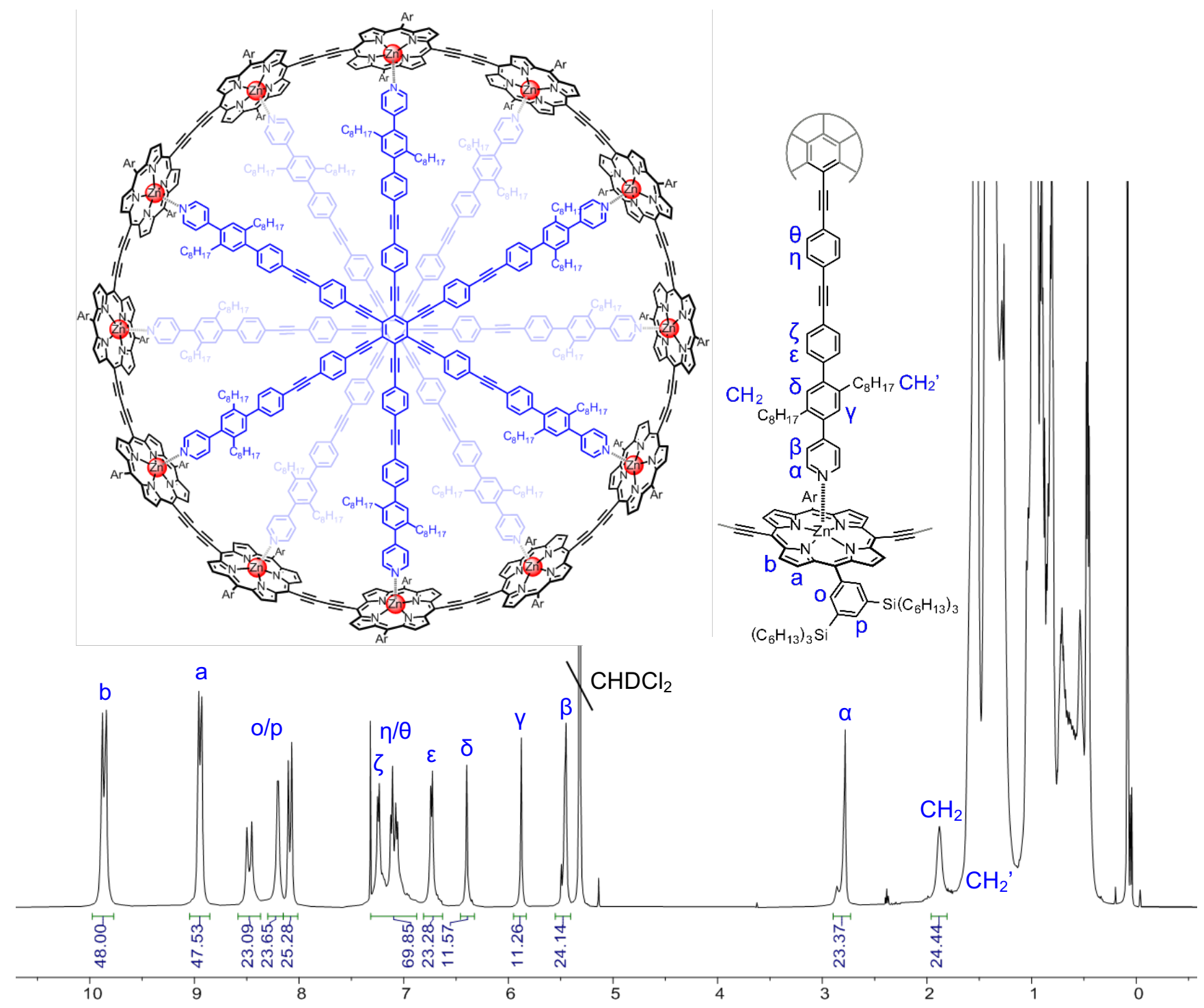

Figure S21. ${ }^{1} \mathrm{H}$ NMR $(500 \mathrm{MHz})$ spectrum of $\boldsymbol{c}$-P12.(T6e $)_{2}$ recorded in $\mathrm{CD}_{2} \mathrm{Cl}_{2}$ at $298 \mathrm{~K}$. 


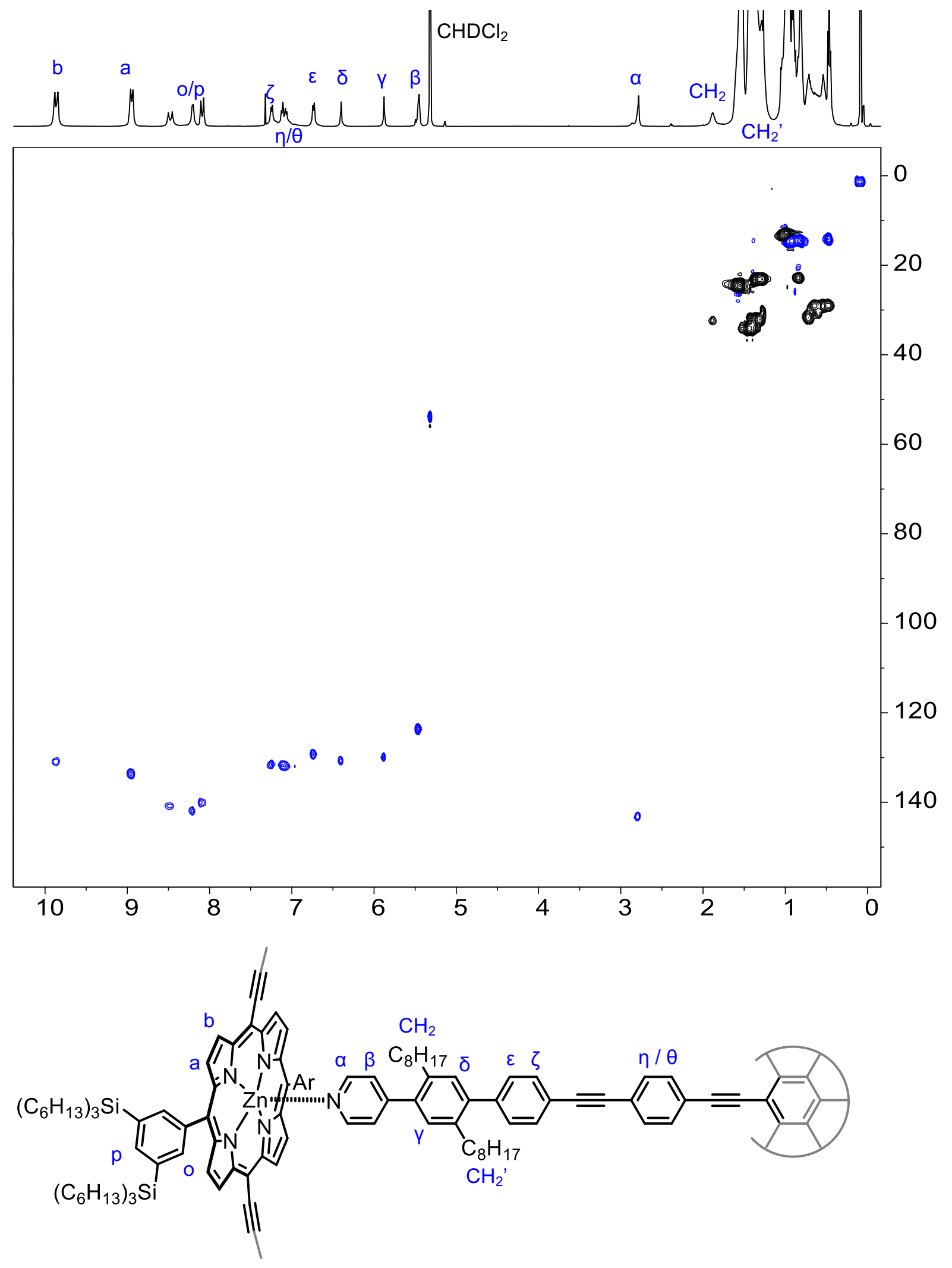

Figure S22. ${ }^{1} \mathrm{H}-{ }^{13} \mathrm{C}-\mathrm{HSQC}$ of $\boldsymbol{c}-\mathrm{P} 12 \cdot(\mathrm{T} 6 \mathrm{e})_{2}$ and peak assignment $\left(500 \mathrm{MHz}, \mathrm{CD}_{2} \mathrm{Cl}_{2}, 298 \mathrm{~K}\right)$. 


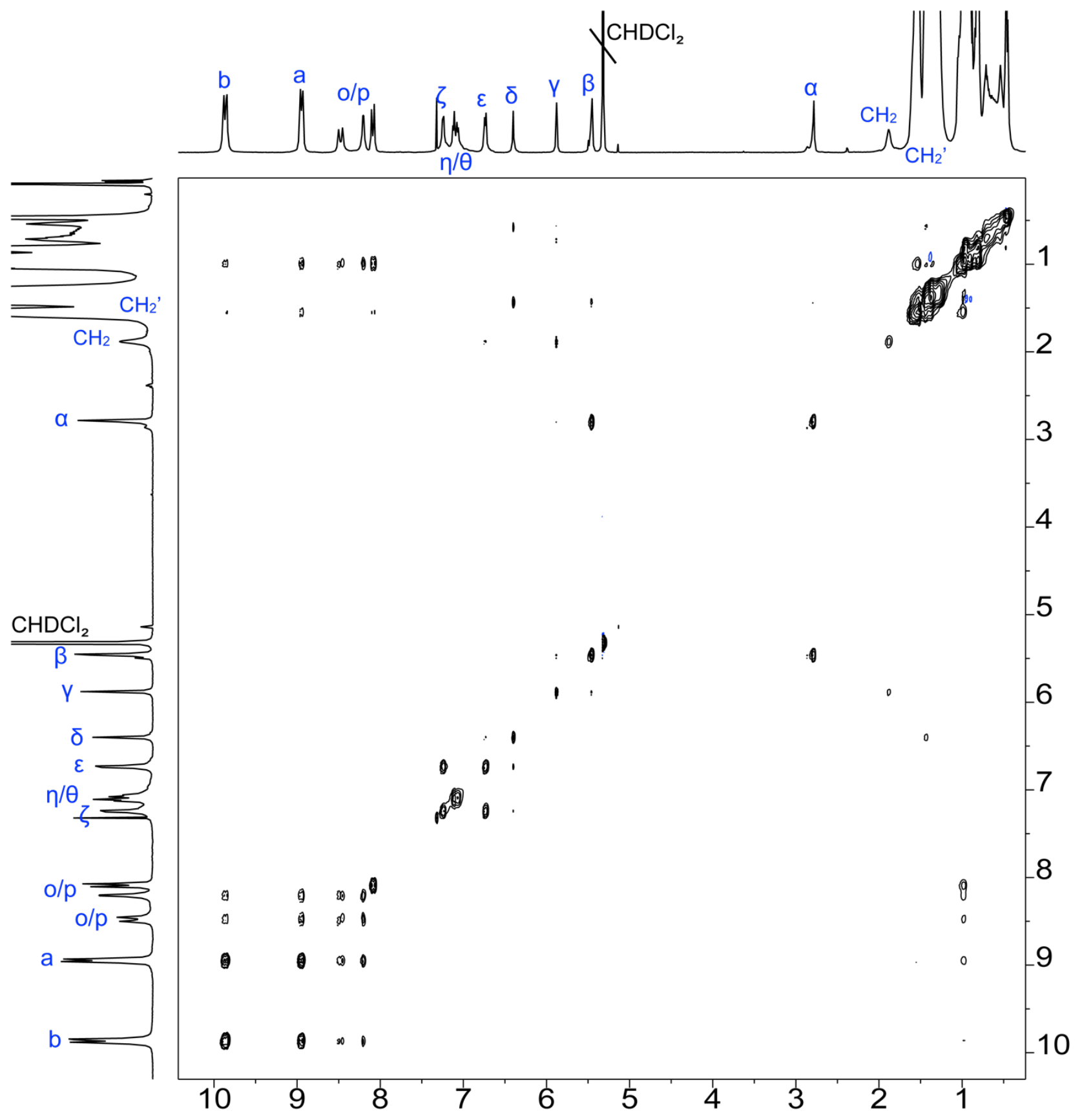

Figure S23. NOESY $(500 \mathrm{MHz})$ spectrum of $\boldsymbol{c}-\mathbf{P} 12 \cdot(\mathrm{T} 6 \mathbf{e})_{2}$ recorded in $\mathrm{CD}_{2} \mathrm{Cl}_{2}$ at $298 \mathrm{~K}$. 
$c-\mathrm{P6} \cdot(\mathrm{T} 3)_{2}$

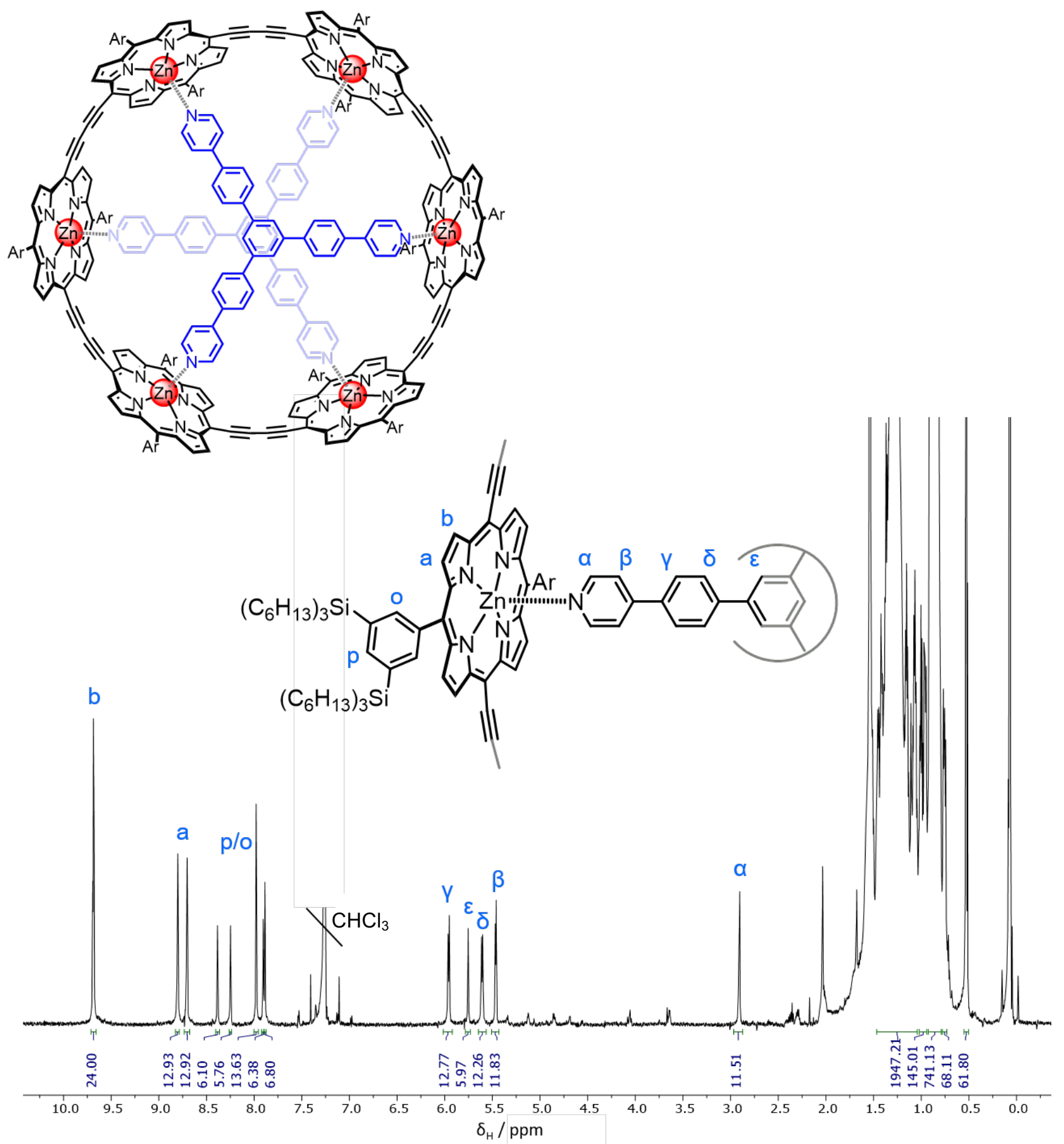

Figure S24. ${ }^{1} \mathrm{H}$ NMR $(700 \mathrm{MHz})$ spectrum of $c$-P6.(T3) $)_{2}$ recorded in $\mathrm{CDCl}_{3}$ at $298 \mathrm{~K}$. 


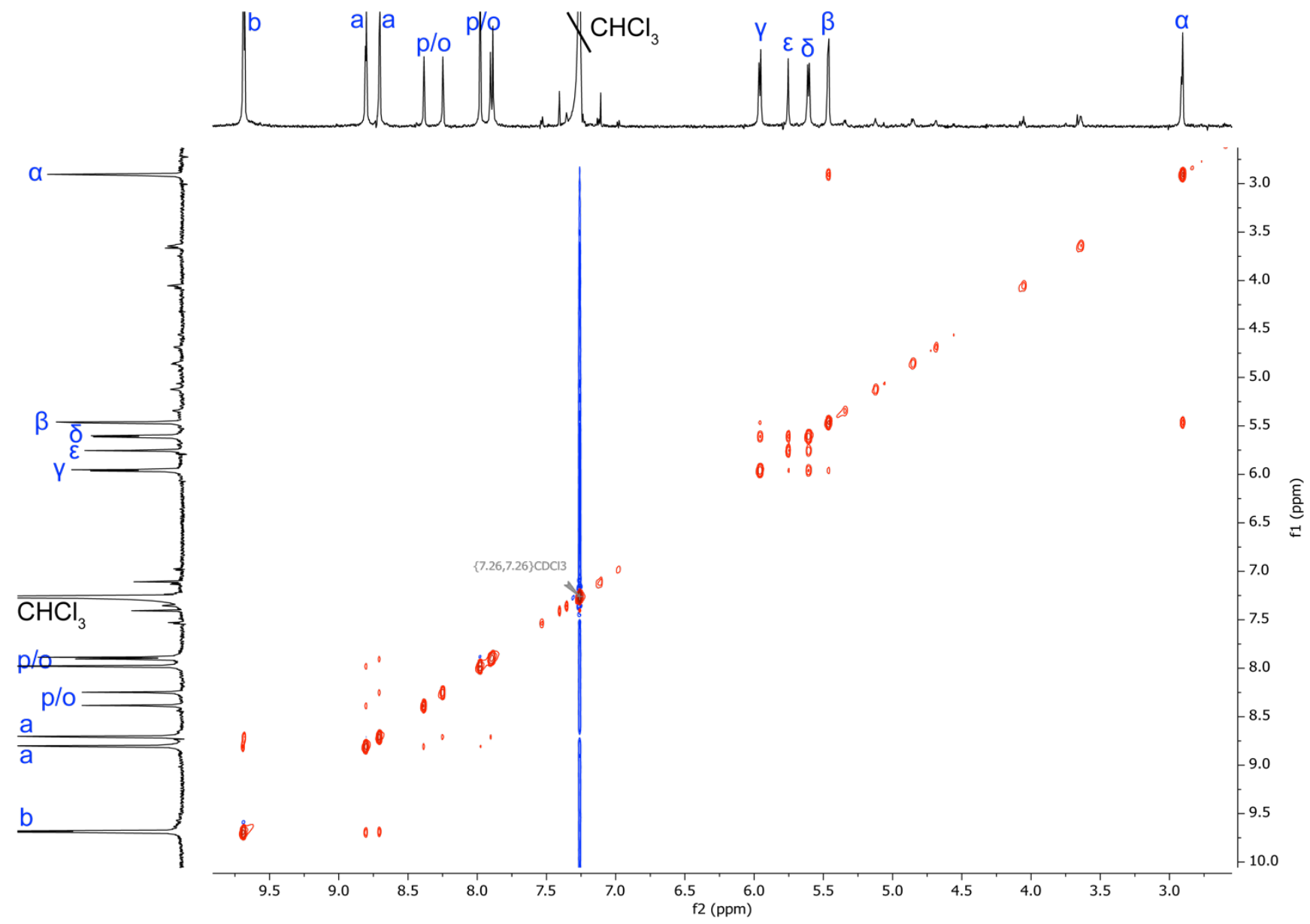

Figure S25. NOESY $(700 \mathrm{MHz})$ spectrum of $c$-P6-(T3) $)_{2}$ recorded in $\mathrm{CDCl}_{3}$ at $298 \mathrm{~K}$. 
$c-\mathrm{P6} \cdot(\mathrm{T} 3 \mathrm{~N})_{2}$

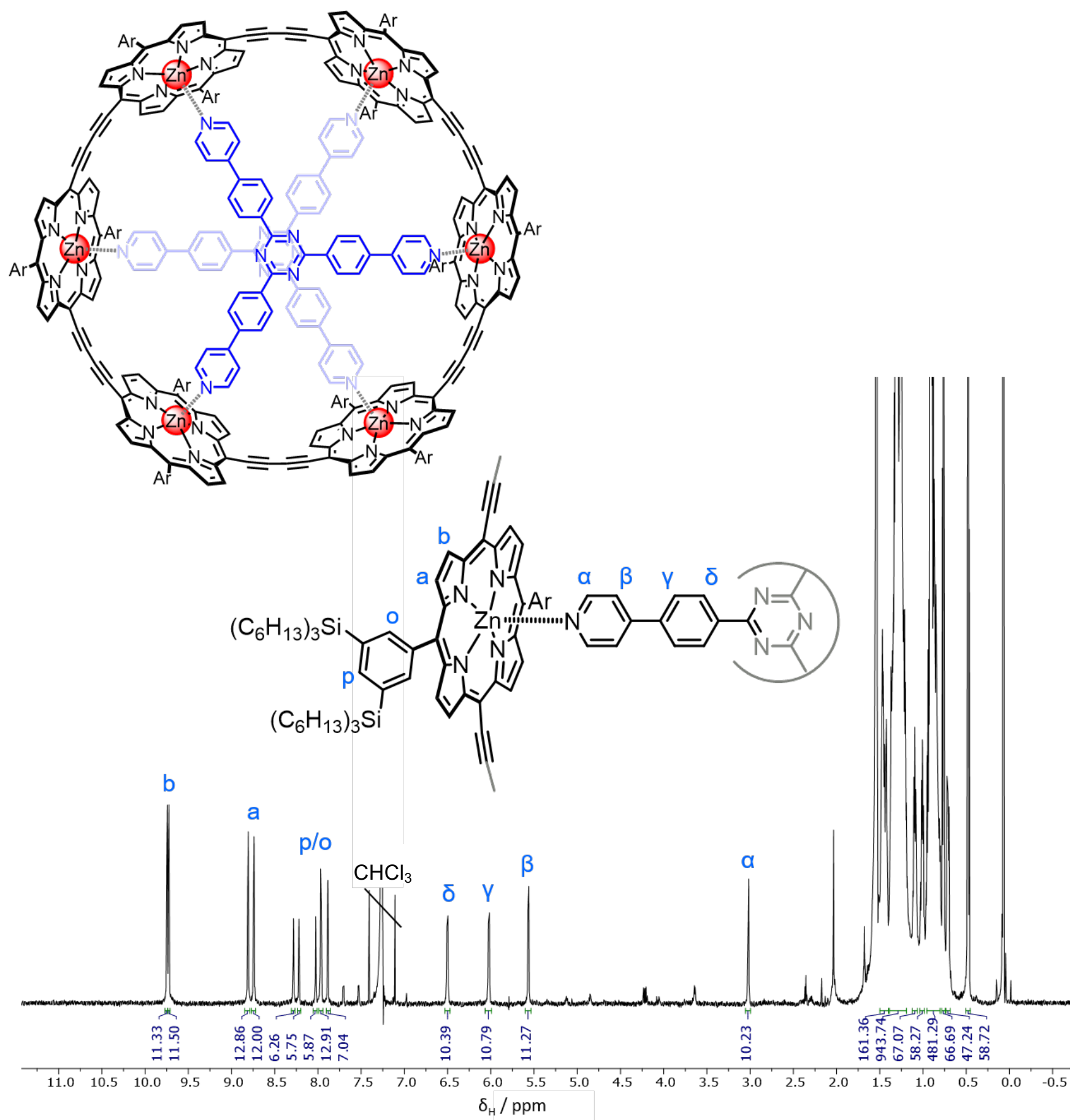

Figure S26. ${ }^{1} \mathrm{H}$ NMR $(700 \mathrm{MHz})$ spectrum of $\boldsymbol{c}-\mathbf{P 6} \cdot(\mathrm{T} 3 \mathrm{~N})_{2}$ recorded in $\mathrm{CDCl}_{3}$ at $298 \mathrm{~K}$. 


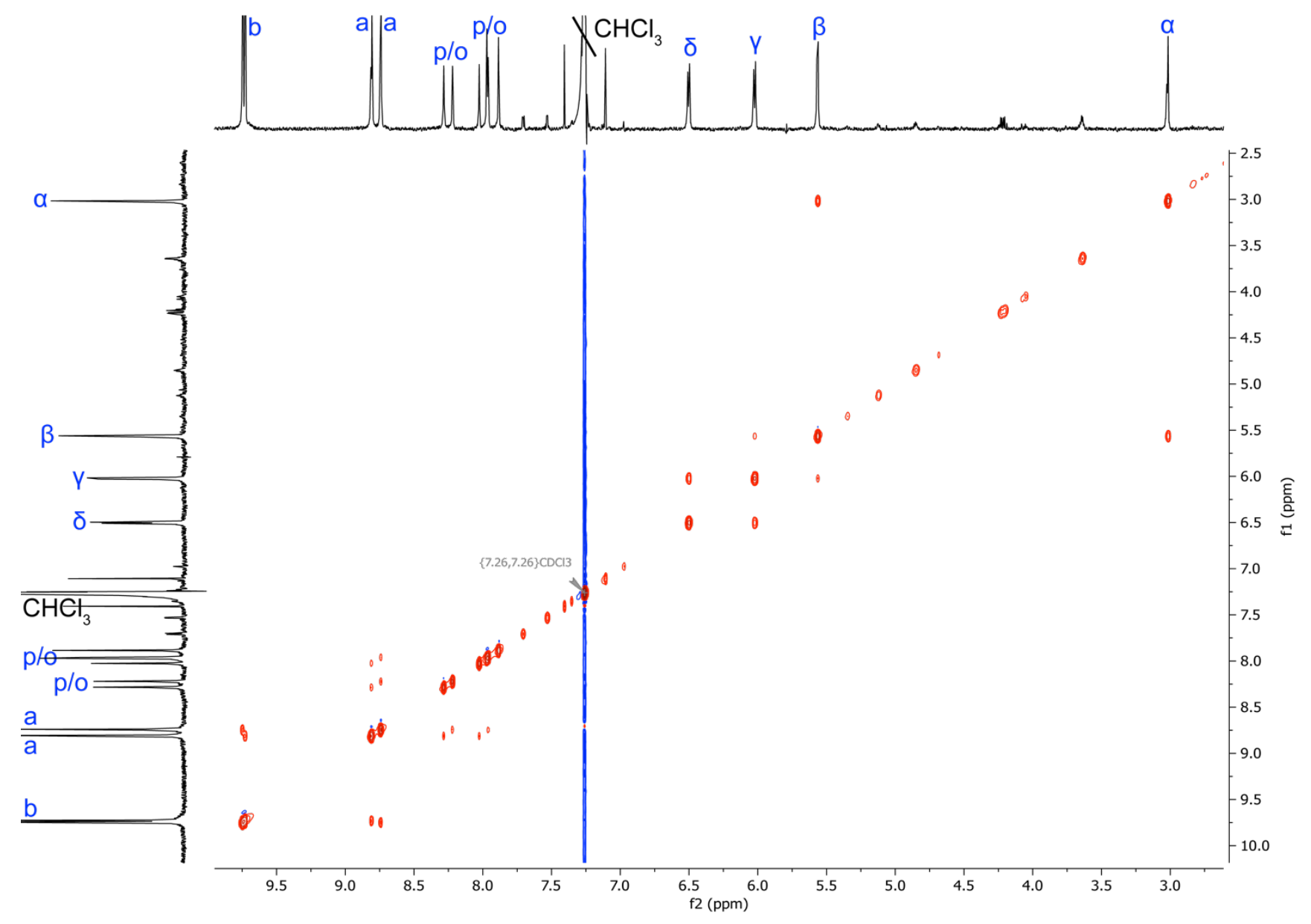

Figure S27. NOESY $(700 \mathrm{MHz})$ spectrum of $\boldsymbol{c}-\mathrm{P6} \cdot(\mathrm{T} 3 \mathrm{~N})_{2}$ recorded in $\mathrm{CDCl}_{3}$ at $298 \mathrm{~K}$. 


\section{UV-vis-NIR Titrations}

\subsection{Determination of Formation Constants}

The formation constants of the templates T3 and T3N with $\boldsymbol{c}$-P6, and T6e with $\boldsymbol{c}$-P12 were determined by UV-vis-NIR denaturation titrations with a large excess of the competing ligand pyridine. ${ }^{11}$ From the denaturation constant $\left(K_{\mathrm{dn}}\right)$ and the binding constant of pyridine to a single porphyrin site $\left(K_{\mathrm{py}}\right)$, the formation constant $\left(K_{\mathrm{f}}\right)$ can be calculated using Equation $\mathrm{S} 1$.

$$
K_{\mathrm{f}}=\frac{K_{\mathrm{py}}^{N}}{K_{\mathrm{dn}}}
$$

where $N$ is the number of pyridine binding sites involved. ${ }^{12}$

Titration of $\boldsymbol{c - P 6}$ with pyridine has shown that the binding constant of pyridine to each porphyrin site is the same as that of the porphyrin monomer. ${ }^{13}$ In other words, the porphyrins in the ring interact with pyridine as if they were not connected to each other. The binding constant of pyridine to the porphyrin monomer was found by reference titrations.

The reference titrations and the denaturation titrations of $\boldsymbol{c}$-P12·(T6e) $)_{2}$ were analyzed using Origin. The denaturation titrations of $\boldsymbol{c}$-P6 $\cdot(\mathbf{T 3})_{2}$ and $\boldsymbol{c}-\mathbf{P 1 2} \cdot(\mathbf{T 3 N})_{2}$ were analyzed using the global analysis software ReactLab ${ }^{\mathrm{TM}}$ Equilibria, a multivariate data analysis program which allows the determination of binding constants in complex multistep equilibria using the whole set of wavelengths.

For the analysis of the denaturation titrations, the binding of the pyridine units and the consequent knock-out of template was simplified to happen in one step. Hence, for the denaturation of a complex with two templates, the model assumes that there are only three colored species in solution at any given time in the titration: the complex with two templates, the complex with one template and all other binding sites saturated with pyridine, and the compound with all porphyrin units bound to pyridine.

$\mathrm{CDCl}_{3}$ was filtered through a plug of basic alumina before use to remove traces of acid and water. All titrations were performed on porphyrins with THS-solubilizing groups.

\subsection{Analysis of 1:1 binding of porphyrins to pyridine}

The reference titration, which is the formation of a 1:1 complex between the porphyrin monomer (P1) and pyridine (py), was fitted to a simple 1:1 binding isotherm shown in Equation S2. ${ }^{14}$

$$
\frac{A-A_{0}}{A_{\mathrm{f}}-A_{0}}=\frac{\left(K_{\mathrm{f}}\left([\mathbf{P} \mathbf{1}]_{0}+[\mathbf{p y}]_{0}\right)+1\right)-\sqrt{\left(K_{\mathrm{f}}\left([\mathbf{P} \mathbf{1}]_{0}+[\mathbf{p y}]_{0}\right)+1\right)^{2}-4 K_{\mathrm{f}}^{2}[\mathbf{P} \mathbf{1}]_{0}[\mathbf{p y}]_{0}}}{2 K_{\mathrm{f}}[\mathbf{P} \mathbf{1}]_{0}}
$$

where $A$ is absorption, $A_{0}$ is the first point in the titration, $A_{\mathrm{f}}$ is the final asymptote of the titration curve, $K_{\mathrm{f}}$ is the formation constant, $[\mathbf{P} 1]_{0}$ is the total concentration of porphyrin, and $[\mathbf{p y}]_{0}$ is the total concentration of pyridine. 


\subsection{Analysis of 'all-or-nothing' denaturation of a 1:2 complex with two identical ligands}

The denaturation titration of the complex $\boldsymbol{c}-\mathbf{P 1 2} \cdot(\mathbf{T 6 e})_{2}$ was found to have many isosbestic points, which suggests that there are only two colored species in solution. If there are only two colored species in solution, the denaturation must be 'all-or-nothing' meaning that $c-P 12 \cdot(T 6 e)_{2}$ goes directly to c-P12·(py) $)_{12}$ without formation of any significant amount of $1: 1$ complex $\boldsymbol{c}-\mathbf{P 1 2} \cdot \mathbf{T 6 e} \cdot(\mathbf{p y})_{\mathbf{6}}$.

The function for fitting the data with this model is derived in this section. We consider the formation constant $K_{\mathrm{f}}$ of $\boldsymbol{c}-\mathbf{P 1 2} \cdot(\mathbf{T 6 e})_{2}$ :

$$
c-\mathrm{P} 12+2 \mathrm{~T} 6 \mathrm{e} \stackrel{K_{\mathrm{f}}}{\rightleftharpoons} c-\mathrm{P} 12(\mathrm{~T} 6 \mathrm{e})_{2}
$$

As described in Section 3.1, we find $K_{\mathrm{f}}$ by performing a competition experiment with pyridine. When an excess of pyridine is added to a solution of the complex, the templates are replaced with the denaturation constant $K_{\mathrm{dn}}$ :

$$
\begin{gathered}
c-\mathrm{P} 12(\mathrm{~T} 6 \mathrm{e})_{2} \\
+12 \mathrm{py} \stackrel{K_{\mathrm{dn}}}{\rightleftharpoons} c-\mathrm{P} 12(\mathrm{py})_{12}+2 \text { T6e } \\
K_{\mathrm{dn}}=\frac{\left[c-\mathrm{P} 12(\mathrm{py})_{12}\right] \cdot[\mathrm{T} 6 \mathrm{e}]^{2}}{\left[c-\mathrm{P} 12(\mathrm{~T} 6 \mathrm{e})_{2}\right] \cdot[\mathrm{py}]^{12}}
\end{gathered}
$$

Rearrangement gives:

$$
0=K_{\mathrm{dn}} \cdot\left[c-\mathrm{P} 12(\mathrm{~T} 6 \mathbf{e})_{2}\right] \cdot[\mathbf{p y}]^{12}-\left[c-\mathrm{P} 12(\mathbf{p y})_{12}\right] \cdot[\mathbf{T} 6 \mathbf{e}]^{2}
$$

The concentration of T6e and $\boldsymbol{c - P 1 2} \cdot(\mathbf{T 6 e})_{2}$ can be expressed using $\boldsymbol{c}-\mathbf{P 1 2} \cdot(\mathbf{p y})_{2}$.

$$
\begin{aligned}
{[\mathrm{T} 6 \mathrm{e}] } & =2 \cdot\left[c-\mathrm{P} 12(\mathbf{p y})_{12}\right] \\
{\left[c-\mathrm{P} 12(\mathrm{~T} 6 \mathrm{e})_{2}\right] } & =[c-\mathrm{P} 12]_{0}-\left[c-\mathrm{P} 12(\mathbf{p y})_{12}\right]
\end{aligned}
$$

Inserting these into the function for $K_{\mathrm{dn}}$ gives:

$$
\begin{aligned}
& 0=K_{\mathrm{dn}} \cdot\left([c-\mathrm{P} 12]_{0}-\left[c-\mathrm{P} 12(\mathbf{p y})_{12}\right]\right) \cdot[\mathbf{p y}]^{12}-\left[c-\mathrm{P} 12(\mathbf{p y})_{12}\right] \cdot\left(2 \cdot\left[c-\mathrm{P} 12(\mathbf{p y})_{12}\right]\right)^{2} \\
& 0=K_{\mathrm{dn}} \cdot[\mathbf{p y}]^{12} \cdot[c-\mathrm{P} 12]_{0}-K_{\mathrm{dn}} \cdot[\mathbf{p y}]^{12} \cdot\left[c-\mathrm{P} 12(\mathbf{p y})_{12}\right]-4 \cdot\left[c-\mathrm{P} 12(\mathbf{p y})_{12}\right]^{3} \\
& 0=-4 \cdot\left[c-\mathrm{P} 12(\mathbf{p y})_{12}\right]^{3}-K_{\mathrm{dn}} \cdot[\mathbf{p y}]^{12} \cdot\left[c-\mathrm{P} 12(\mathbf{p y})_{12}\right]+K_{\mathrm{dn}} \cdot[\mathbf{p y}]^{12} \cdot[c-\mathrm{P} 12]_{0}
\end{aligned}
$$

This is a quadratic equation which has three roots. When solving it, it turns out that two of the roots are complex numbers, so we continue with the solution which is a real number. In this expression, $K=K_{\mathrm{dn}}$ and $n=$ number of porphyrins. 


$$
\begin{aligned}
{\left[\boldsymbol{c}-\mathrm{P} 12(\mathbf{p y})_{\mathbf{1 2}}\right]=} & \frac{1}{2}\left(\frac{\sqrt[3]{\sqrt{3} \cdot \sqrt{K_{\mathrm{dn}}{ }^{3} \cdot[\mathbf{p y}]^{3 n}+27 \cdot K_{\mathrm{dn}}{ }^{2} \cdot[c-\mathrm{P} 12]_{0}^{2} \cdot[\mathbf{p y}]^{2 n}}+9 \cdot K_{\mathrm{dn}} \cdot[c-\mathrm{P} 12]_{0} \cdot[\mathbf{p y}]^{n}}}{3^{\frac{2}{3}}}\right. \\
& \left.-\frac{K_{\mathrm{dn}} \cdot[\mathbf{p y}]^{n}}{\sqrt[3]{3} \cdot \sqrt[3]{\sqrt{3} \cdot \sqrt{K_{\mathrm{dn}}{ }^{3} \cdot[\mathbf{p y}]^{3 n}+27 \cdot K_{\mathrm{dn}}{ }^{2} \cdot[c-\mathrm{P} 12]_{0}^{2} \cdot[\mathbf{p y}]^{2 n}}+9 \cdot K_{\mathrm{dn}} \cdot[c-\mathrm{P} 12]_{0} \cdot[\mathbf{p y}]^{n}}}\right)
\end{aligned}
$$

In order to normalize the function, we divide by the total concentration of porphyrin nanoring on both sides of the equation.

$$
\begin{aligned}
\frac{\left[c-\mathrm{P} 12(\mathbf{p y})_{12}\right]}{[c-\mathrm{P} 12]_{0}}= & \frac{1}{2[c-\mathrm{P} 12]_{0}}\left(\frac{\sqrt[3]{\sqrt{3} \cdot \sqrt{K_{\mathrm{dn}}{ }^{3} \cdot[\mathbf{p y}]^{3 n}+27 \cdot K_{\mathrm{dn}}{ }^{2} \cdot[c-\mathrm{P} 12]_{0}^{2} \cdot[\mathbf{p y}]^{2 n}}+9 \cdot K_{\mathrm{dn}} \cdot[c-\mathrm{P} 12]_{0} \cdot[\mathrm{py}]^{n}}}{3^{\frac{2}{3}}}\right. \\
& \left.-\frac{K_{\mathrm{dn}} \cdot[\mathbf{p y}]^{n}}{\sqrt[3]{3} \cdot \sqrt[3]{\sqrt{3} \cdot \sqrt{{K_{\mathrm{dn}}}^{3} \cdot[\mathbf{p y}]^{3 n}+27 \cdot K_{\mathrm{dn}}{ }^{2} \cdot[c-\mathrm{P} 12]_{0}^{2} \cdot[\mathrm{py}]^{2 n}}+9 \cdot K_{\mathrm{dn}} \cdot[c-\mathrm{P} 12]_{0} \cdot[\mathbf{p y}]^{n}}}\right)
\end{aligned}
$$

At the initial state of the titration, all porphyrin species are bound. At a specific wavelength, the absorption $A_{0}$ can be calculated as:

$$
A_{0}=\varepsilon_{c-\mathrm{P} 12(\mathrm{~T} 6 \mathrm{e})_{2}} \cdot[c-\mathrm{P} 12]_{0} \cdot l
$$

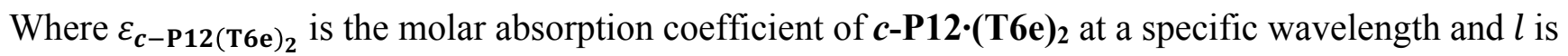
the path length of the cuvette.

At the final stage of the titration, the templates are replaced and all porphyrin species are bound to pyridine. At a specific wavelength, the absorption $A_{\mathrm{f}}$ can be calculated as:

$$
A_{\mathrm{f}}=\varepsilon_{c-\mathrm{P} 12(\mathrm{py})_{12}} \cdot[c-\mathrm{P} 12]_{0} \cdot l
$$

The absorption $A$ at any given moment in the titration can be calculated as:

$$
\begin{gathered}
A=\varepsilon_{c-\mathrm{P} 12(\mathrm{~T} 6 \mathrm{e})_{2}} \cdot\left[c-\mathrm{P} 12(\mathrm{~T} 6 \mathrm{e})_{2}\right] \cdot l+\varepsilon_{c-\mathrm{P} 12(\mathbf{p y})_{12}} \cdot\left[c-\mathrm{P} 12(\mathbf{p y})_{12}\right] \cdot l \\
A=\varepsilon_{c-\mathrm{P} 12(\mathrm{~T} 6 \mathrm{e})_{2}} \cdot\left([c-\mathrm{P} 12]_{0}-\left[c-\mathrm{P} 12(\mathbf{p y})_{12}\right]\right) \cdot l+\varepsilon_{c-\mathrm{P} 12(\mathbf{p y})_{12}} \cdot\left[c-\mathrm{P} 12(\mathbf{p y})_{12}\right] \cdot l
\end{gathered}
$$


Substituting the equations for $A_{0}$ and $A_{\mathrm{f}}$ into this equation gives after rearrangements:

$$
\frac{A-A_{0}}{A_{\mathrm{f}}-A_{0}}=\frac{\left[c-\mathrm{P} 12(\mathrm{py})_{12}\right]}{[c-\mathrm{P} 12]_{0}}
$$

Since we found the expression for $\frac{\left[c-\mathrm{P} 12(\mathrm{py})_{12}\right]}{[c-\mathrm{P} 12]_{0}}$ already, we now substitute that into this equation:

$$
\begin{gathered}
\frac{A-A_{0}}{A_{\mathrm{f}}-A_{0}}=\frac{1}{2 \cdot[c-\mathrm{P} 12]_{0}}\left(\frac{\sqrt[3]{\sqrt{3} \cdot \sqrt{K_{\mathrm{dn}}{ }^{3} \cdot[\mathbf{p y}]^{3 n}+27 \cdot K_{\mathrm{dn}}{ }^{2} \cdot[c-\mathrm{P} 12]_{0}^{2} \cdot[\mathbf{p y}]^{2 n}}+9 \cdot K_{\mathrm{dn}} \cdot[c-\mathrm{P} 12]_{0} \cdot[\mathbf{p y}]^{n}}}{3^{\frac{2}{3}}}\right. \\
\left.-\frac{K_{\mathrm{dn}} \cdot[\mathbf{p y}]^{n}}{\sqrt[3]{3} \cdot \sqrt[3]{\sqrt{3} \cdot \sqrt{K_{\mathrm{dn}}{ }^{3} \cdot[\mathbf{p y}]^{3 n}+27 \cdot K_{\mathrm{dn}}{ }^{2} \cdot[c-\mathrm{P} 12]_{0}^{2} \cdot[\mathbf{p y}]^{2 n}}+9 \cdot K_{\mathrm{dn}} \cdot[c-\mathrm{P} 12]_{0} \cdot[\mathbf{p y}]^{n}}}\right)
\end{gathered}
$$

Throughout the titration, pyridine is in large excess, so we approximate that the concentration of free pyridine in solution is equal to the total concentration of pyridine.

$$
[\mathbf{p y}]=[\mathbf{p y}]_{0}
$$

When we fit titration data in Origin, it is $A$ that we are fitting on the $y$-axis. Therefore, we rearrange the expression so it can be typed into the program directly:

$$
\begin{aligned}
A=\frac{\left(A_{\mathrm{f}}-A_{0}\right)}{2 \cdot[c-\mathrm{P} 12]_{0}}\left(\frac{\sqrt[3]{\sqrt{3} \cdot \sqrt{{K_{\mathrm{dn}}}^{3} \cdot[\mathbf{p y}]^{3 n}+27 \cdot K_{\mathrm{dn}}^{2} \cdot[c-\mathrm{P} 12]_{0}^{2} \cdot[\mathbf{p y}]^{2 n}}+9 \cdot K_{\mathrm{dn}} \cdot[c-\mathrm{P} 12]_{0} \cdot[\mathbf{p y}]^{n}}}{3^{\frac{2}{3}}}\right. \\
\left.-\frac{K_{\mathrm{dn}} \cdot[\mathbf{p y}]^{n}}{\sqrt[3]{3} \cdot \sqrt[3]{\sqrt{3} \cdot \sqrt{{K_{\mathrm{dn}}}^{3} \cdot[\mathbf{p y}]^{3 n}+27 \cdot K_{\mathrm{dn}}{ }^{2} \cdot[c-\mathrm{P} 12]_{0}^{2} \cdot[\mathbf{p y}]^{2 n}}+9 \cdot K_{\mathrm{dn}} \cdot[c-\mathrm{P} 12]_{0} \cdot[\mathbf{p y}]^{n}}}\right) \\
+A_{0}
\end{aligned}
$$

\subsection{Using ReactLab Equilibria to determine equilibrium constants}

The multiple step denaturation titrations were analyzed via nonlinear regression using a global analysis multiple regression to model the entire spectra simultaneously (ReactLab EQUILIBRIA software by Jplus Consulting). This allowed us to determine both the binding constants directly (expressed as $\left.\log \left(K_{\mathrm{f}}\right)\right)$ and the spectra of the species involved in the equilibrium processes. 
Figure S28 shows an example of the analysis performed with ReactLab Equilibria, in this case for titration $\boldsymbol{c}$-P6 $\cdot(\mathbf{T 3 N})_{2}$ in toluene run 1. In this analysis, $\mathrm{M}$ is $\boldsymbol{c}-\mathbf{P 6}, \mathrm{T}$ is $\mathbf{T 3 N}$ and $\mathrm{P}$ is pyridine. We enter into the program the binding constants for three pyridine units binding to $\mathrm{MT}\left(\left(K_{\mathrm{py}}\right)^{3}\right.$, as described in Section 3.1) and the binding constant for six pyridine units binding to $\mathrm{M}\left(\left(K_{\mathrm{py}}\right)^{6}\right)$ in order to define the species MTP3 and MP6. Then, we define the steps we want to find binding constants for: $\mathrm{M}+\mathrm{T} \rightarrow \mathrm{MT}$ $\left(K_{\mathrm{f} 1}\right)$ and $\mathrm{MT}+\mathrm{T} \rightarrow \mathrm{MT} 2\left(K_{\mathrm{f} 2}\right)$. The binding constants we know, the ones with pyridine are locked (here called FALSE) and the ones we want to find are allowed to vary (called TRUE). This model does not include stepwise binding of pyridine to form e.g. MP5 or MP4. The exclusion of this is valid because the binding of template to the porphyrin nanoring is extremely strong, so whenever the concentration of pyridine is high enough to knock out the template, it is also high enough to completely saturate the free porphyrin binding sites with pyridine. Hence, unbound porphyrin units are never present in the titration, and effectively we go directly from MT2 $\rightarrow$ MTP3 $\rightarrow$ MP6.

\begin{tabular}{|c|c|c|c|c|c|c|}
\hline Reactants & $\begin{array}{c}\text { Reaction } \\
\text { Type }\end{array}$ & Products & Label & $\begin{array}{c}\text { Parameters } \\
\log K / \beta\end{array}$ & \pm & Fit $\mathbf{b}$ \\
\hline $\mathrm{MT}+3 \mathrm{P}$ & $=$ & MTP3 & & 12.34 & & FALSE \\
\hline $\mathrm{M}+6 \mathrm{P}$ & $=$ & MP6 & & 24.68 & & FALSE \\
\hline $\mathrm{M}+\mathrm{T}$ & $=$ & $\mathrm{MT}$ & & 16.49 & 0.002 & TRUE \\
\hline $\mathrm{MT}+\mathrm{T}$ & $=$ & MT2 & & 12.19 & 0.025 & TRUE \\
\hline
\end{tabular}

Figure S28: Part of the interface in ReactLab Equilibria showing the model used for the analysis. The titration of $\boldsymbol{c}$-P6·(T3N) 2 in toluene run 1 is used as example.

However, in order to find the binding constants, we need to define all the species involved in our model (Figure S29): P and T which are non-absorbing in the titration, M and MT which are effectively never present as we just discussed, and then MT2, MTP3, and MP6. The spectra of the defined species can be fixed to a known spectrum or be allowed to vary. In this case, the spectra of MP6, M, and MT were fixed, while MT2 and MTP3 were allowed to vary freely.

\begin{tabular}{|c|c|c|c|c|c|c|c|}
\hline Species & $\mathrm{P}$ & $\mathrm{M}$ & $\mathrm{T}$ & $\mathrm{MTP}$ & $\mathrm{MP6}$ & $\mathrm{MT}$ & MT2 \\
\hline
\end{tabular}

Figure S29: Part of the interface in ReactLab Equilibria showing the defined species used for the analysis. The titration of c-P6.(T3N) $)_{2}$ in toluene run 1 is used as example.

For all titration analyzed with ReactLab, the results are presented as the determined formation constants, the programs prediction of the three spectra MT2, MTP3 and MP6, and a plot of data points with the binding isotherm at three characteristic wavelengths. 


\subsection{Calculation of Statistical Factors}

To understand the stability constants of different complexes, it is useful to factor out statistical contributions. A measured equilibrium constant $K_{\text {eq }}$ can be factorized into its statistical component $K_{\sigma}$ and its statistically corrected value $K_{\text {chem }}$ according to the following equation:

$$
\begin{gathered}
w A+x B \rightleftharpoons y C+z D \\
K_{\mathrm{eq}}=\frac{Q_{C}^{y} Q_{D}^{z}}{Q_{A}^{w} Q_{B}^{x}}=\frac{\sigma_{A}^{w} \sigma_{B}^{x}}{\sigma_{C}^{y} \sigma_{D}^{z}} \cdot \frac{Q_{C}^{\prime}{ }_{C} Q_{D}^{\prime z}}{Q_{A}^{\prime w} Q_{B}^{\prime x}}=K_{\sigma} \cdot K_{\mathrm{chem}}
\end{gathered}
$$

where for each species $i, Q_{i}$ is the partition coefficient, $Q_{i}^{\prime}$ is the statistically corrected partition coefficient, and $\sigma_{i}$ is the symmetry number. ${ }^{15-18}$

Values of $K_{\sigma}$ were calculated using Benson's symmetry number method. ${ }^{15,18}$ The symmetry number $(\sigma)$ of each species is the product of its external symmetry number, $\sigma_{\text {ext }}$, (calculated from the point group of the molecule) and its internal symmetry number, $\sigma_{\text {int }}$, (calculated from the number of degenerate internal rotors). The values of $\sigma$ for all the complexes involved are shown in Table S3. The external symmetry number is defined as the number of different but indistinguishable atomic arrangements that can be obtained by rotating a given molecule as a whole as a rigid object. The internal symmetry number is defined as the number of different but indistinguishable atomic arrangements that can be obtained by internal rotations around single bonds.

\begin{tabular}{|c|c|c|c|c|}
\hline compounds & point group & $\sigma_{\text {int }}$ & $\sigma_{\text {ext }}$ & $\boldsymbol{\sigma}$ \\
\hline pyridine & $C_{2 v}$ & 1 & 2 & 2 \\
\hline T3, T3N & $D_{3 \mathrm{~h}}$ & 1 & 6 & 6 \\
\hline T6e & $D_{6 \mathrm{~h}}$ & 1 & 12 & 12 \\
\hline$c-\mathrm{P} 6, c-\mathrm{P} 6 \cdot \mathrm{py}_{6}, c-\mathrm{P} 12 \cdot \mathrm{T} 6 \mathrm{e}, c-\mathrm{P} 12 \cdot \mathrm{T} 6 \mathrm{e} \cdot \mathrm{py}_{6}$ & $D_{6 \mathrm{~h}}$ & $2^{6}$ & 12 & 768 \\
\hline$c-\mathrm{P} 12, c-\mathrm{P} 12 \cdot \mathrm{py}_{12}$ & $D_{12 \mathrm{~h}}$ & $2^{12}$ & 24 & 98304 \\
\hline$c-\mathrm{P} 6 \cdot \mathrm{T} 3, c-\mathrm{P} 6 \cdot \mathrm{T} 3 \mathrm{~N}, c-\mathrm{P} 6 \cdot \mathrm{T} 3 \cdot \mathrm{py}_{3}, c-\mathrm{P} 6 \cdot \mathrm{T} 3 \mathrm{~N} \cdot \mathrm{py}_{3}$ & $D_{3 \mathrm{~h}}$ & $2^{3}$ & 6 & 48 \\
\hline$c-\mathrm{P} 6 \cdot(\mathrm{T} 3)_{2}, c-\mathrm{P} 6 \cdot(\mathrm{T} 3 \mathrm{~N})_{2}$ & $D_{3 \mathrm{~d}}$ & 1 & 6 & 6 \\
\hline$c-\mathrm{P} 12 \cdot(\mathrm{T} 6 \mathrm{e})_{2}$ & $D_{6 \mathrm{~d}}$ & 1 & 12 & 12 \\
\hline
\end{tabular}

Table S3. Internal, external and total symmetry numbers for each component.*

* Note that when counting internal rotations and calculating $\sigma_{\text {int }}$, we do not include rotors that are unaffected by the binding process, such as the para-phenylene links in $\mathbf{T 3}$, because if a rotor is unaffected by the binding process it has no influence on $K_{\sigma}$.

In order to factor out statistical contributions we have calculated the statistical factors $\left(K_{\sigma}\right)$ for all the species involved in the break-up titrations. Figure S30 shows the analysis of the break-up of $\boldsymbol{c}$-P6•(T3) 


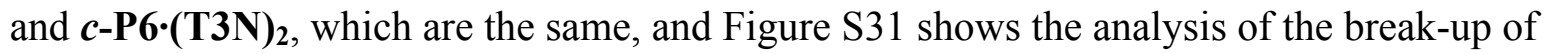
c-P12-(T6e) $)_{2}$. In these figures, the equilibria are drawn with regular reaction arrows to show the direction of the equilibrium constants. $K_{\sigma}$ and $K_{\text {chem }}$ were only calculated for the formation constants, and the statistically corrected formation constants were then inserted in the equations for the denaturation constants following the equation for denaturation:

$$
K_{f}=\frac{K_{p y}^{n}}{K_{d n}}
$$

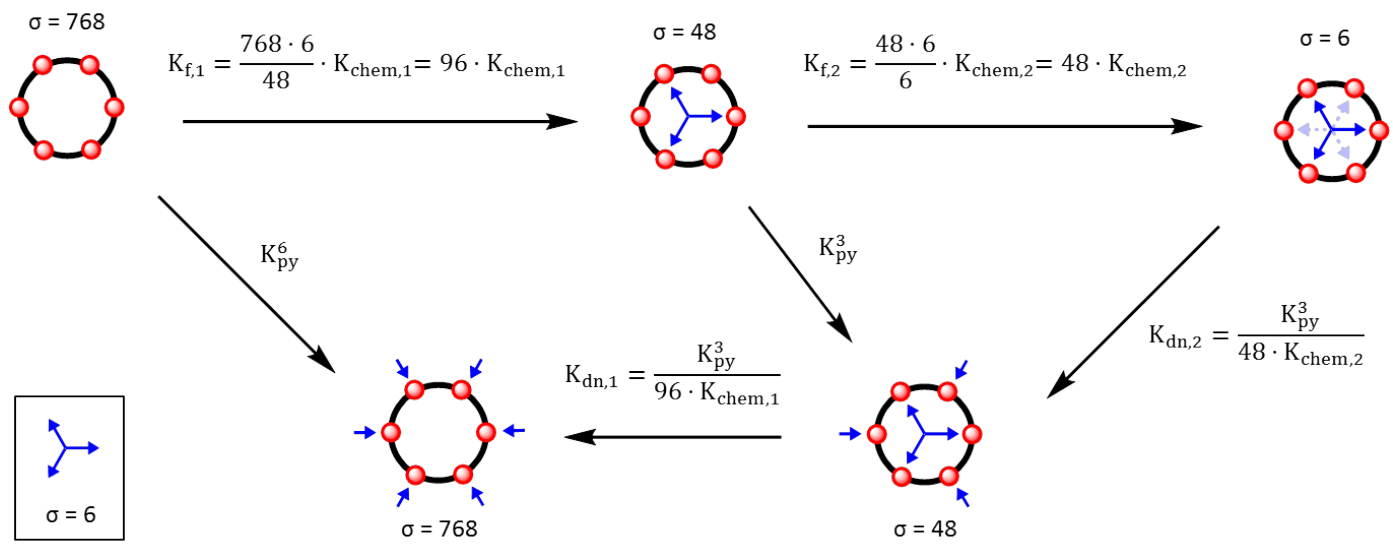

Figure S30. Statistical factors involved in the stepwise formation and denaturation of $c-P 6 \cdot(T 3)_{2}$ and $c-P 6 \cdot(T 3 N)_{2}$.

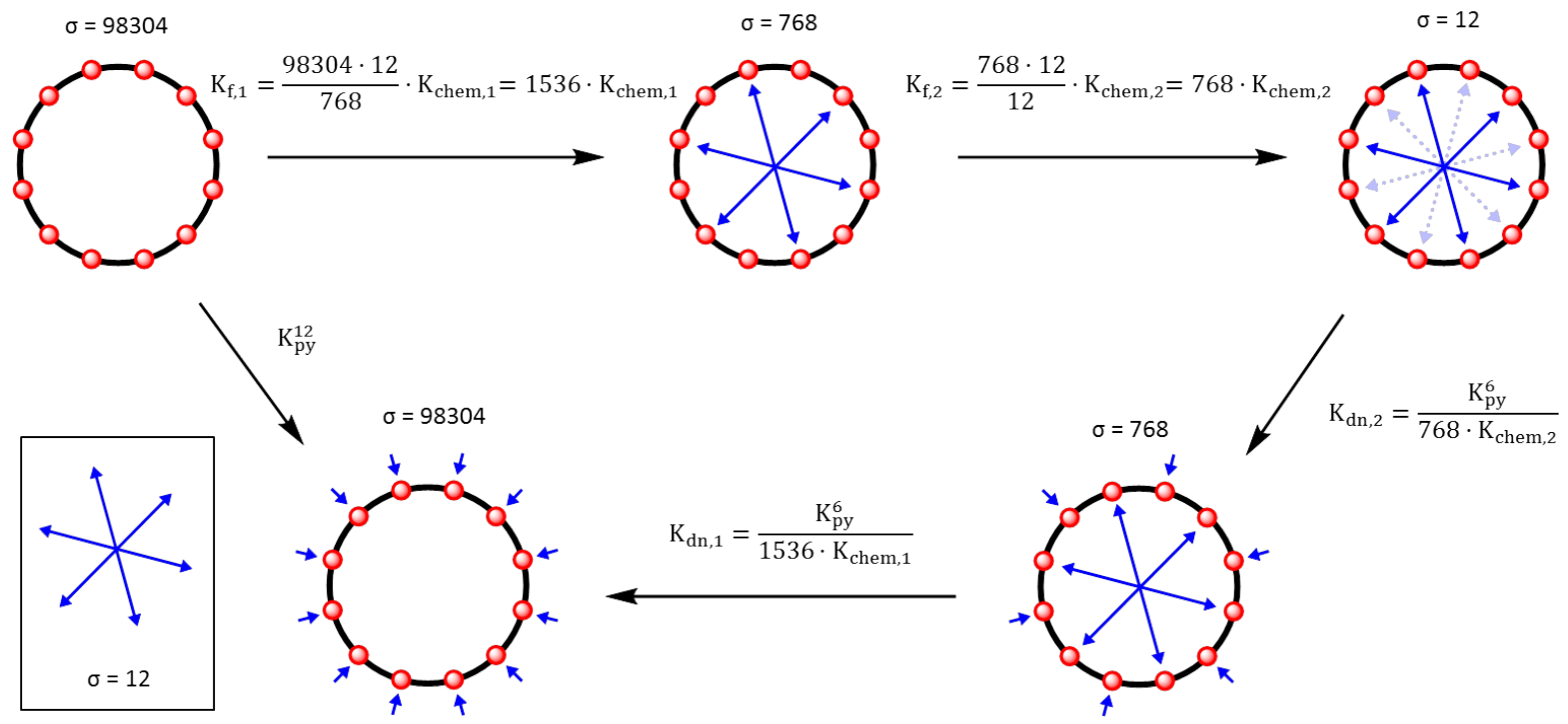

Figure S31. Statistical factors involved in the stepwise formation and denaturation of $c-P 12 \cdot(T 6 e){ }_{2}$. 


\subsection{Reference Titrations}

Reference titrations were performed to determine the binding constant $K_{\text {py }}$ of pyridine to a porphyrin monomer in pure $\mathrm{CDCl}_{3}$. The titrations were performed on a monomer (P1) shown in Figure S32. For the binding constant in toluene, the previously reported value of $(1.3 \pm 0.1) \times 10^{4} \mathrm{M}^{-1}$ was used. ${ }^{19}$

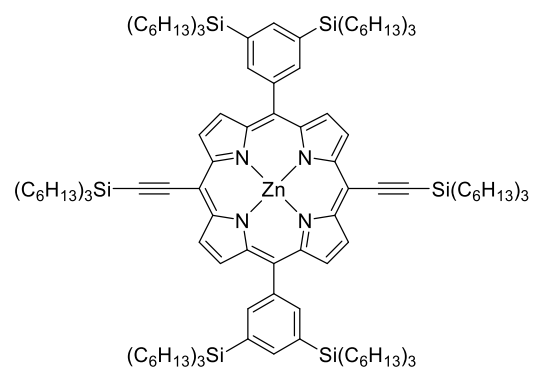

Figure S32: The porphyrin monomer P1 used for reference titrations.
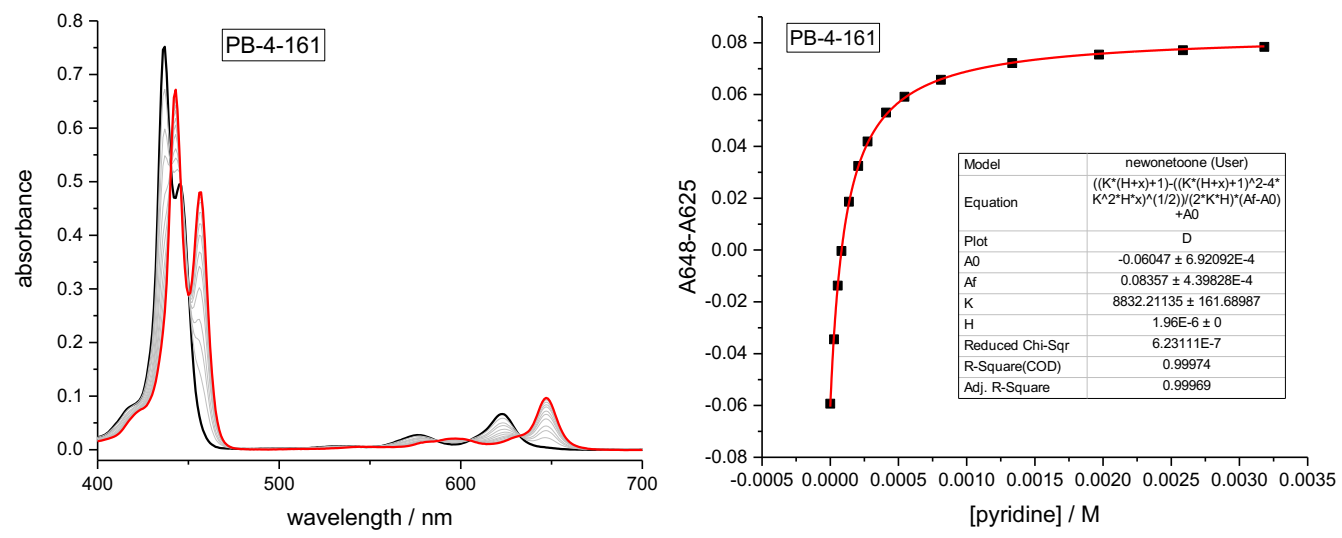

Figure S33. UV-vis-NIR titration of pyridine and P1 (run 1, $\mathrm{CDCl}_{3}, 298 \mathrm{~K},[\mathrm{P} 1]=1.96 \mu \mathrm{M}, \mathrm{K}_{\mathrm{py}}=8800 \mathrm{M}^{-1}$ )
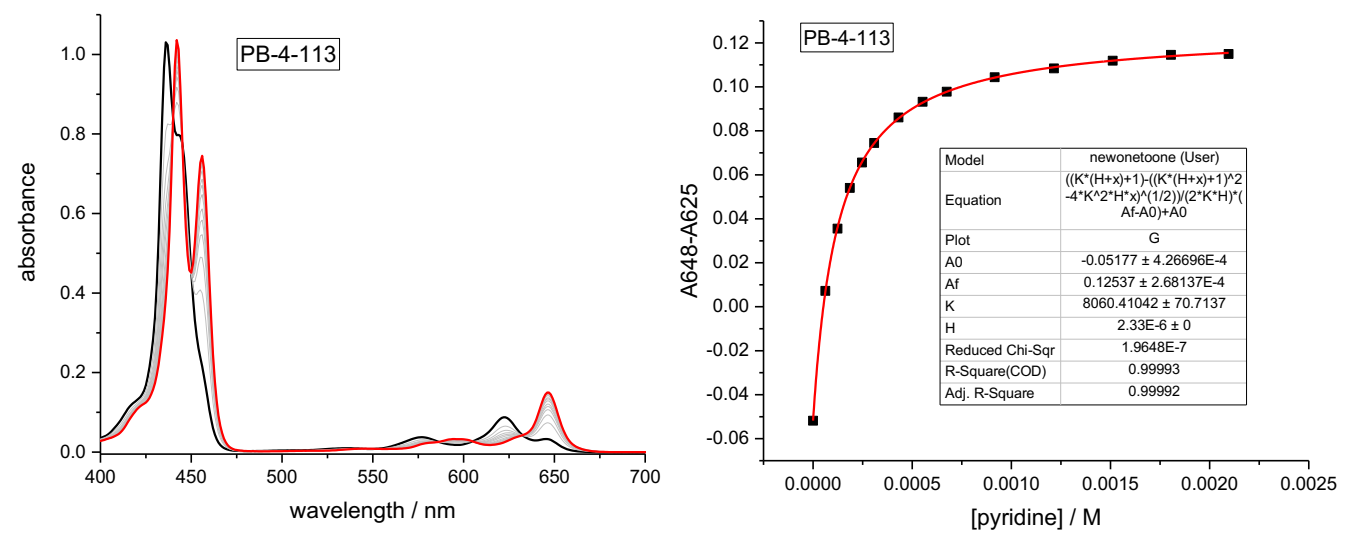

Figure S34. UV-vis-NIR titration of pyridine and P1 (run 2, $\mathrm{CDCl}_{3}, 298 \mathrm{~K},[\mathrm{P} 1]=2.33 \mu \mathrm{M}, \mathrm{K}_{\mathrm{py}}=8100 \mathrm{M}^{-1}$ )

The mean value of $K_{\mathrm{py}}$ in $\mathrm{CDCl}_{3}$ was calculated to be $(8.4 \pm 0.5) \times 10^{3} \mathrm{M}^{-1}$. Errors are reported as the sample standard deviation. 


\subsection{Denaturation Titrations}
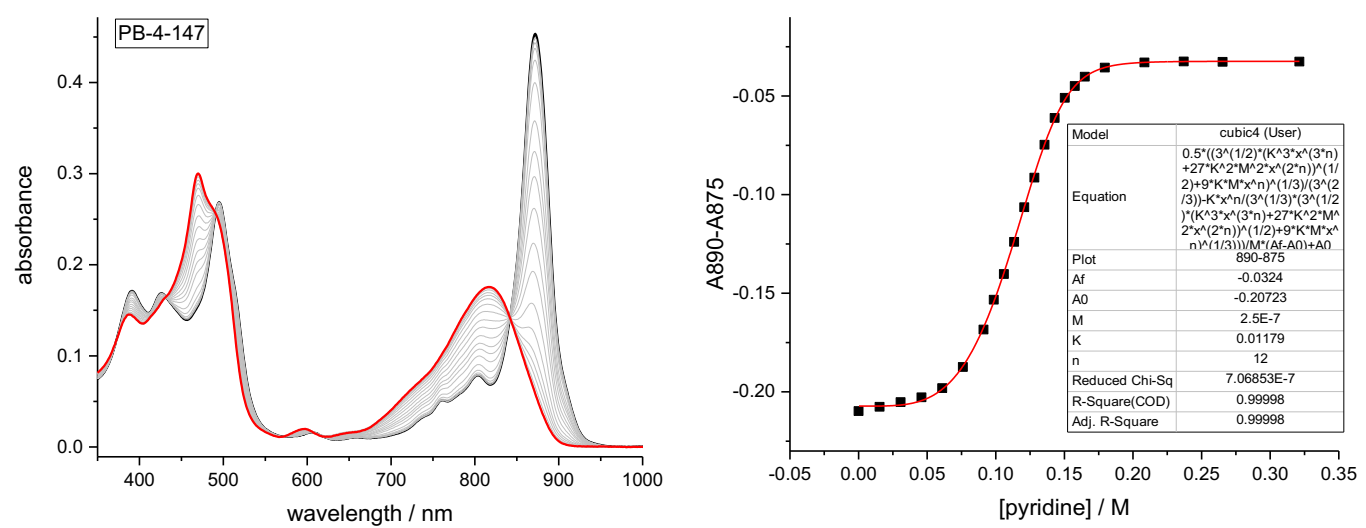

Figure S35. UV-vis-NIR titration of pyridine and $\mathbf{c - P 1 2 \cdot ( T 6 e )})_{2}$ illustrating the removal of the two T6e templates. (run $1, \mathrm{CDCl}_{3}$, $\left.298 \mathrm{~K},\left[\boldsymbol{c}-\mathrm{P} 12 \cdot(\mathrm{T} 6 \mathrm{e})_{2}\right]=0.25 \mu \mathrm{M}, K_{\mathrm{dn}}=0.0118 \mathrm{M}^{-10}\right)$. The fitted binding isotherm is compared to the experimental data points at $\mathrm{A} 890 \mathrm{~nm}-\mathrm{A} 875 \mathrm{~nm}$. PB-4-147.
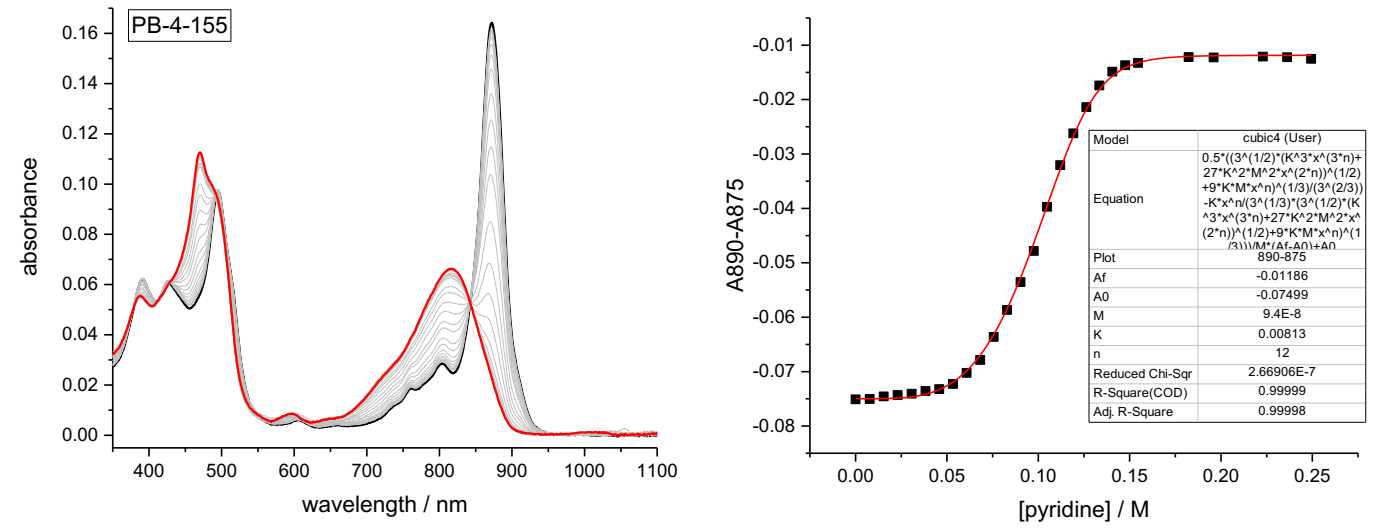

Figure S36. UV-vis-NIR titration of pyridine and $c-\mathrm{P} 12 \cdot(\mathrm{T6e})_{2}$ illustrating the removal of the two $\mathrm{T}^{2} \mathrm{e}$ templates. (run 2 , CDCl 3 , $\left.298 \mathrm{~K},\left[c-\mathrm{P} 12 \cdot(\mathrm{T6e})_{2}\right]=0.094 \mu \mathrm{M}, K_{\mathrm{dn}}=0.00813 \mathrm{M}^{-10}\right)$. The fitted binding isotherm is compared to the experimental data points at $A 890 \mathrm{~nm}-\mathrm{A} 875 \mathrm{~nm}$. PB-4-155.
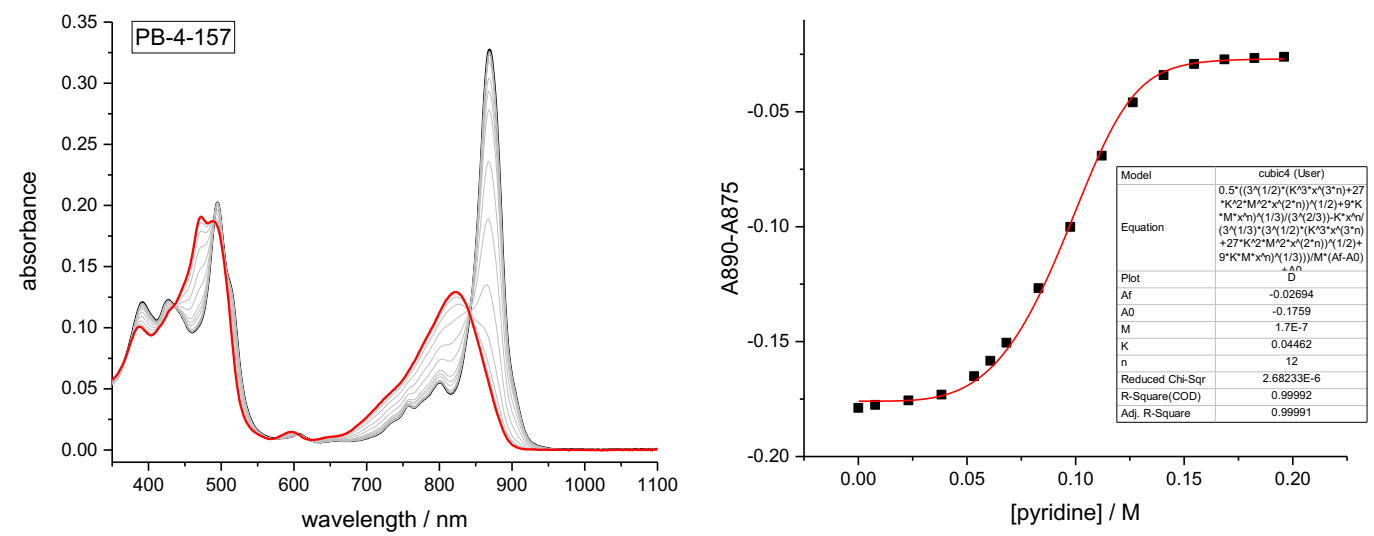

Figure S37. UV-vis-NIR titration of pyridine and $c-P 12 \cdot(\mathrm{T6e})_{2}$ illustrating the removal of the two T6e templates. (run 1 , toluene, $\left.298 \mathrm{~K},\left[\boldsymbol{c}-\mathbf{P} 12 \cdot(\mathrm{T6e})_{2}\right]=0.17 \mu \mathrm{M}, K_{\mathrm{dn}}=0.0446 \mathrm{M}^{-10}\right)$. The fitted binding isotherm is compared to the experimental data points at $A 890 \mathrm{~nm}-\mathrm{A} 875 \mathrm{~nm}$. PB-4-157. 

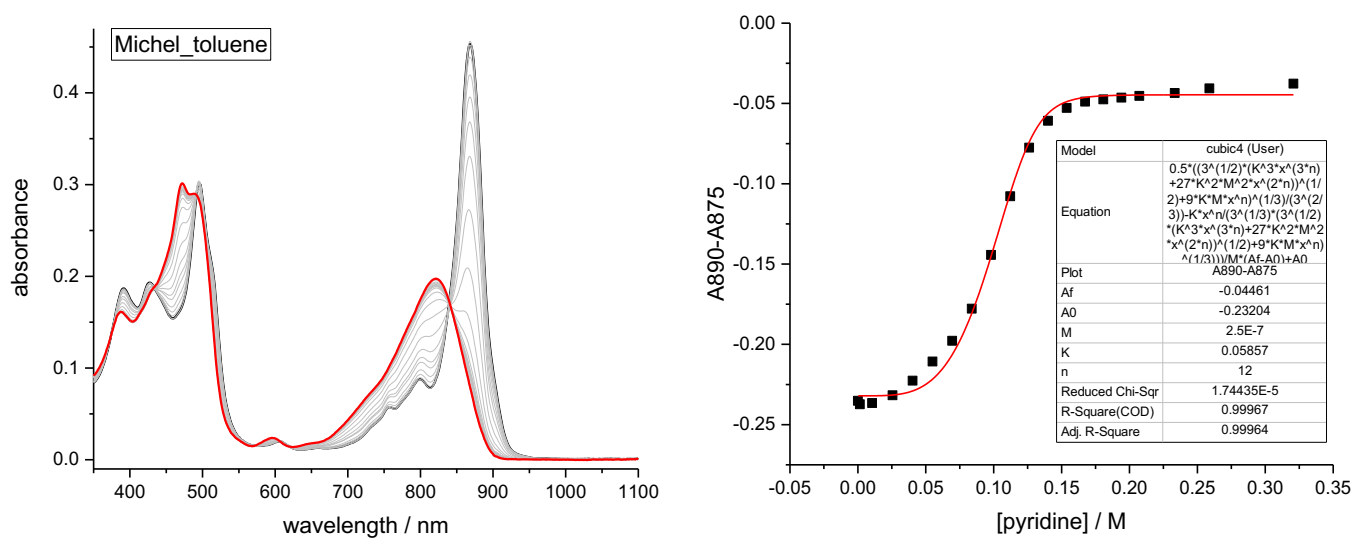

Figure S38. UV-vis-NIR titration of pyridine and $c-P 12 \cdot(\mathrm{T6e})_{2}$ illustrating the removal of the two T6e templates. (run 2 , toluene, $\left.298 \mathrm{~K},\left[\boldsymbol{c}-\mathrm{P} 12 \cdot(\mathrm{T6e})_{2}\right]=0.25 \mu \mathrm{M}, K_{\mathrm{dn}}=0.0586 \mathrm{M}^{-10}\right)$. The fitted binding isotherm is compared to the experimental data points at A890 nm - A875 nm. Michel_000.
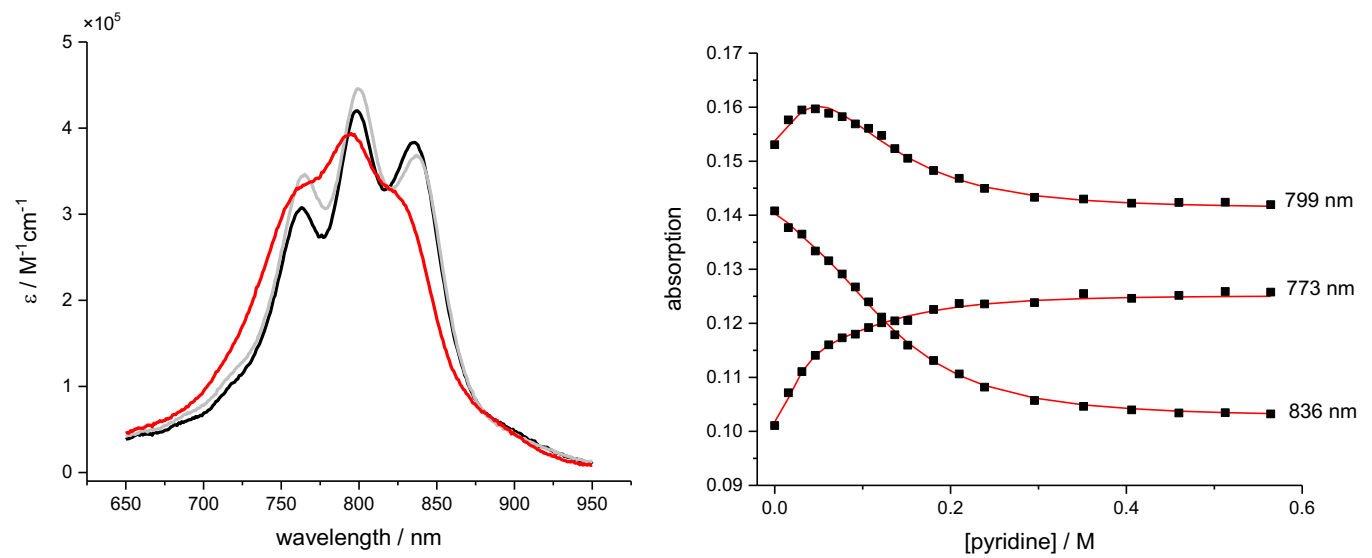

Figure S39. UV-vis-NIR-NIR titration of pyridine and $\mathbf{c}-\mathbf{P 6} 6 \cdot(\mathrm{T} 3)_{2}$ illustrating the removal of the two T3 templates. (run 1 , $\left.\mathrm{CDCl}_{3}, 298 \mathrm{~K},\left[\mathbf{c}-\mathrm{P6} \cdot(\mathrm{T} 3)_{2}\right]=0.37 \mu \mathrm{M}, K_{\mathrm{f}, 1}=2.75 \times 10^{15} \mathrm{M}^{-1} K_{\mathrm{f}, 2}=4.90 \times 10^{13} \mathrm{M}^{-1}\right)$. The fitted binding isotherm is compared to the experimental data points at characteristic wavelengths, and the fitted spectra of the three species in solution are

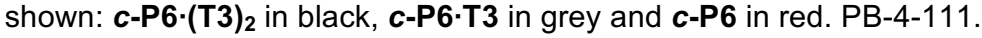
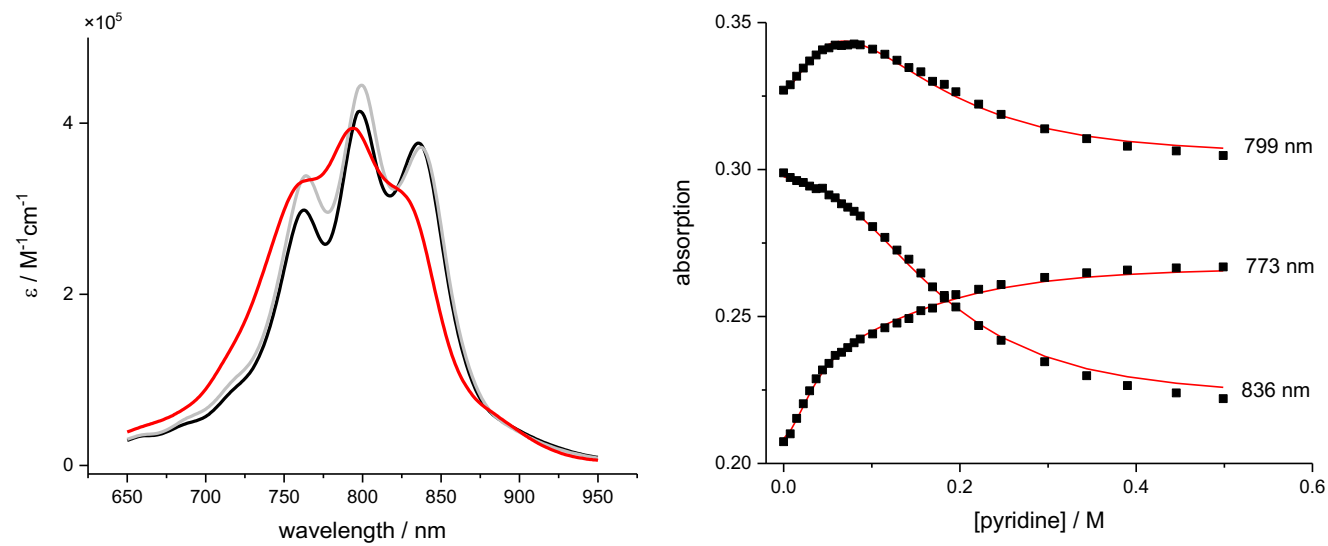

Figure S40. UV-vis-NIR-NIR titration of pyridine and c-P6.(T3) ${ }_{2}$ illustrating the removal of the two T3 templates. (run 2 , $\mathrm{CDCl}_{3}, 298 \mathrm{~K},\left[\mathbf{c}-\mathrm{P6} \cdot(\mathrm{T} 3)_{2}\right]=0.79 \mu \mathrm{M}, K_{\mathrm{f}, 1}=2.75 \times 10^{15} \mathrm{M}^{-1} K_{\mathrm{f}, 2}=5.62 \times 10^{13} \mathrm{M}^{-1}$ ). The fitted binding isotherm is compared to the experimental data points at characteristic wavelengths, and the fitted spectra of the three species in solution are shown: $\boldsymbol{c}$-P6·(T3) ${ }_{2}$ in black, $\boldsymbol{c}-\mathbf{P 6}$-T3 in grey and $\boldsymbol{c}$-P6 in red. PB-5-49. 

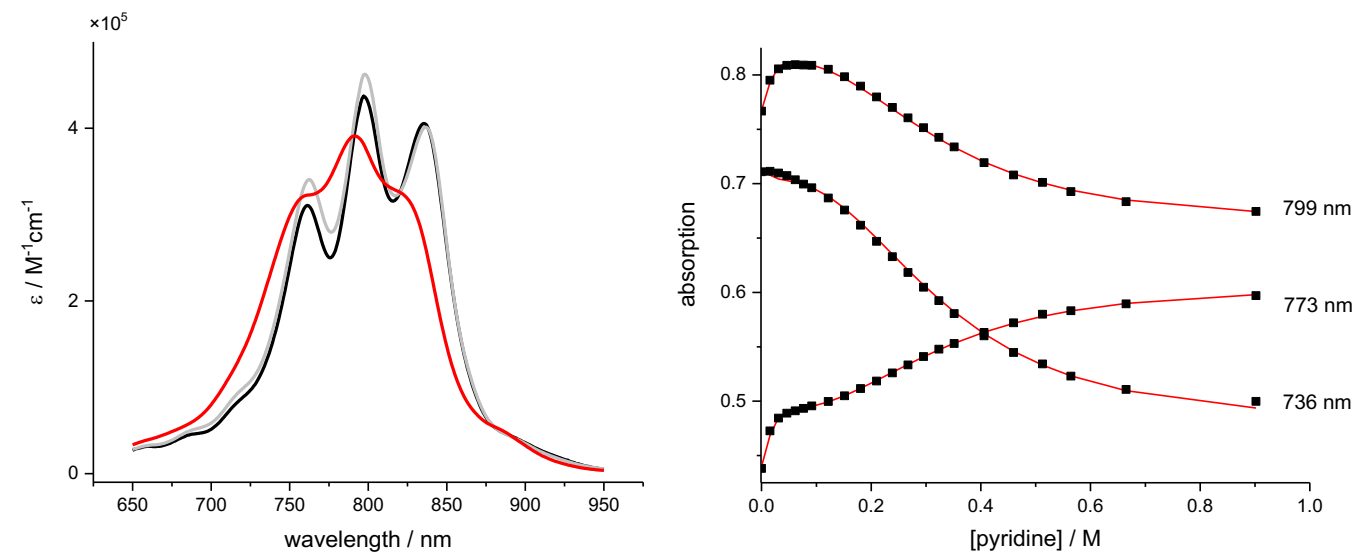

Figure S41. UV-vis-NIR titration of pyridine and $\boldsymbol{c}$-P6-(T3) ${ }_{2}$ illustrating the removal of the two T3 templates. (run 1 , toluene, $298 \mathrm{~K},\left[\boldsymbol{c}\right.$-P6 $\left.(\mathrm{T} 3)_{2}\right]=1.76 \mu \mathrm{M}, K_{\mathrm{f}, 1}=2.88 \times 10^{16} \mathrm{M}^{-1} K_{\mathrm{f}, 2}=6.92 \times 10^{12} \mathrm{M}^{-1}$ ). The fitted binding isotherm is compared to the experimental data points at characteristic wavelengths, and the fitted spectra of the three species in solution are shown: c-P6.(T3) ${ }_{2}$ in black, c-P6-T3 in grey and $c$-P6 in red. PB-4-63.
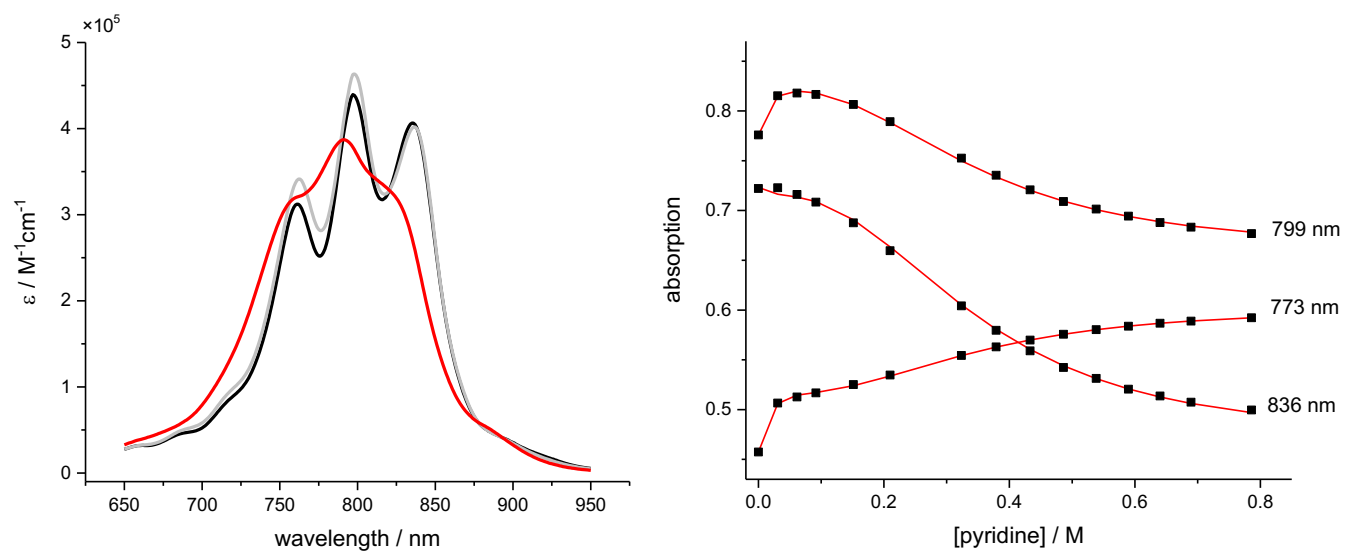

Figure S42. UV-vis-NIR titration of pyridine and $\boldsymbol{c}$-P6-(T3) ${ }_{2}$ illustrating the removal of the two T3 templates. (run 2, toluene, $\left.298 \mathrm{~K},\left[\boldsymbol{c}-\mathrm{P6} \cdot(\mathrm{T} 3)_{2}\right]=1.78 \mu \mathrm{M}, K_{\mathrm{f}, 1}=3.47 \times 10^{16} \mathrm{M}^{-1} K_{\mathrm{f}, 2}=8.51 \times 10^{12} \mathrm{M}^{-1}\right)$. The fitted binding isotherm is compared to the experimental data points at characteristic wavelengths, and the fitted spectra of the three species in solution are shown: c-P6-(T3) 2 in black, $\mathbf{c - P 6 \cdot T 3}$ in grey and $c-\mathbf{P 6}$ in red. PB-4-57.
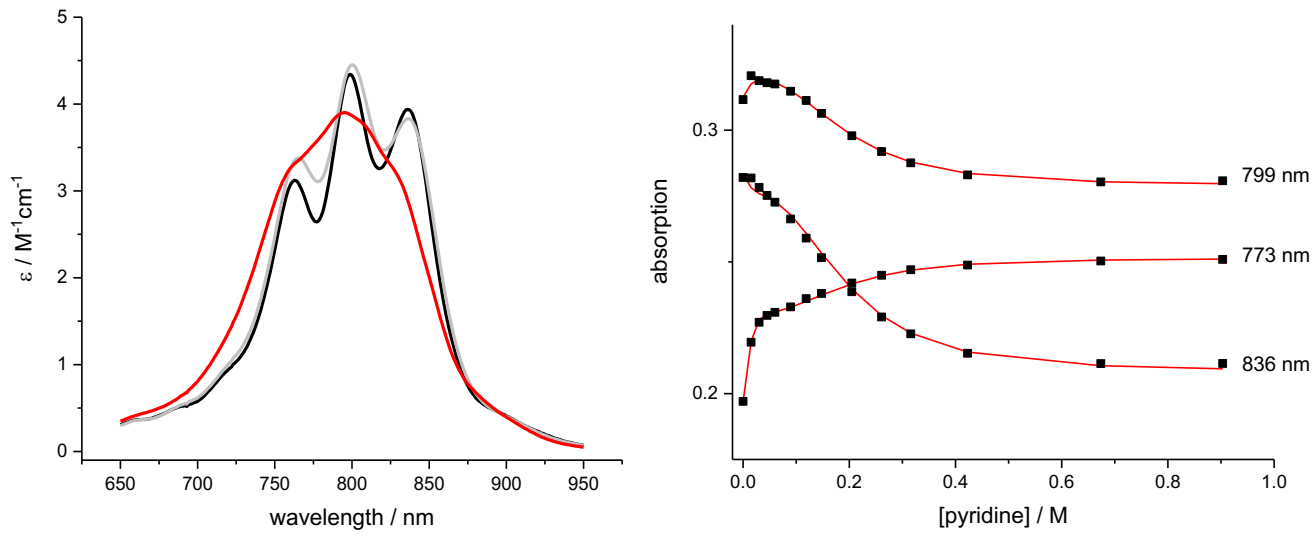

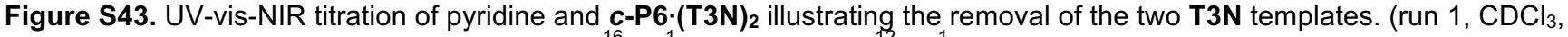
$298 \mathrm{~K},\left[\boldsymbol{c}\right.$-P6 $\left.\left.\cdot(\mathrm{T} 3 \mathrm{~N})_{2}\right]=0.72 \mu \mathrm{M}, K_{\mathrm{f}, 1}=1.45 \times 10^{16} \mathrm{M}^{-1} K_{\mathrm{f}, 2}=7.08 \times 10^{12} \mathrm{M}^{-1}\right)$. The fitted binding isotherm is compared to the experimental data points at characteristic wavelengths, and the fitted spectra of the three species in solution are shown: c-P6-(T3N) $)_{2}$ in black, $\boldsymbol{c}-\mathbf{P 6} 6 \cdot \mathbf{T} 3 \mathbf{N}$ in grey and $\boldsymbol{c}-\mathbf{P 6}$ in red. PB-4-141. 

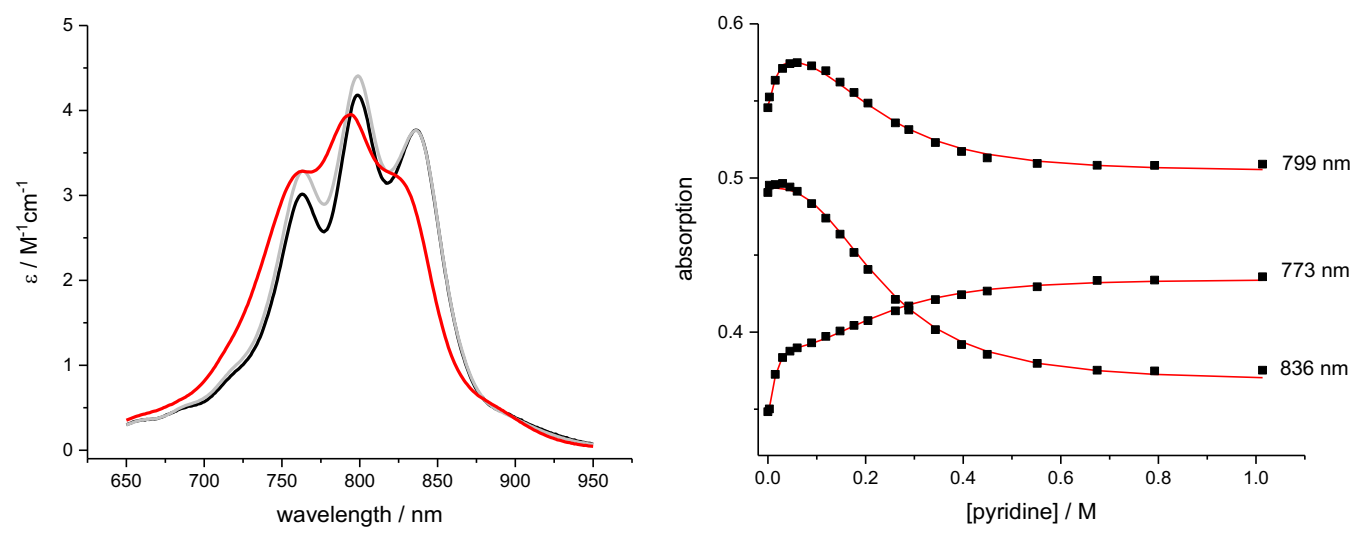

Figure S44. UV-vis-NIR titration of pyridine and $c-P 6 \cdot(T 3 N)_{2}$ illustrating the removal of the two T3N templates. (run 2, CDCl 3 , $298 \mathrm{~K},\left[c-\mathrm{P} 6 \cdot(\mathrm{T} 3 \mathrm{~N})_{2}\right]=1.31 \mu \mathrm{M}, K_{\mathrm{f}, 1}=1.48 \times 10^{16} \mathrm{M}^{-1} K_{\mathrm{f}, 2}=7.94 \times 10^{12} \mathrm{M}^{-1}$ ). The fitted binding isotherm is compared to the experimental data points at characteristic wavelengths, and the fitted spectra of the three species in solution are shown: c-P6-(T3N) $)_{2}$ in black, $c-P 6 \cdot T 3 N$ in grey and $c-P 6$ in red. PB-4-135.
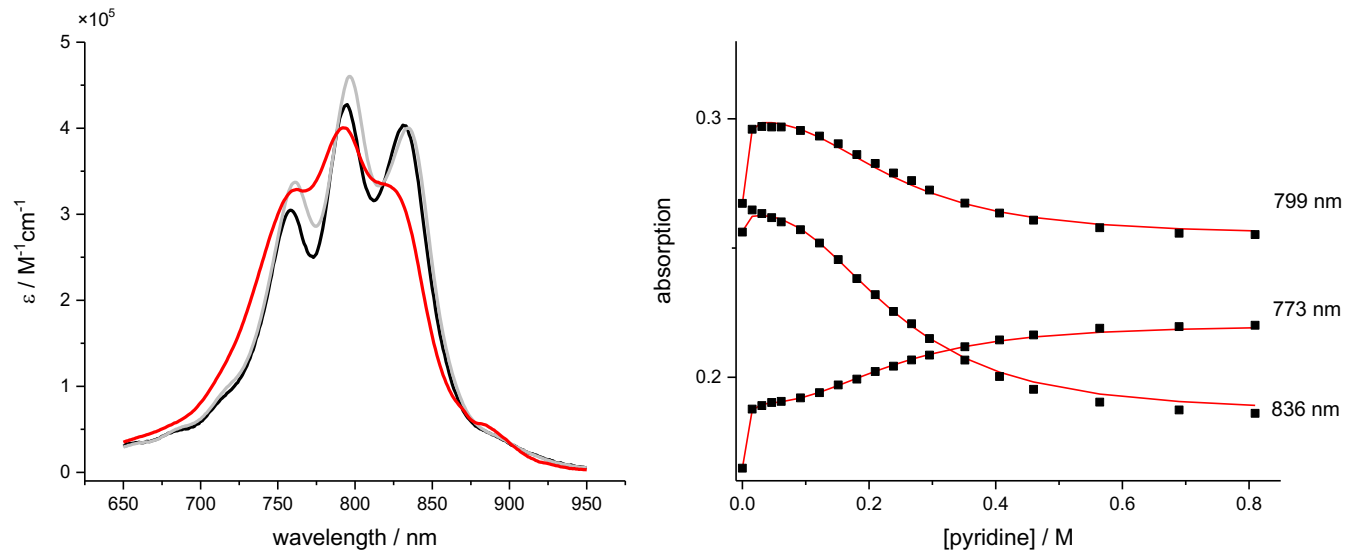

Figure S45. UV-vis-NIR titration of pyridine and $\boldsymbol{c}-\mathbf{P 6} \cdot(\mathbf{T} 3 \mathrm{~N})_{2}$ illustrating the removal of the two T3N templates. (run 1 , toluene, $\left.298 \mathrm{~K},\left[\mathrm{c}-\mathrm{P6} \cdot(\mathrm{T} 3 \mathrm{~N})_{2}\right]=0.66 \mu \mathrm{M}, K_{\mathrm{f}, 1}=3.09 \times 10^{16} \mathrm{M}^{-1} K_{\mathrm{f}, 2}=1.55 \times 10^{12} \mathrm{M}^{-1}\right)$. The fitted binding isotherm is compared to the experimental data points at characteristic wavelengths, and the fitted spectra of the three species in solution

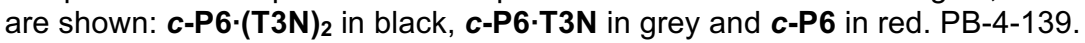
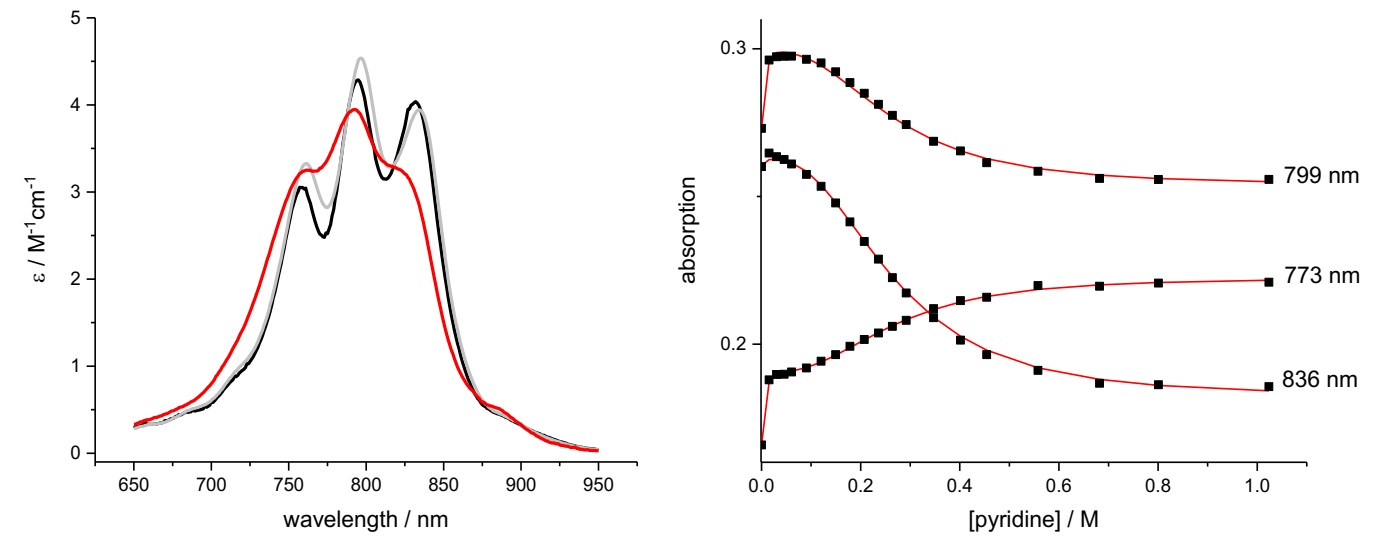

Figure S46. UV-vis-NIR titration of pyridine and $\mathbf{c - P 6 \cdot ( T 3 N )})_{2}$ illustrating the removal of the two T3N templates. (run 2 , toluene, $\left.298 \mathrm{~K},\left[c-P 6 \cdot(T 3 N)_{2}\right]=0.67 \mu \mathrm{M}, K_{\mathrm{f}, 1}=4.07 \times 10^{16} \mathrm{M}^{-1} K_{\mathrm{f}, 2}=2.04 \times 10^{12} \mathrm{M}^{-1}\right)$. The fitted binding isotherm is compared to the experimental data points at characteristic wavelengths, and the fitted spectra of the three species in solution are shown: $\boldsymbol{c}-\mathbf{P 6} 6(\mathrm{~T} 3 \mathbf{N})_{2}$ in black, $\boldsymbol{c}-\mathbf{P 6} \cdot \mathbf{T} 3 \mathbf{N}$ in grey and $\boldsymbol{c - P 6}$ in red. PB-4-137. 
Tables S4 and S5 show the measured $K_{\mathrm{dn}}$ values and calculated $K_{\mathrm{f}}$ values and cooperativity factors for c-P12-(T6e) $)_{2}$ titrations respectively. Tables S6 and S7 show the measured $K_{\mathrm{f}}$ values and the calculated statistically corrected values and cooperativity factors for $c-\mathbf{P 6} \cdot(\mathbf{T 3})_{2}$ and $\boldsymbol{c}-\mathbf{P 6} \cdot(\mathbf{T 3 N})_{2}$ titrations. The errors were determined by propagating the errors from the $K_{\text {py }}$ values used and the sample standard deviation of $K_{\mathrm{dn}}$. When ReactLab Equilibria was used to analyze the data, the value of $\log K_{\mathrm{f}}$ is given directly. $K_{\mathrm{f}}$ is based on $K_{\mathrm{py}}$, and the errors come from $K_{\mathrm{py}}$.

Table S4. Summary of denaturation constants for $c-\mathrm{P} 12 \cdot(\mathrm{T} 6 \mathrm{e})_{2}$

\begin{tabular}{|c|c|c|c|c|}
\hline complex & solvent & $K_{\mathrm{dn}}$ run $1 \mathrm{M}^{-10}$ & $K_{\text {dn }}$ run $2 M^{-10}$ & $K_{\mathrm{dn}} \mathbf{M}^{-10}$ \\
\hline$c-\mathrm{P} 12 \cdot(\mathrm{T} 6 \mathrm{e})_{2}$ & $\mathrm{CDCl}_{3}$ & 0.0118 & 0.00813 & $0.0131 \pm 0.003$ \\
\hline$c-\mathrm{P} 12 \cdot(\mathrm{T} 6 \mathrm{e})_{2}$ & toluene & 0.0446 & 0.0586 & $0.0516 \pm 0.010$ \\
\hline
\end{tabular}

Table S5. Formation constants and cooperativity factor for c-P12·(T6e) 2

\begin{tabular}{lllll} 
complex & solvent & $\log K_{\mathrm{f}}$ & $\log K_{\text {chem }}$ & $\alpha$ \\
c-P12·(T6e) $)_{2}$ & $\mathrm{CDCl}_{3}$ & $49.09 \pm 0.33$ & $43.02 \pm 0.33$ & $>40$ \\
\hline $\boldsymbol{c}-\mathrm{P} 12 \cdot(\mathrm{T} 6 \mathrm{e})_{2}$ & toluene & $50.65 \pm 0.41$ & $44.58 \pm 0.40$ & $>40$
\end{tabular}

${ }^{*}$ the lower limit of a was estimated, see Section 3.8.

Table S6. Summary of formation constants and cooperativity factor for $c-P 6 \cdot(T 3)_{2}$ and $c-P 6 \cdot(T 3 N)_{2}$

\begin{tabular}{|c|c|c|c|c|c|c|c|}
\hline complex & solvent & $\begin{array}{l}\log K_{f, 1} \\
\operatorname{run} 1\end{array}$ & $\begin{array}{l}\log K_{f, 1} \\
\operatorname{run} 2\end{array}$ & $\begin{array}{l}\log K_{f, 2} \\
\operatorname{run} 1\end{array}$ & $\begin{array}{l}\log K_{f, 2} \\
\text { run } 2\end{array}$ & $\log K_{\mathrm{f}, 1}$ & $\log K_{\mathrm{f}, 2}$ \\
\hline \multirow[t]{2}{*}{$c-\mathrm{P} 6 \cdot(\mathrm{T} 3)_{2}$} & $\mathrm{CDCl}_{3}$ & $15.44 \pm 0.09$ & $15.44 \pm 0.09$ & $13.69 \pm 0.09$ & $13.75 \pm 0.09$ & $15.44 \pm 0.09$ & $13.72 \pm 0.09$ \\
\hline & toluene & $16.46 \pm 0.11$ & $16.54 \pm 0.11$ & $12.84 \pm 0.11$ & $12.93 \pm 0.11$ & $16.50 \pm 0.11$ & $12.89 \pm 0.11$ \\
\hline \multirow[t]{2}{*}{$c-\mathrm{P} 6 \cdot(\mathrm{T} 3 \mathrm{~N})_{2}$} & $\mathrm{CDCl}_{3}$ & $16.16 \pm 0.09$ & $16.17 \pm 0.09$ & $12.85 \pm 0.09$ & $12.90 \pm 0.09$ & $16.17 \pm 0.09$ & $12.88 \pm 0.09$ \\
\hline & toluene & $16.49 \pm 0.11$ & $16.61 \pm 0.11$ & $12.19 \pm 0.11$ & $12.31 \pm 0.11$ & $16.55 \pm 0.11$ & $12.25 \pm 0.11$ \\
\hline
\end{tabular}

Table S7. Statistically corrected formation constants and cooperativity factor for $c-\mathrm{P} 6 \cdot(\mathrm{T} 3)_{2}$ and $c-\mathrm{P} 6 \cdot(\mathrm{T} 3 \mathrm{~N})_{2}$

\begin{tabular}{llccc} 
complex & solvent & log $K_{\text {chem, } 1}$ & log $K_{\text {chem,2 }}$ & $\alpha$ \\
\hline $\boldsymbol{c - P 6}(\mathrm{T} 3)_{2}$ & $\mathrm{CDCl}_{3}$ & $13.46 \pm 0.09$ & $12.04 \pm 0.09$ & $(3.83 \pm 1.10) \times 10^{-2}$ \\
\hline $\boldsymbol{c - P 6}(\mathrm{T} 3 \mathrm{~N})_{2}$ & toluene & $14.52 \pm 0.11$ & $11.21 \pm 0.11$ & $(4.86 \pm 1.73) \times 10^{-4}$ \\
& $\mathrm{CDCl}_{3}$ & $14.18 \pm 0.09$ & $11.19 \pm 0.09$ & $(1.03 \pm 0.30) \times 10^{-3}$ \\
& toluene & $14.57 \pm 0.11$ & $10.57 \pm 0.11$ & $(1.00 \pm 0.36) \times 10^{-4}$
\end{tabular}




\subsection{Estimation of Cooperativity Factor for $c$-P12·(T6e)}

The 'all-or-nothing' model used to fit the titration data for the denaturation of $\boldsymbol{c}$-P12·(T6e) $)_{2}$ to determine $K_{\mathrm{dn}}$. The fact that the data fit this model tells us that there is strong cooperativity, but we cannot measure the cooperativity factor $(\alpha)$ because it is too high. However, we can estimate the smallest value of $\alpha$ that would still allow the data to be perceived as 'all-or-nothing'.

$K_{\mathrm{dn}}$, which we have determined, is the product of $K_{\mathrm{dn} 1}$ and $K_{\mathrm{dn} 2}$.

$$
\begin{gathered}
K_{\mathrm{dn}}=K_{\mathrm{dn} 1} \cdot K_{\mathrm{dn} 2} \\
K_{\mathrm{dn}}=\frac{\left[c-\mathrm{P} 12(\mathbf{p y})_{12}\right] \cdot[\mathbf{T} 6 \mathbf{e}]^{2}}{\left[\boldsymbol{c}-\mathrm{P} 12(\mathbf{T} 6 \mathbf{e})_{2}\right] \cdot[\mathbf{p y}]^{12}}
\end{gathered}
$$

$K_{\mathrm{dn} 1}$ and $K_{\mathrm{dn} 2}$ are defined as:

$$
\begin{aligned}
K_{\mathrm{dn} 1} & =\frac{\left[c-\mathrm{P} 12(\mathbf{p y})_{12}\right] \cdot[\mathbf{T 6 e}]}{\left[c-\mathrm{P} 12(\mathbf{T 6 e})(\mathbf{p y})_{6}\right] \cdot[\mathbf{p y}]^{6}} \\
K_{\mathrm{dn} 2} & =\frac{\left[c-\mathrm{P} 12(\mathbf{T 6 e})(\mathbf{p y})_{6}\right] \cdot[\mathrm{T} 6 \mathbf{e}]}{\left[c-\mathrm{P} 12(\mathbf{T 6 e})_{2}\right] \cdot[\mathbf{p y}]^{6}}
\end{aligned}
$$

If we divide $K_{\mathrm{dn} 2}$ by $K_{\mathrm{dn} 1}$ we get:

$$
\begin{gathered}
\frac{K_{\mathrm{dn} 2}}{K_{\mathrm{dn} 1}}=\frac{\left[c-\mathrm{P} 12(\mathrm{T6e})(\mathbf{p y})_{6}\right] \cdot[\mathbf{T 6 e}] \cdot\left[c-\mathrm{P} 12(\mathbf{T 6 e})(\mathbf{p y})_{6}\right] \cdot[\mathbf{p y}]^{6}}{\left[c-\mathrm{P} 12(\mathbf{T 6 e})_{2}\right] \cdot[\mathbf{p y}]^{6} \cdot\left[c-\mathrm{P} 12(\mathbf{p y})_{12}\right] \cdot[\mathbf{T 6 e}]} \\
\frac{K_{\mathrm{dn} 2}}{K_{\mathrm{dn} 1}}=\frac{\left[c-\mathrm{P} 12(\mathrm{~T} 6 \mathbf{e})(\mathbf{p y})_{6}\right]^{2}}{\left[c-\mathrm{P} 12(\mathrm{~T} 6 \mathbf{e})_{2}\right] \cdot\left[c-\mathrm{P} 12(\mathbf{p y})_{12}\right]}=\frac{K_{\mathrm{f}, 1}}{K_{\mathrm{f}, 2}}=\frac{2}{\alpha}
\end{gathered}
$$

This ratio will be the same at any point in the titration. The 'all-or-nothing' model is an approximation that can be used if the concentration of the intermediate $1: 1$ complex $\mathbf{c - P 1 2} \cdot \mathbf{T 6 e} \cdot \mathbf{p y} \mathbf{y}_{\mathbf{6}}$ is so small that it is not detected. We estimate that if there were $10 \% \boldsymbol{c}$-P12·T6e·py $\mathbf{6}$ present in the middle of the titration (so it is not completely all-or-nothing), it would not be detected because the amount would be too small and the data would give the impression of being 'all-or-nothing' and give a good fit to the 'all-ornothing' model. If the knock-out is to any degree stepwise, the point in the denaturation when the concentration of intermediate would be highest would be the middle, when half of the template molecules are replaced. If we allow for the 10\% 1:1 complex to be present without being detected, the ratio of complexes at the middle point of the titration will be: $45 \%$ c-P12 $(\mathbf{T 6 e})_{2}, 10 \%$

$\boldsymbol{c - P 1 2} \cdot(\mathbf{T 6 e}) \cdot(\mathbf{p y})_{6}$ and $45 \% \boldsymbol{c - P 1 2} \cdot(\mathbf{p y})_{12}$. We then insert into the expression for the ratio of $K_{\mathrm{dn} 2}$ and $K_{\mathrm{dn} 1}$ :

$$
\begin{gathered}
\frac{2}{\alpha}=\frac{0.10^{2}}{0.45 \cdot 0.45}=4.94 \cdot 10^{-2} \\
\alpha=40.5
\end{gathered}
$$

This is a lower limit to the value of $\alpha$ for $c-P 12 \cdot(T 6 e)_{2}$. 


\section{NMR Spectroscopy Binding and Kinetics Experiments}

\subsection{Confirmation of equilibrium constants by ${ }^{1} \mathrm{H}$ NMR spectroscopy}

The cooperativity of the binding events was investigated by ${ }^{1} \mathrm{H}$ NMR spectroscopy, by making $1: 1$ solutions of template and nanoring and letting the mixtures reach equilibrium. The ${ }^{1} \mathrm{H}$ NMR spectra of the 1:1 mixtures are shown in Figure S47. Equilibrium was reached by adding a trace amount of pyridine and letting the solution stand at $298 \mathrm{~K}$ until the ${ }^{1} \mathrm{H}$ NMR spectra stopped changing. The spectrum of $\boldsymbol{c}$-P12 and T6e shows that there is no trace of the 1:1 complex $\boldsymbol{c}$-P12-T6e. The spectrum of

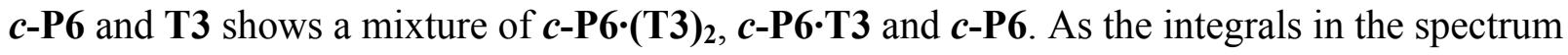
corresponds to the relative concentration, the equilibrium constant can be calculated directly:

$$
K_{\mathrm{eq}}=\frac{\left[c-\mathrm{P} 6(\mathrm{~T} 3)_{2}\right] \cdot[c-\mathrm{P} 6]}{[c-\mathrm{P} 6(\mathrm{~T} 3)]^{2}}=\frac{[1 / 24] \cdot[1.02 / 24]}{[3.94 / 12]^{2}}=0.016 \pm 0.006
$$

The uncertainty in $K_{\text {eq }}$ is calculated by propagating a $3 \%$ uncertainty in NMR integrations. This equilibrium constant can also be found as the ratio between $K_{\mathrm{f}, 1}$ and $K_{\mathrm{f}, 2}$, and if we use the values in Table S6, we get almost the same value for the equilibrium constant.

$$
K_{\mathrm{eq}}=\frac{K_{\mathrm{f}, 2}}{K_{\mathrm{f}, 1}}=\frac{10^{13.72}}{10^{15.44}}=0.019 \pm 0.006
$$

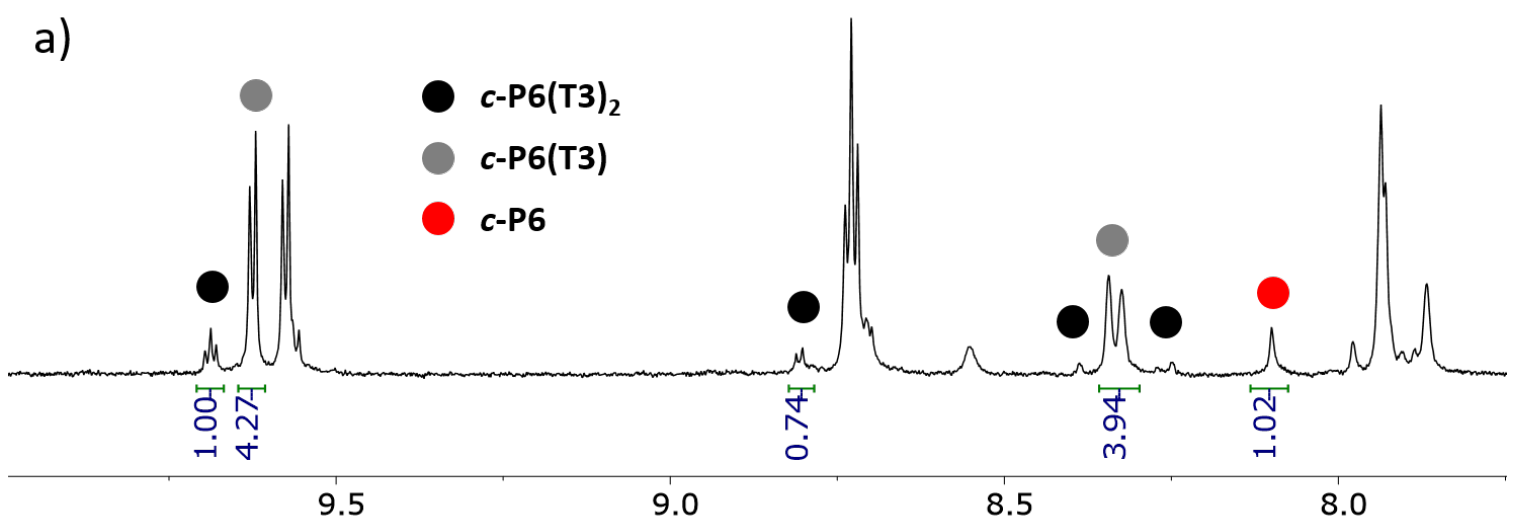

b)

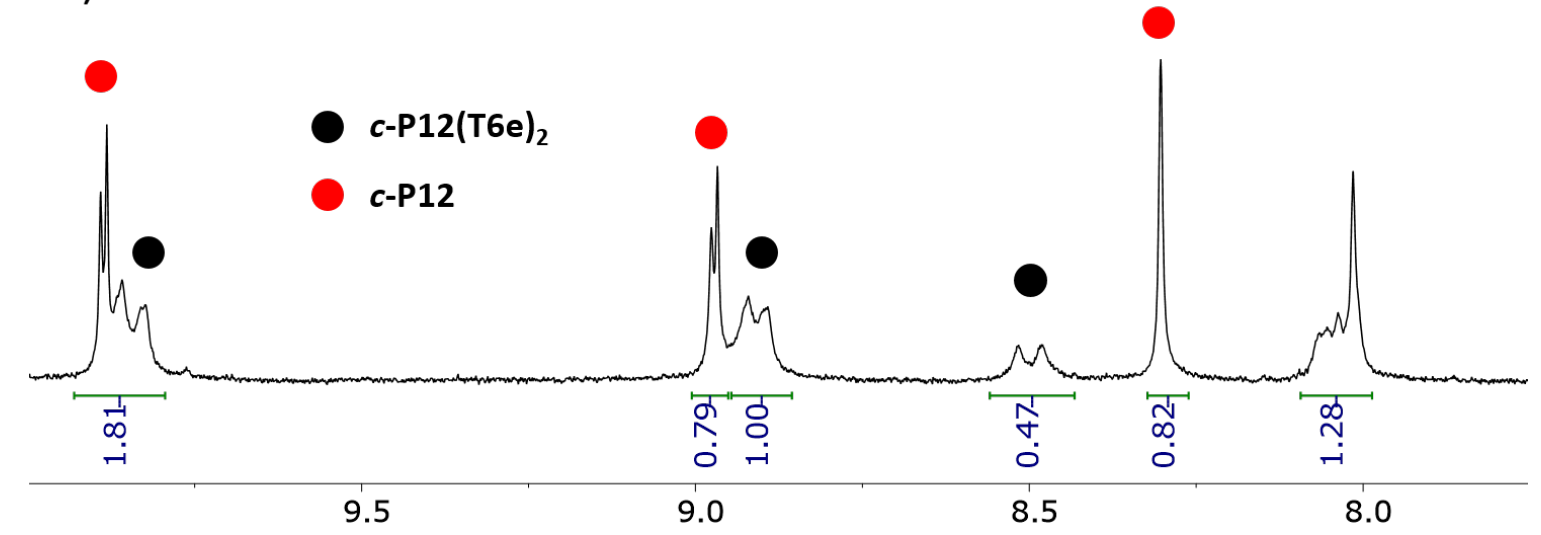

Figure S47. ${ }^{1} \mathrm{H}$ NMR (500 MHz) spectra of $1: 1$ mole ratios of a) $\mathbf{c}-\mathbf{P} 6$ and T3, and b) $\boldsymbol{c}-\mathbf{P} 12$ and T6e after they have reached equilibrium. $\mathrm{CDCl}_{3}$ with a trace amount of pyridine- $\mathrm{d}_{5}, 500 \mathrm{MHz}, 298 \mathrm{~K}$. 


\subsection{Calculation of the diffusion controlled rate of reaction}

The diffusion coefficient $D$ was calculated using the Stokes-Einstein equation. ${ }^{20}$

$$
D=\frac{k_{B} T}{6 \pi \eta r}
$$

Where $k_{B}$ is the Boltzmann constant, $T$ is the absolute temperature, $\eta$ is the dynamic viscosity and $r$ is the radius of the particle.

$$
D=\frac{1.38 \cdot 10^{-23} \frac{\mathrm{J}}{\mathrm{K}} \cdot 298.15 \mathrm{~K}}{6 \cdot \pi \cdot 0.536 \mathrm{mPas} \cdot 1.2 \mathrm{~nm}}=3.39 \times 10^{-10} \mathrm{~m}^{2} \mathrm{~s}^{-1}
$$

The diffusion rate was then calculated using equation S37.

$$
k_{\text {diff }}=4 \pi D_{\text {sum }} R_{0} N_{A}
$$

Where $R_{0}$ is the distance at which the particles can react, and $D_{\text {sum }}$ is the sum of the diffusion coefficients for the two reacting species.

$$
k_{\text {diff }}=4 \pi \cdot 2 \cdot 3.39 \cdot 10^{-10} \mathrm{~m}^{2} \mathrm{~s}^{-1} \cdot 2.4 \mathrm{~nm}=1.2 \times 10^{10} \mathrm{M}^{-1} \mathrm{~s}^{-1}
$$

\subsection{Experimental details for exchange in $\mathrm{CDCl}_{3}$}

Two stock solutions were made: $5.29 \times 10^{-5} \mathrm{M} \boldsymbol{c}$-P6 $\mathbf{P}(\mathbf{T 3})_{2}$ in $\mathrm{CDCl}_{3}$, and $3.80 \times 10^{-5} \mathrm{M} \boldsymbol{c}$-P6 in $\mathrm{CDCl}_{3}$. These concentrations were determined using UV-vis absorption and the extinction coefficients.

Experiment A: $100 \mu \mathrm{L} \boldsymbol{c}$-P6-(T3) $)_{2}$ in $\mathrm{CDCl}_{3}, 100 \mu \mathrm{L} \boldsymbol{c}$-P6 in $\mathrm{CDCl}_{3}$ and $400 \mu \mathrm{L} \mathrm{CDCl}_{3}$ was mixed in an NMR tube making the total concentration of porphyrin nanoring $1.52 \times 10^{-5} \mathrm{M}$.

Experiment B: $100 \mu \mathrm{L} \boldsymbol{c}$-P6 $(\mathbf{T 3})_{2}$ in $\mathrm{CDCl}_{3}, 200 \mu \mathrm{L} \boldsymbol{c}$-P6 in $\mathrm{CDCl}_{3}$ and $300 \mu \mathrm{L} \mathrm{CDCl}_{3}$ was mixed in an NMR tube making the total concentration of porphyrin nanoring $2.15 \times 10^{-5} \mathrm{M}$. The tubes were sealed with an NMR cap with aluminum foil and parafilm to prevent solvent evaporation. The tubes were kept in darkness at $298 \mathrm{~K}$, and ${ }^{1} \mathrm{H}$ NMR spectra were recorded over time.

Figure S48 shows the consumption of $\boldsymbol{c}$-P6.(T3) $)_{2}$ in each of the two experiments, and Figures S49 and S50 shows some of the NMR spectra used in the analysis.

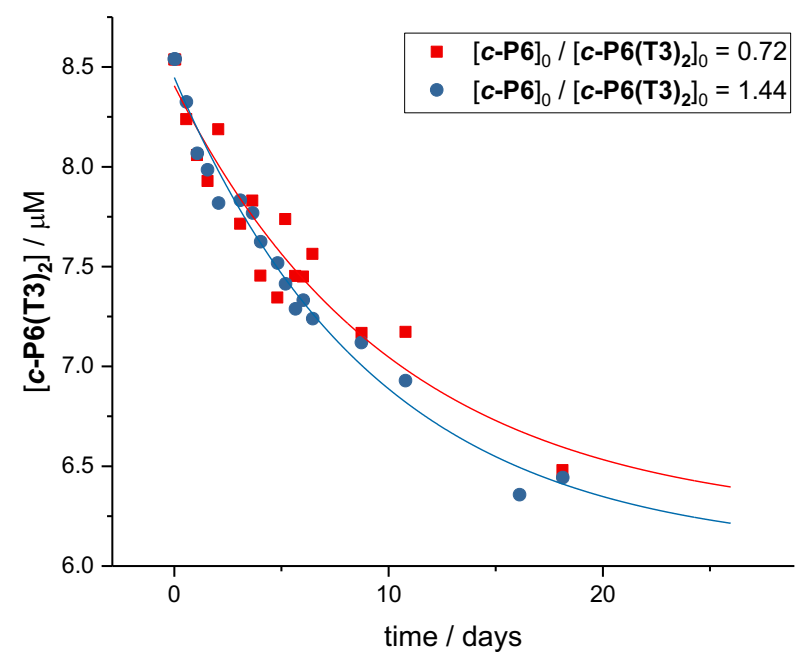

Figure S48. Concentration of $\mathbf{c - P 6} \cdot(\mathrm{T} 3)_{2}$ over time in experiment $A$ (red) and $B$ (blue). The data points are fit to simple exponential decays for illustration $\left(y=y_{0}+P_{0}{ }^{*} \exp \left(-x^{*} k\right)\right)$. 


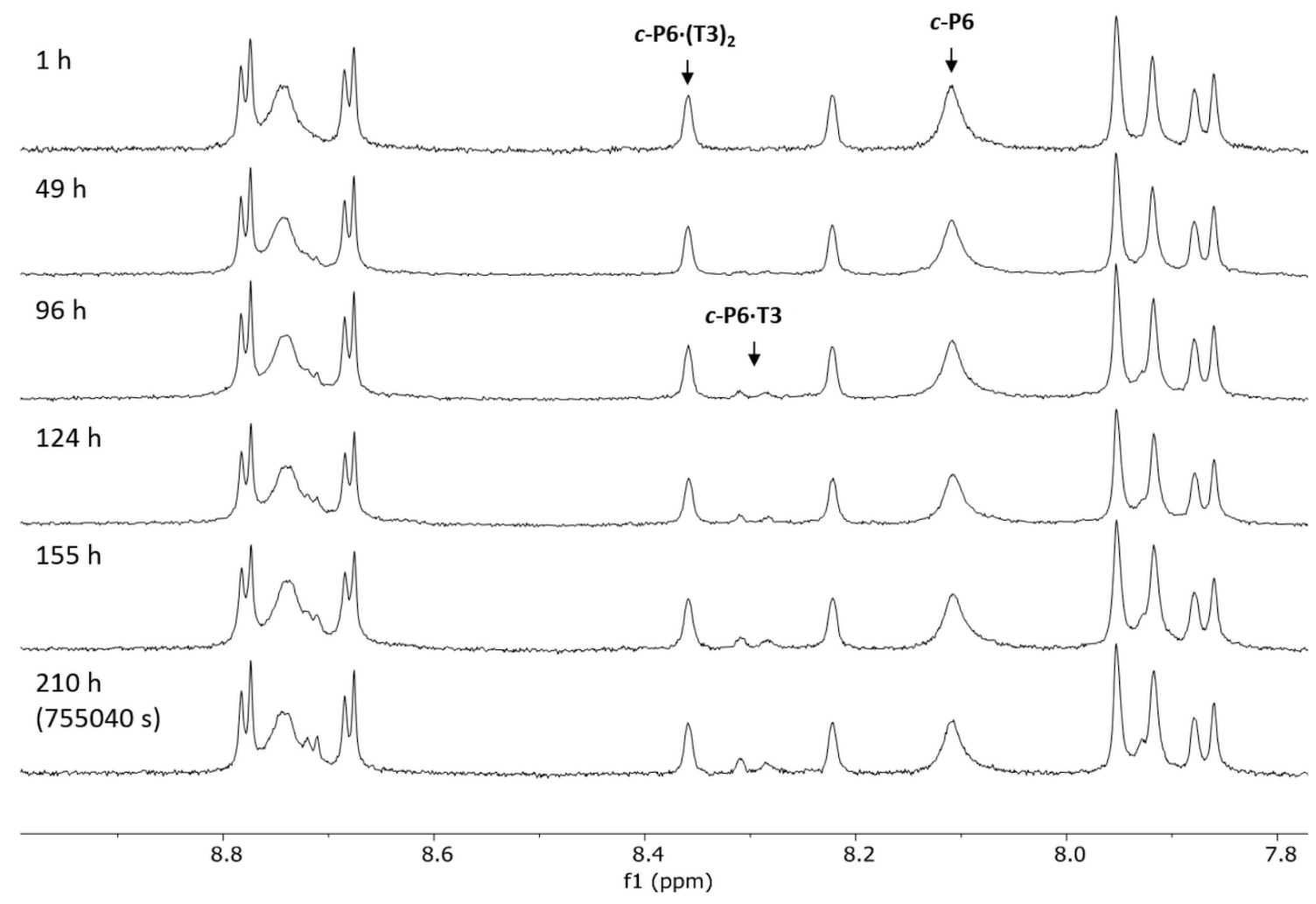

Figure S49. Selected ${ }^{1} \mathrm{H}$ NMR $(500 \mathrm{MHz})$ spectra over time of experiment $\mathrm{A}$. Indicated are three signals which are specific to the three components in the solution. It is these signal that are integrated and used in the analysis. $\mathrm{CDCl}_{3}, 298 \mathrm{~K}$.

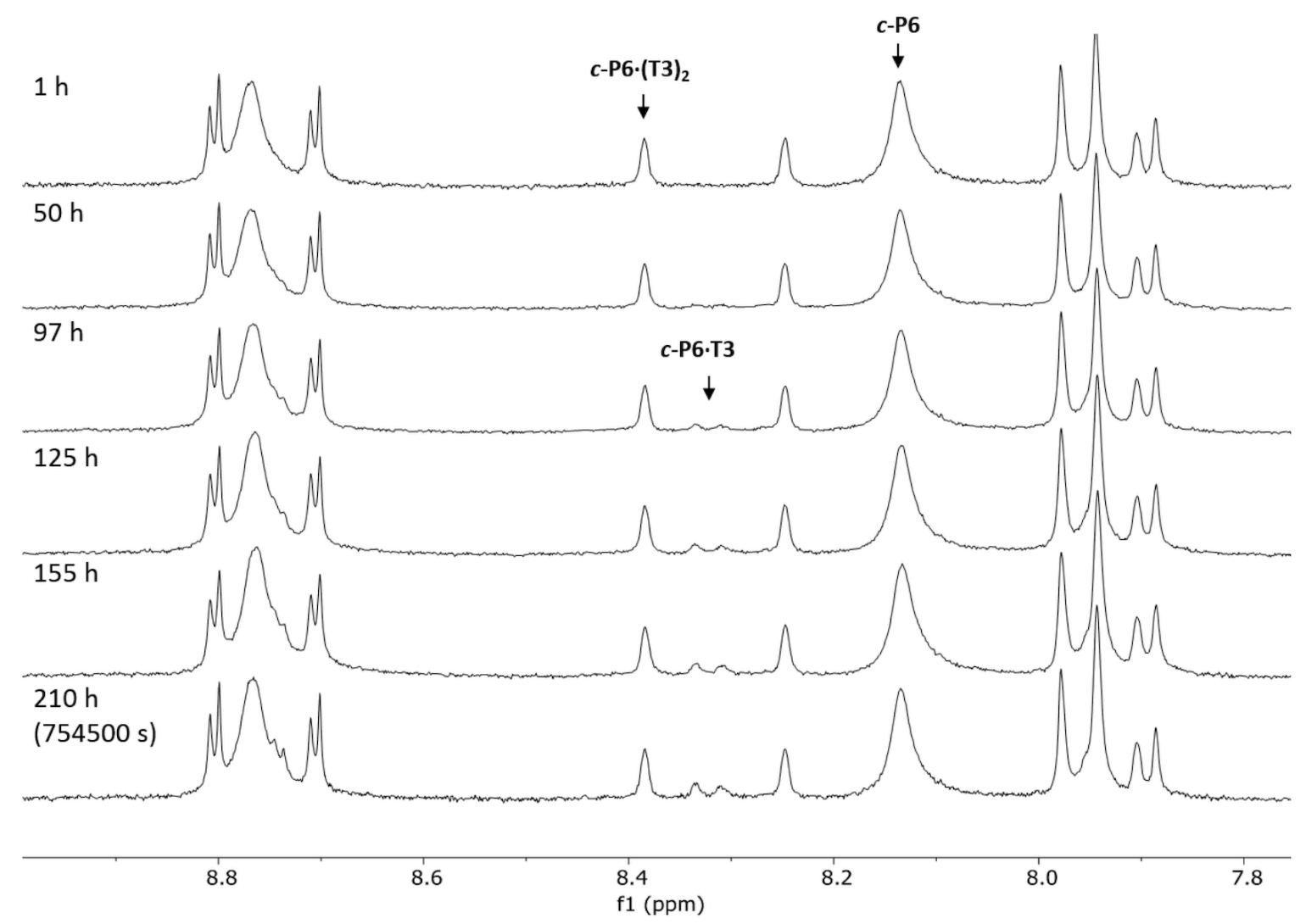

Figure S50. Selected ${ }^{1} \mathrm{H}$ NMR $(500 \mathrm{MHz})$ spectra over time of experiment $\mathrm{B}$. Indicated are three signals which are specific to the three components in the solution. It is these signal that are integrated and used in the analysis. $\mathrm{CDCl}_{3}, 298 \mathrm{~K}$ 


\subsection{Exchange in $\mathrm{CDCl}_{3}$ catalyzed by pyridine}

The stock solutions of $\boldsymbol{c}-\mathbf{P 6} \cdot(\mathbf{T 3})_{2}$ and $\boldsymbol{c}$-P6 from before were used again. Stock solutions with pyridne$\mathrm{d}_{5}$ in $\mathrm{CDCl}_{3}$ were prepared: 'Stock 1': $5 \mu \mathrm{L}$ pyridne- $\mathrm{d}_{5}$ was mixed with $1000 \mu \mathrm{L} \mathrm{CDCl}_{3}$. 'Stock 2': 5 $\mu \mathrm{L}$ 'Stock 1' was mixed with $1000 \mu \mathrm{L} \mathrm{CDCl}_{3}$. 'Stock 3': $10 \mu \mathrm{L}$ 'Stock 1' was mixed with $1000 \mu \mathrm{L}$ $\mathrm{CDCl}_{3}$.

Experiment C: $100 \mu \mathrm{L} \boldsymbol{c}$-P6-(T3) $)_{2}$ in $\mathrm{CDCl}_{3}, 100 \mu \mathrm{L} \boldsymbol{c}$-P6 in $\mathrm{CDCl}_{3}$ and $400 \mu \mathrm{L}$ 'Stock 2' was mixed in an NMR tube making the total concentration of porphyrin nanoring $1.52 \times 10^{-5} \mathrm{M}$ and the total concentration of pyridine- $\mathrm{d}_{5} 0.20 \mathrm{mM}$.

Experiment D: $100 \mu \mathrm{L} \boldsymbol{c}$-P6-(T3) $)_{2}$ in $\mathrm{CDCl}_{3}, 100 \mu \mathrm{L} \boldsymbol{c}$-P6 in $\mathrm{CDCl}_{3}$ and $400 \mu \mathrm{L}$ 'Stock 3' was mixed in an NMR tube making the total concentration of porphyrin nanoring $1.52 \times 10^{-5} \mathrm{M}$ and the total concentration of pyridine- $\mathrm{d}_{5} 0.41 \mathrm{mM}$.

The tubes were sealed with an NMR cap with aluminum foil and parafilm to prevent solvent evaporation. The tubes were kept in darkness at room temperature, and ${ }^{1} \mathrm{H}$ NMR spectra were recorded over time.

Figure S51 shows the consumption of $\boldsymbol{c}-\mathbf{P 6} \cdot(\mathbf{T 3})_{2}$ in each of the two experiments, and Figure S52 and S53 shows some of the NMR spectra used in the analysis.

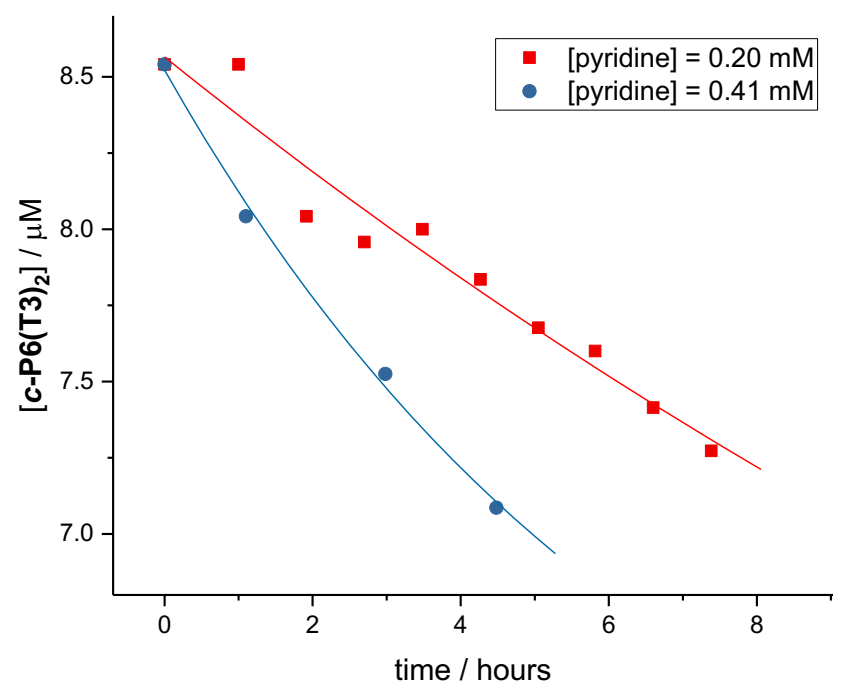

Figure S51. Concentration of $\boldsymbol{c}-\mathbf{P 6} \cdot(\mathrm{T} 3)_{2}$ over time in experiment $\mathrm{C}$ (red) and D (blue). The data points are fit to simple exponential decays for illustration $\left(y=y_{0}+P_{0}{ }^{*} \exp \left(-x^{*} k\right)\right)$. 


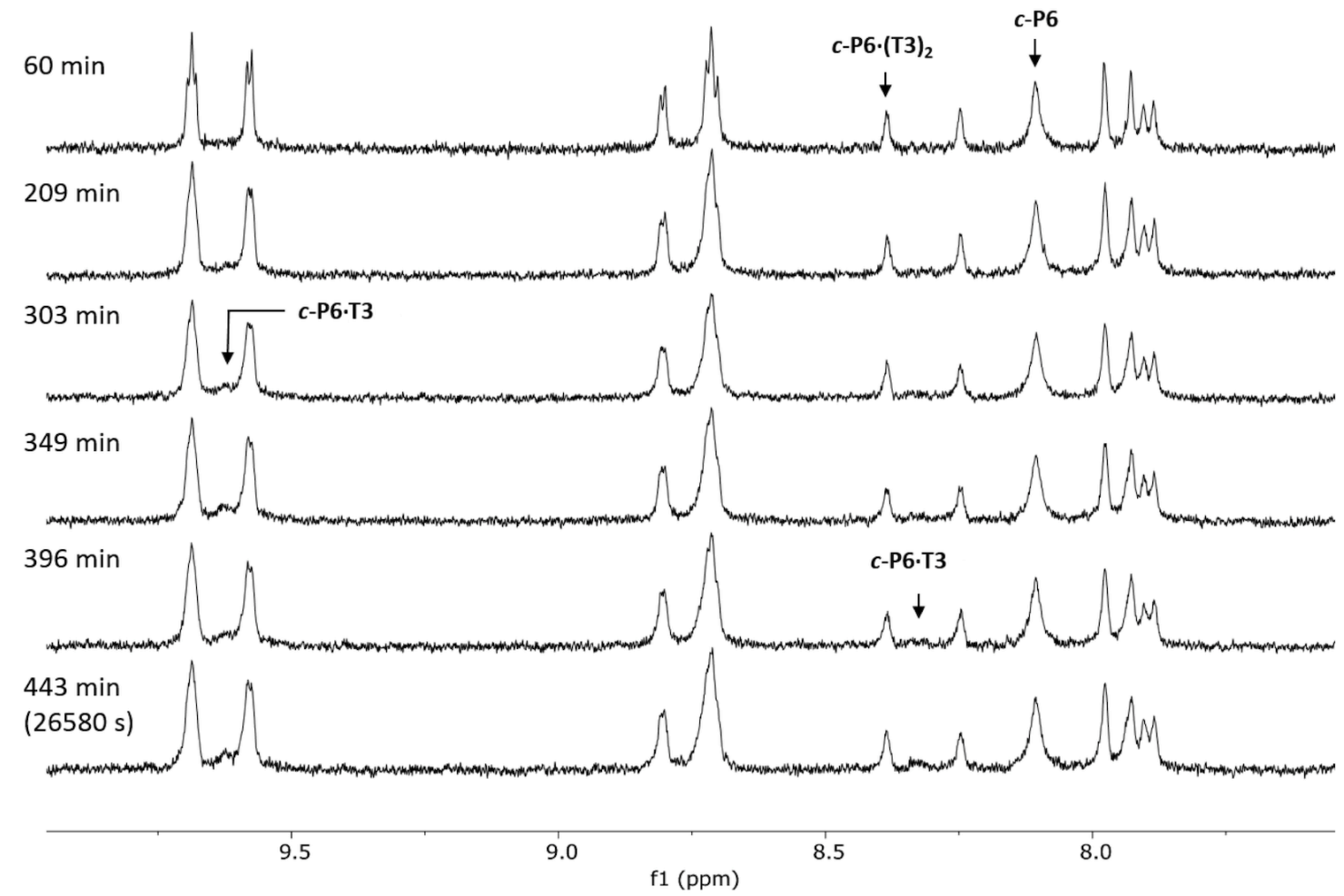

Figure S52. Selected ${ }^{1} \mathrm{H}$ NMR $(400 \mathrm{MHz})$ spectra over time of experiment $\mathrm{C}$. Indicated are four signals which are specific to the three components in the solution. It is these signal that are integrated and used in the analysis. For determining the concentration of $\boldsymbol{c - P 6 \cdot T 3}$, an average of the two indicated signals were used in an attempt to make the result more reliable. $\mathrm{CDCl}_{3}, 298 \mathrm{~K}$.

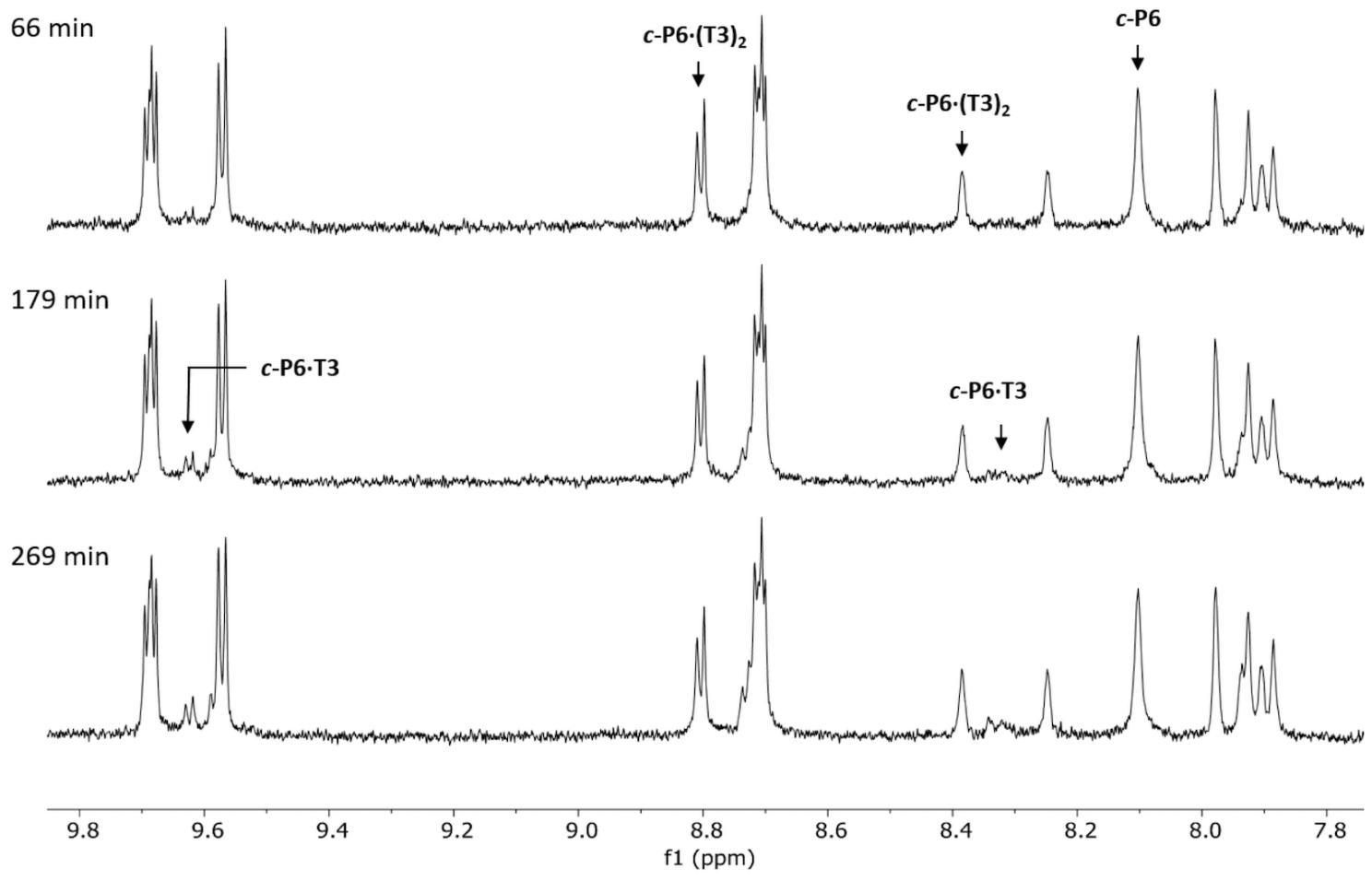

Figure S53. Selected ${ }^{1} \mathrm{H}$ NMR (400 MHz) spectra over time of experiment $\mathrm{D}$. Indicated are five signals which are specific to the three components in the solution. It is these signal that are integrated and used in the analysis. For determining the concentration of $\mathbf{c - P 6 - T 3}$, an average of the two indicated signals were used in an attempt to make the result more reliable. $\mathrm{CDCl}_{3}, 298 \mathrm{~K}$. 


\subsection{Initial rate analysis}

Ligand exchange is proposed to occur via the following dissociative mechanism.

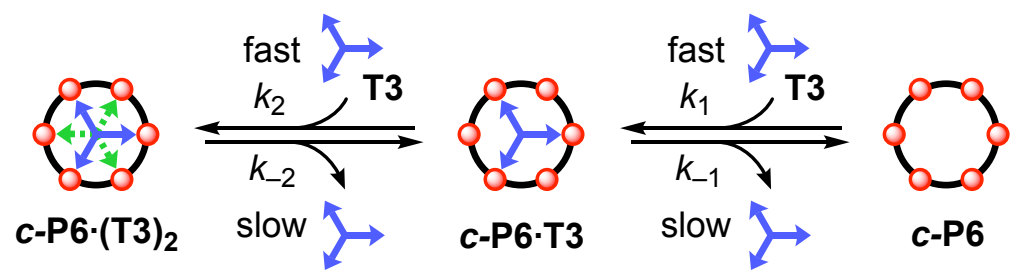

Scheme S2. Proposed mechanism of exchange between $c-P 6 \cdot(T 3)_{2} c-P 6 \cdot T 3$ and $c-P 6$.

The rate equation for the change in concentration of $\boldsymbol{c}-\mathbf{P 6} \cdot(\mathbf{T 3})_{2}$ according to the proposed mechanism is:

$$
\frac{\mathrm{d}\left[c-\mathrm{P} 6(\mathrm{~T} 3)_{2}\right]}{\mathrm{d} t}=-k_{-2}\left[c-\mathrm{P} 6(\mathrm{~T} 3)_{2}\right]+k_{2}[c-\mathrm{P} 6(\mathrm{~T} 3)][\mathrm{T} 3]
$$

At the very beginning of the experiment, the solution almost only contains $c-\mathbf{P 6} \cdot(\mathbf{T 3})_{2}$ and $c-\mathbf{P 6}$ and the term $k_{2}[c-\mathbf{P 6} \cdot(\mathbf{T 3})][\mathbf{T 6}]$ is very small because $[\boldsymbol{c - P 6} \cdot \mathbf{T 3}]$ and [T6] are low. Therefore, the initial reaction kinetics are pseudo first order, and the initial rate equation is simplified to:

$$
\frac{\mathrm{d}\left[c-\mathrm{P} 6(\mathrm{~T} 3)_{2}\right]}{\mathrm{d} t}=-k_{-2}\left[c-\mathrm{P} 6(\mathrm{~T} 3)_{2}\right]
$$

For the rough estimate of an initial rate, the first few data points were used.

Table S8. Initial rate analysis for experiment A and experiment B (see Figure S48).

\begin{tabular}{|l|l|l|} 
& A & B \\
\hline$[c-P 6]_{\text {initial }}$ & $6.15 \times 10^{-6} \mathrm{M}$ & $12.30 \times 10^{-6} \mathrm{M}$ \\
\hline$\left[\mathrm{c}-\mathrm{P} 6 \cdot(\mathrm{T} 3)_{2}\right]_{\text {initial }}$ & $8.54 \times 10^{-6} \mathrm{M}$ & $8.54 \times 10^{-6} \mathrm{M}$ \\
\hline$\left[\mathrm{c}-\mathrm{P} 6 \cdot(\mathrm{T} 3)_{2}\right]_{\text {final }}$ & $7.17 \times 10^{-6} \mathrm{M}$ & $7.12 \times 10^{-6} \mathrm{M}$ \\
\hline change in [c-P6-(T3) 2$]$ & $-1.37 \times 10^{-6} \mathrm{M}$ & $-1.42 \times 10^{-6} \mathrm{M}$ \\
\hline change in time & $755040 \mathrm{~s}$ & $754500 \mathrm{~s}$ \\
\hline initial rate & $-1.81 \times 10^{-12} \mathrm{M} / \mathrm{s}$ & $-1.88 \times 10^{-12} \mathrm{M} / \mathrm{s}$ \\
\hline
\end{tabular}

Since the initial rate for experiment B is not double that of A, but they are in fact effectively the same, it can be concluded that the concentration of $\boldsymbol{c}$-P6 is not rate-determining in the initial stage of the experiment. This supports the proposed mechanism where the rate-determining step is unimolecular.

To test the effect of having pyridine present to catalyze the exchange, we conducted two more experiments with pyridine in two different concentrations. Again, we limit our analysis to the first few 
data points, where there is a large excess of $\boldsymbol{c}-\mathbf{P 6} \cdot(\mathbf{T 3})_{2}$ and $\boldsymbol{c}$-P6 in solution, so there is no reaction between $c-\mathbf{P 6} \cdot \mathbf{T} 3$ and $\mathbf{T 3}$, and the rate is determined by $k_{-2, \mathrm{py}}$.

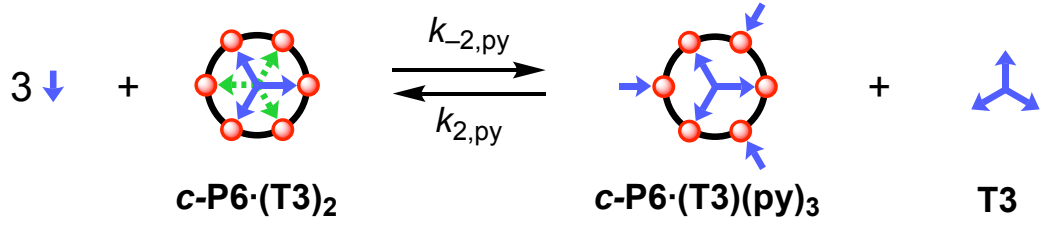

Scheme S3. Initial pyridine-catalyzed consumption of $c-\mathrm{P} 6 \cdot(\mathrm{T} 3)_{2}$.

Using the same assumptions as described above, the initial rate equation for the pyridine catalyzed reaction is proposed to look like this:

$$
\frac{\mathrm{d}\left[c-\mathrm{P} 6(\mathrm{~T} 3)_{2}\right]}{\mathrm{d} t}=-k_{-2, \mathrm{py}}\left[c-\mathrm{P} 6(\mathrm{~T} 3)_{2}\right][\mathrm{py}]^{\mathrm{x}}
$$

Table S9. Initial rate analysis for experiment $C$ and experiment $D$ (see Figure S51).

\begin{tabular}{|l|l|l|} 
& $\mathbf{C}([\mathrm{py}]=0.2 \mathrm{mM})$ & $\mathbf{D}([\mathrm{py}]=0.4 \mathrm{mM})$ \\
\hline$\left[\mathrm{c}-\mathrm{P} 6 \cdot(\mathrm{T} 3)_{2}\right]_{\text {initial }}$ & $8.54 \times 10^{-6} \mathrm{M}$ & $8.54 \times 10^{-6} \mathrm{M}$ \\
\hline$\left[\mathrm{c}-\mathrm{P6} \cdot(\mathrm{T} 3)_{2}\right]_{\text {final }}$ & $7.27 \times 10^{-6} \mathrm{M}$ & $7.09 \times 10^{-6} \mathrm{M}$ \\
\hline change in [c-P6-(T3) 2$]$ & $-1.27 \times 10^{-6} \mathrm{M}$ & $-1.45 \times 10^{-6} \mathrm{M}$ \\
\hline change in time & $26580 \mathrm{~s}$ & $16140 \mathrm{~s}$ \\
\hline initial rate & $-4.78 \times 10^{-11} \mathrm{M} / \mathrm{s}$ & $-8.98 \times 10^{-11} \mathrm{M} / \mathrm{s}$ \\
\hline
\end{tabular}

The initial rate for the experiment with $0.4 \mathrm{mM}$ pyridine is 1.9 times higher than for the experiment with $0.2 \mathrm{mM}$ pyridine. The data suggest that the reaction is first order with respect to the concentration of pyridine. 


\subsection{Determining rate constants}

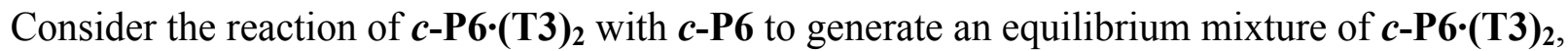

$\boldsymbol{c}$-P6-T3 and $\boldsymbol{c}$-P6 (Scheme S2, Figures 8 and 9). Initially the concentrations of $\boldsymbol{c - P 6 \cdot ( T 3 )})_{2}$ and $\boldsymbol{c}$-P6 are similar and the concentration of $\boldsymbol{c - P 6} \cdot \mathbf{T 3}$ is low. The concentration of unbound $\mathbf{T 3}$ is always low because $K_{\mathrm{f}, 1}, K_{\mathrm{f}, 2}, k_{1}$ and $k_{2}$ are all high. If we apply the steady state approximation that the concentration of $\mathbf{T 3}$ is constant, then we can derive the following expression for the rate of reaction:

$$
\frac{\mathrm{d}\left[c-\mathrm{P} 6(\mathrm{~T} 3)_{2}\right]}{\mathrm{d} t}=\frac{k_{-1} k_{2}[c-\mathrm{P} 6(\mathrm{~T} 3)]^{2}-k_{1} k_{-2}\left[c-\mathrm{P} 6(\mathrm{~T} 3)_{2}\right][c-\mathrm{P} 6]}{\left(k_{1}[c-\mathrm{P} 6]+k_{2}[c-\mathrm{P} 6(\mathrm{~T} 3)]\right)}
$$

If $[\boldsymbol{c - P 6} \cdot \mathbf{T 3}]$ is low, $[\boldsymbol{c - P 6} \cdot \mathbf{T 3}]^{2}$ becomes negligible and we can make the approximation that $k_{1}=k_{2}$. Thus equation S42 approximates to equation S43.

$$
\frac{\mathrm{d}\left[c-\mathrm{P} 6(\mathrm{~T} 3)_{2}\right]}{\mathrm{d} t}=\frac{-k_{-2}\left[c-\mathrm{P} 6(\mathrm{~T} 3)_{2}\right][c-\mathrm{P} 6]}{([c-\mathrm{P} 6]+[c-\mathrm{P} 6(\mathrm{~T} 3)])}
$$

The concentrations for the first 7 days of reaction are plotted in Figure S54 and Table S10.

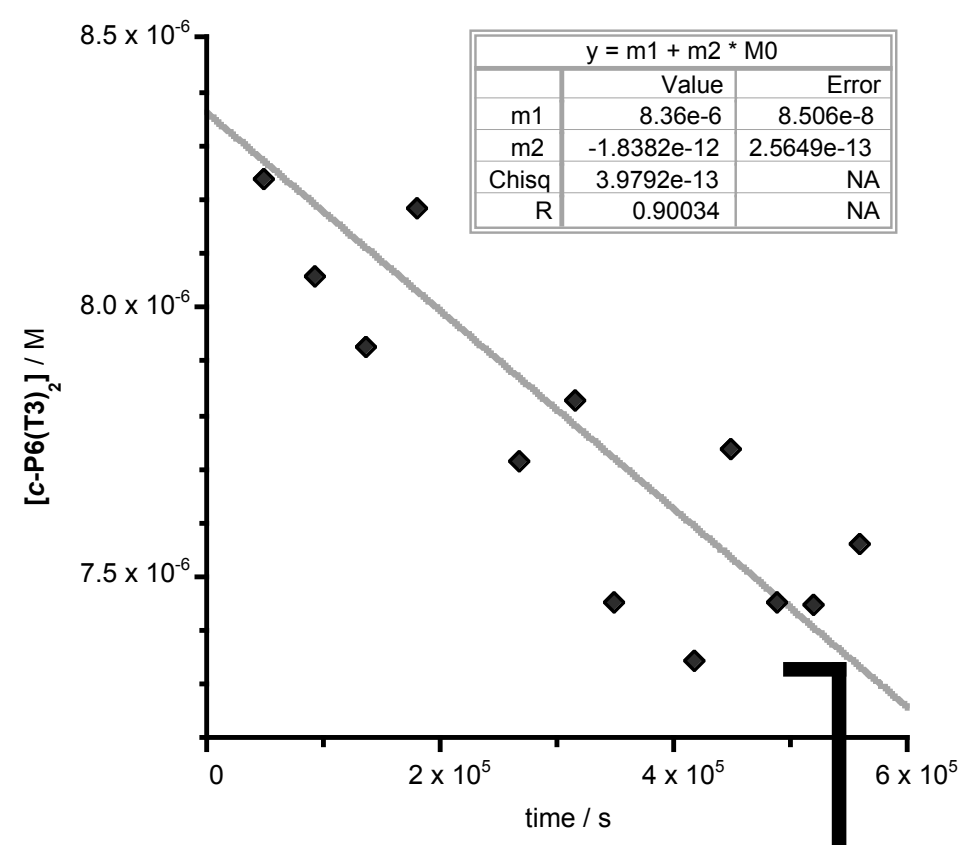

Table S10. Initial rate data for Figure S54.

\begin{tabular}{|l|l|}
\hline time period & $0-6 \times 10^{5} \mathrm{~s}$ \\
\hline $\mathrm{d}\left[\mathrm{c}-\mathrm{P6} \cdot(\mathrm{T} 3)_{2}\right] / \mathrm{d} t$ & $-1.84 \pm 0.26 \times 10^{-12} \mathrm{M} \mathrm{s}^{-1}$ \\
\hline$\left[\mathrm{c}-\mathrm{P} 6 \cdot(\mathrm{T} 3)_{2}\right]_{\text {mid-period }}$ & $7.81 \pm 0.09 \times 10^{-6} \mathrm{M}$ \\
\hline$[\mathrm{c}-\mathrm{P} 6 \cdot \mathrm{T} 3]_{\text {mid-period }}$ & $1.49 \pm 0.12 \times 10^{-6} \mathrm{M}$ \\
\hline$[\mathrm{c}-\mathrm{P} 6]_{\text {mid-period }}$ & $5.90 \pm 0.08 \times 10^{-6} \mathrm{M}$ \\
\hline
\end{tabular}

Figure S54. Plot of [c-P6(T3) 2 ] over time for experiment A (and Figure 8 ) for the first 7 days.

The data in Table S10 can be used with equation S42 to calculate $k_{-2}=3.0 \pm 0.4 \times 10^{-7} \mathrm{~s}^{-1}$. 


\section{Stacked Vernier template directed synthesis}

\subsection{Analytical GPC calibration curves}

A GPC column separates molecules depending on volume, but the sizes of two molecules of the same molecular weight can be very different. However, if all the molecules tested have similar chemistry and it can be assumed that the molecular volume is increasing linearly with molecular weight, then a calibration plot of $\log (\mathrm{M})$ versus retention time $t$ will produce a straight line. This is empirical, and it will only work well in the intermediate range of the GPC column (not too close to the upper limit where everything is eluted).

We measured the retention times of a range of cyclic and linear porphyrin oligomers with tert-butyl and THS sidechains and used the data to make four calibration curves shown in Figure S55.

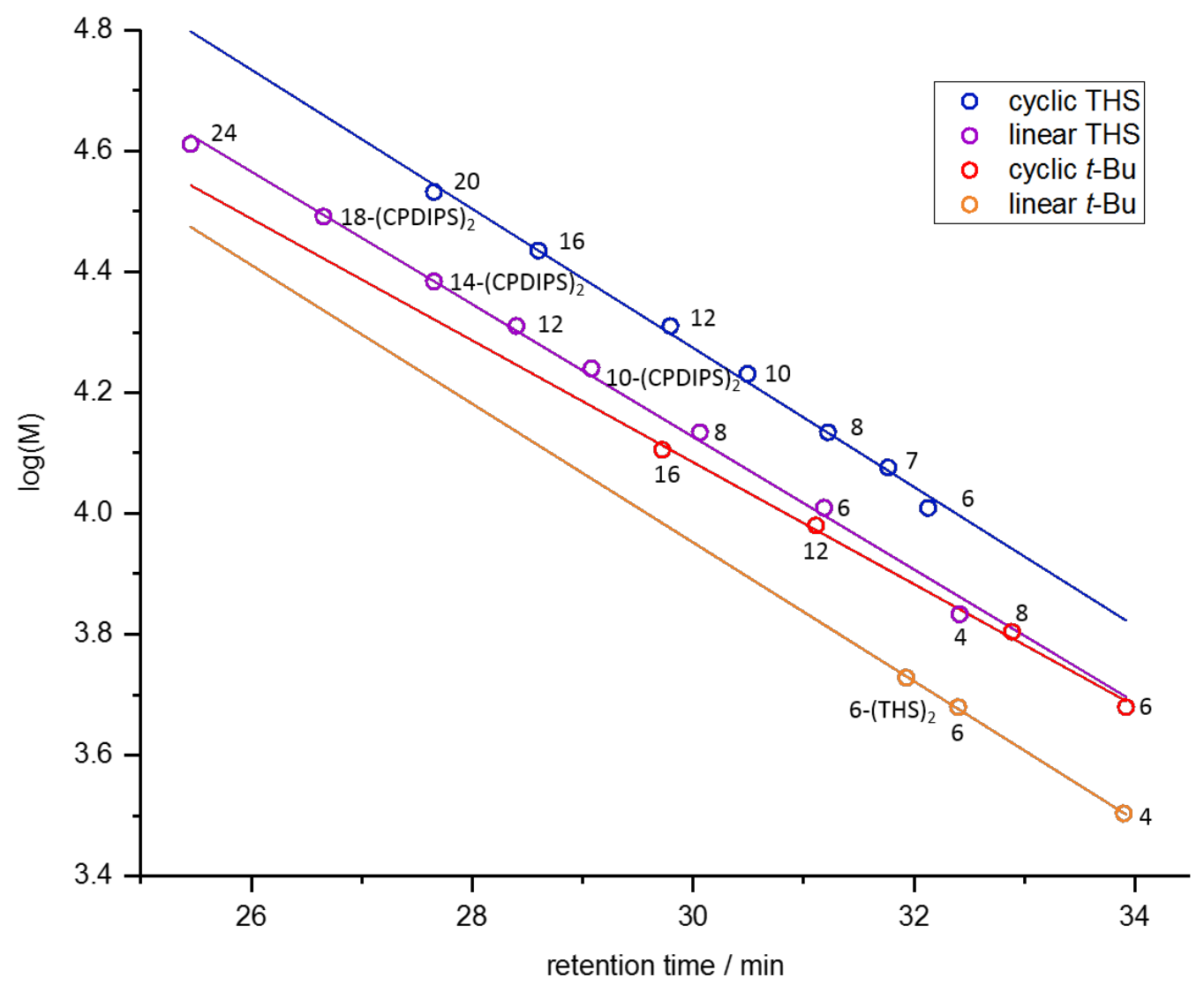

Figure S55. Analytical GPC retention times for THS and $t$-Bu porphyrin oligomers. The GPC retention times were measured using two JIAGEL-H columns in series (3H-A then $4 \mathrm{H}-\mathrm{A})$, with THF:1\% pyridine eluent and a $1 \mathrm{~mL} / \mathrm{min}$ flow rate. The plot shows $\log (M)$ versus retention time, and the lines show linear regression fits for each group of $\operatorname{compounds:} \log (M)=a * R T+b$ where RT is retention time. 


\subsection{Experimental procedures for test reactions}

5.2.1. $\boldsymbol{c}$-P12 Formation Run 1. Stock solutions were prepared for all reagents: $\boldsymbol{l}$-P4 $\mathbf{T}_{\mathrm{THS}}(9.00 \mathrm{mg}, 1.32$ $\mu \mathrm{mol})$ was dissolved in chloroform $(2.0 \mathrm{~mL}) . \boldsymbol{l}$-P4 $\boldsymbol{t}_{\text {-Bu }}(2.96 \mathrm{mg}, 0.929 \mu \mathrm{mol})$ was dissolved in chloroform $(4.0 \mathrm{~mL})$ and pyridine $(200 \mu \mathrm{L})$. T6e $(10.3 \mathrm{mg}, 2.91 \mu \mathrm{mol})$ was dissolved in chloroform (4.0 mL). T6 $(2.06 \mathrm{mg}, 2.07 \mu \mathrm{mol})$ was dissolved in chloroform $(2.0 \mathrm{~mL})$. This gave stock solutions with the concentrations:

$\left[\boldsymbol{l}-\mathbf{P} 4_{\text {THS }}\right]=0.660 \mathrm{mM}$.

$\left[\boldsymbol{l}-\mathbf{P} 4_{t-\mathrm{Bu}}\right]=0.221 \mathrm{mM}$.

$[\mathbf{T 6 e}]=0.728 \mathrm{mM}$.

$[\mathbf{T 6}]=1.03 \mathrm{mM}$.

Then, four reactions were set up:

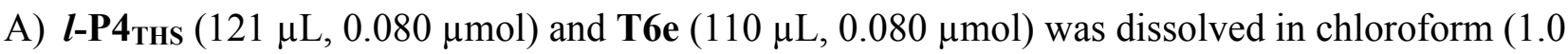
$\mathrm{mL})$, concentrated to dryness, and dried in vacuum. $\mathrm{CDCl}_{3}(370 \mu \mathrm{L})$ and DIPA $(5 \mu \mathrm{L}, 35.7$ $\mu \mathrm{mol})$ was added and everything went in solution.

B) $\boldsymbol{l}$-P4 $\mathbf{T H S}_{\mathrm{TH}}(121 \mu \mathrm{L}, 0.080 \mu \mathrm{mol})$ and $\mathbf{T 6}(78 \mu \mathrm{L}, 0.080 \mu \mathrm{mol})$ was dissolved in chloroform $(1.0$ $\mathrm{mL})$, concentrated to dryness, and dried in vacuum. $\mathrm{CDCl}_{3}(370 \mu \mathrm{L})$ and DIPA $(5 \mu \mathrm{L}, 35.7$ $\mu \mathrm{mol})$ was added and everything went in solution.

C) $\boldsymbol{l}$-P4 $\mathbf{t}_{\text {-Bu }}(362 \mu \mathrm{L}, 0.080 \mu \mathrm{mol})$ and T6e $(110 \mu \mathrm{L}, 0.080 \mu \mathrm{mol})$ was dissolved in chloroform (1.0 $\mathrm{mL})$, concentrated to dryness, and dried in vacuum. $\mathrm{CDCl}_{3}(370 \mu \mathrm{L})$ and DIPA $(5 \mu \mathrm{L}, 35.7$ $\mu \mathrm{mol})$ was added and everything went in solution.

D) $\boldsymbol{l}$-P4 $\mathbf{t}_{\text {-Bu }}(362 \mu \mathrm{L}, 0.080 \mu \mathrm{mol})$ and T6 $(78 \mu \mathrm{L}, 0.080 \mu \mathrm{mol})$ was dissolved in chloroform (1.0 $\mathrm{mL})$, concentrated to dryness, and dried in vacuum. $\mathrm{CDCl}_{3}(370 \mu \mathrm{L})$ and DIPA $(5 \mu \mathrm{L}, 35.7$ $\mu \mathrm{mol})$ was added and everything went in solution.

A catalyst stock solution was then prepared: $\mathrm{Pd}\left(\mathrm{PPh}_{3}\right)_{2} \mathrm{Cl}_{2}(1.73 \mathrm{mg}, 2.46 \mu \mathrm{mol}), \mathrm{CuI}(2.56 \mathrm{mg}, 13.4$ $\mu \mathrm{mol})$, benzoquinone $(4.34 \mathrm{mg}, 40.1 \mu \mathrm{mol})$, DIPA $(400 \mu \mathrm{L}, 2.85 \mathrm{mmol})$ and $\mathrm{CDCl}_{3}(2100 \mu \mathrm{L})$ was mixed and stirred for 10 minutes until everything was dissolved.

To each reaction, $\mathrm{A}-\mathrm{D}, 125 \mu \mathrm{L}$ of catalyst stock solution was added, which means each reaction gets: $\mathrm{Pd}\left(\mathrm{PPh}_{3}\right)_{2} \mathrm{Cl}_{2}(86.5 \mu \mathrm{g}, 0.123 \mu \mathrm{mol}), \mathrm{CuI}(128 \mu \mathrm{g}, 0.670 \mu \mathrm{mol})$, benzoquinone $(217 \mu \mathrm{g}, 2.01 \mu \mathrm{mol})$, DIPA $(20 \mu \mathrm{L}, 143 \mu \mathrm{mol})$ and $\mathrm{CDCl}_{3}(105 \mu \mathrm{L})$.

All reactions A-D were stirred at room temperature. After 24 hours, a portion of THF $1 \%$ pyridine $(5.0$ $\mathrm{mL})$ was added to each of the reactions. The solutions were each filtered through a syringe filter $(0.45$ $\mu \mathrm{m})$ to remove larger particles and then $50 \mu \mathrm{L}$ of each solution were injected onto an analytical GPC column.

In order to find the conversion between integral in the spectrum and actual concentration, $\boldsymbol{l}$-P4 $\mathbf{4}_{\text {THS }}(121$ $\mu \mathrm{L}, 0.080 \mu \mathrm{mol})$ and $\boldsymbol{l}$-P4 $\mathbf{4}_{\text {-Bu }}(362 \mu \mathrm{L}, 0.080 \mu \mathrm{mol})$ were each dissolved in THF $1 \%$ pyridine $(5.0 \mathrm{~mL})$ and filtered through syringe filters, before $50 \mu \mathrm{L}$ of each solution were injected onto the analytical GPC column. 
5.2.2. $\boldsymbol{c}$-P12 Formation Run 2. Stock solutions were prepared for all reagents: $\boldsymbol{l}_{\mathbf{P}} \mathbf{P}_{\mathbf{T H S}}(13.4 \mathrm{mg}, 1.97$ $\mu \mathrm{mol})$ was dissolved in chloroform $(1.0 \mathrm{~mL}) . \boldsymbol{l}$-P4 $\mathbf{t}_{\boldsymbol{t} \text {-Bu }}(3.45 \mathrm{mg}, 1.08 \mu \mathrm{mol})$ was dissolved in chloroform $(2.0 \mathrm{~mL})$ and pyridine $(200 \mu \mathrm{L})$. T6e $(2.66 \mathrm{mg}, 0.750 \mu \mathrm{mol})$ was dissolved in chloroform $(1.0 \mathrm{~mL})$. This gave stock solutions with the concentrations:

$\left[\boldsymbol{l}_{-\mathrm{P4}} \mathrm{THS}\right]=1.96 \mathrm{mM}$.

$\left[\boldsymbol{l}-\mathbf{P} 4_{t-\mathrm{Bu}}\right]=0.492 \mathrm{mM}$.

$[\mathbf{T 6 e}]=0.750 \mathrm{mM}$.

$[\mathbf{T 6}]=1.03 \mathrm{mM}$ (the stock solution from $\boldsymbol{c}$-P12 formation run 1 was used).

Then, four reactions were set up:

A) $\boldsymbol{l}$-P4 $\mathbf{T H S}_{\mathbf{T H S}}(163 \mu \mathrm{L}, 0.32 \mu \mathrm{mol})$ and T6e $(421 \mu \mathrm{L}, 0.32 \mu \mathrm{mol})$ was dissolved in chloroform (1.0 $\mathrm{mL})$, concentrated to dryness, and dried in vacuum. $\mathrm{CDCl}_{3}(1480 \mu \mathrm{L})$ and DIPA $(20 \mu \mathrm{L}, 0.14$ mmol) was added and everything went in solution.

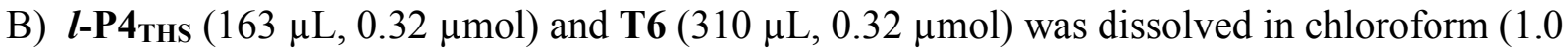
$\mathrm{mL})$, concentrated to dryness, and dried in vacuum. $\mathrm{CDCl}_{3}(1480 \mu \mathrm{L})$ and DIPA $(20 \mu \mathrm{L}, 0.14$ $\mathrm{mmol})$ was added and everything went in solution.

C) $\boldsymbol{l}$-P4 $\mathbf{t}_{\boldsymbol{t} \text {-Bu }}(650 \mu \mathrm{L}, 0.32 \mu \mathrm{mol})$ and T6e $(421 \mu \mathrm{L}, 0.32 \mu \mathrm{mol})$ was dissolved in chloroform $(1.0$ $\mathrm{mL})$, concentrated to dryness, and dried in vacuum. $\mathrm{CDCl}_{3}(1480 \mu \mathrm{L})$ and DIPA $(20 \mu \mathrm{L}, 0.14$ mmol) was added and everything went in solution.

D) $\boldsymbol{l}$-P4 $\mathbf{t}_{\text {-Bu }}(650 \mu \mathrm{L}, 0.32 \mu \mathrm{mol})$ and $\mathbf{T 6}(310 \mu \mathrm{L}, 0.32 \mu \mathrm{mol})$ was dissolved in chloroform (1.0 $\mathrm{mL})$, concentrated to dryness, and dried in vacuum. $\mathrm{CDCl}_{3}(1480 \mu \mathrm{L})$ and DIPA $(20 \mu \mathrm{L}, 0.14$ mmol) was added and everything went in solution.

A catalyst stock solution was then prepared: $\mathrm{Pd}\left(\mathrm{PPh}_{3}\right)_{2} \mathrm{Cl}_{2}(2.80 \mathrm{mg}, 3.99 \mu \mathrm{mol}), \mathrm{CuI}(3.21 \mathrm{mg}, 16.9$ $\mu \mathrm{mol})$, benzoquinone $(4.95 \mathrm{mg}, 45.8 \mu \mathrm{mol})$, DIPA $(400 \mu \mathrm{L}, 2.85 \mathrm{mmol})$ and $\mathrm{CDCl}_{3}(2100 \mu \mathrm{L})$ was mixed and stirred for 10 minutes until everything was dissolved.

To each reaction, A-D, $500 \mu \mathrm{L}$ of catalyst stock solution was added.

All reactions A-D were stirred at room temperature. After 24 hours, $100 \mu \mathrm{L}$ was taken from each reaction mixture and run over a plug of basic alumina $\left(\mathrm{CHCl}_{3}: \mathrm{PE}:\right.$ pyridine $\left.=20: 70: 10\right)$. Reaction mixture $\mathrm{C}$ was also filtered through a silica plug with the same solvent mixture. Then all solvent was removed and the reaction mixtures were dissolved in $1.5 \mathrm{~mL}$ THF $1 \%$ pyridine. The solutions were each filtered through a syringe filter $(0.45 \mu \mathrm{m})$ to remove larger particles and then $50 \mu \mathrm{L}$ of each solution were injected onto an analytical GPC column.

In order to find the conversion between integral in the spectrum and actual concentration, $\boldsymbol{l}-\mathbf{P} \mathbf{4}_{\mathrm{THS}}(10$ $\mu \mathrm{L}, 19.6 \mathrm{nmol})$ and $\boldsymbol{l}$-P4 $\boldsymbol{t}_{\boldsymbol{t} \text {-Bu }}(20 \mu \mathrm{L}, 9.84 \mathrm{nmol})$ were each dissolved in THF $1 \%$ pyridine $(1500 \mu \mathrm{L})$ and filtered through syringe filters, before $50 \mu \mathrm{L}$ of each solution were injected onto the analytical GPC column. 
Another method of calibration was tried to test how reliable the method is. Stock solutions were made of $\boldsymbol{c}$-P12 ${ }_{\text {THS }}\left(3.86 \times 10^{-6} \mathrm{M}\right), \boldsymbol{c}$-P12 $\boldsymbol{t}$-Bu $\left(3.03 \times 10^{-6} \mathrm{M}\right)$ and $\boldsymbol{c}$-P8 $\mathbf{T H S}_{\mathrm{THS}}\left(2.01 \times 10^{-6} \mathrm{M}\right) .50 \mu \mathrm{L}$ was injected onto the GPC from each stock solution to get external standards. The yields measured with these standards were very similar to the ones measured using $\boldsymbol{l}$-P4 as standards. $\boldsymbol{l}$-P4 was chosen as the best option because there is less risk of experimental weighing error if the same stock solution is used for both experiment and calibration.

5.2.3. $\boldsymbol{c}$-P6 Formation Run 1. Stock solutions were prepared for all reagents: $\boldsymbol{l}$-P2 $\mathbf{2}_{\mathrm{THS}}(5.8 \mathrm{mg}, 1.7$ $\mu \mathrm{mol})$ was dissolved in chloroform $(2.0 \mathrm{~mL}) . \boldsymbol{l}-\mathbf{P} \boldsymbol{2}_{\boldsymbol{t} \text {-Bu }}(6.4 \mathrm{mg}, 4.0 \mu \mathrm{mol})$ was dissolved in chloroform $(4.0 \mathrm{~mL})$ and pyridine $(200 \mu \mathrm{L})$. T3 $(4.76 \mathrm{mg}, 8.85 \mu \mathrm{mol})$ was dissolved in chloroform $(5.0 \mathrm{~mL})$. T3N $(4.31 \mathrm{mg}, 7.97 \mu \mathrm{mol})$ was dissolved in chloroform $(5.0 \mathrm{~mL})$. This gave stock solutions with the concentrations:

$\left[\boldsymbol{l}-\mathbf{P} \mathbf{2}_{\mathrm{THS}}\right]=0.851 \mathrm{mM}$.

$\left[\boldsymbol{l}\right.$-P2 $\left.\boldsymbol{t}_{\boldsymbol{t} \text { Bu }}\right]=0.958 \mathrm{mM}$.

$[\mathbf{T 3}]=1.78 \mathrm{mM}$.

$[\mathrm{T3N}]=1.60 \mathrm{mM}$.

$[\mathbf{T 6}]=1.03 \mathrm{mM}$ (the stock solution from $\boldsymbol{c}$-P12 formation run 1 was used).

Then, six reactions were set up:

A) $\boldsymbol{l}$-P2 $\mathbf{2}_{\mathrm{THS}}(188 \mu \mathrm{L}, 0.16 \mu \mathrm{mol})$ and $\mathbf{T 3}(90 \mu \mathrm{L}, 0.16 \mu \mathrm{mol})$ was dissolved in chloroform $(1.0 \mathrm{~mL})$, concentrated to dryness, and dried in vacuum. $\mathrm{CDCl}_{3}(740 \mu \mathrm{L})$ and DIPA $(10 \mu \mathrm{L}, 71.3 \mu \mathrm{mol})$ was added and everything went in solution.

B) $\boldsymbol{l}$-P2 $\mathbf{T H S}_{\text {TH }}(188 \mu \mathrm{L}, 0.16 \mu \mathrm{mol})$ and $\mathbf{T 3 N}(100 \mu \mathrm{L}, 0.16 \mu \mathrm{mol})$ was dissolved in chloroform (1.0 $\mathrm{mL})$, concentrated to dryness, and dried in vacuum. $\mathrm{CDCl}_{3}(740 \mu \mathrm{L})$ and DIPA $(10 \mu \mathrm{L}, 71.3$ $\mu \mathrm{mol})$ was added and everything went in solution.

C) $\boldsymbol{l}$-P2 $\mathbf{T H S}_{\mathbf{T H}}(188 \mu \mathrm{L}, 0.16 \mu \mathrm{mol})$ and T6 $(78 \mu \mathrm{L}, 0.080 \mu \mathrm{mol})$ was dissolved in chloroform (1.0 $\mathrm{mL})$, concentrated to dryness, and dried in vacuum. $\mathrm{CDCl}_{3}(740 \mu \mathrm{L})$ and DIPA $(10 \mu \mathrm{L}, 71.3$ $\mu \mathrm{mol})$ was added and everything went in solution.

D) $\boldsymbol{l}$-P2 $\mathbf{t}_{\boldsymbol{t} \text {-Bu }}(167 \mu \mathrm{L}, 0.16 \mu \mathrm{mol})$ and $\mathbf{T 3}(90 \mu \mathrm{L}, 0.16 \mu \mathrm{mol})$ was dissolved in chloroform $(1.0 \mathrm{~mL})$, concentrated to dryness, and dried in vacuum. $\mathrm{CDCl}_{3}(740 \mu \mathrm{L})$ and DIPA $(10 \mu \mathrm{L}, 71.3 \mu \mathrm{mol})$ was added and everything went in solution.

E) $\boldsymbol{l}$-P2 $\boldsymbol{t}_{\text {-Bu }}(167 \mu \mathrm{L}, 0.080 \mu \mathrm{mol})$ and T3N $(100 \mu \mathrm{L}, 0.16 \mu \mathrm{mol})$ was dissolved in chloroform (1.0 $\mathrm{mL})$, concentrated to dryness, and dried in vacuum. $\mathrm{CDCl}_{3}(740 \mu \mathrm{L})$ and DIPA $(10 \mu \mathrm{L}, 71.3$ $\mu \mathrm{mol})$ was added and everything went in solution.

F) $\boldsymbol{l}$-P2 $\boldsymbol{t}_{\boldsymbol{t} \text {-Bu }}(167 \mu \mathrm{L}, 0.080 \mu \mathrm{mol})$ and $\mathbf{T 6}(78 \mu \mathrm{L}, 0.080 \mu \mathrm{mol})$ was dissolved in chloroform (1.0 $\mathrm{mL})$, concentrated to dryness, and dried in vacuum. $\mathrm{CDCl}_{3}(740 \mu \mathrm{L})$ and DIPA $(10 \mu \mathrm{L}, 71.3$ $\mu \mathrm{mol})$ was added and everything went in solution.

A catalyst stock solution was then prepared: $\mathrm{Pd}\left(\mathrm{PPh}_{3}\right)_{2} \mathrm{Cl}_{2}(1.45 \mathrm{mg}, 2.07 \mu \mathrm{mol}), \mathrm{CuI}(2.78 \mathrm{mg}, 14.6$ $\mu \mathrm{mol})$, benzoquinone $(3.12 \mathrm{mg}, 28.9 \mu \mathrm{mol})$, DIPA $(400 \mu \mathrm{L}, 2.85 \mathrm{mmol})$ and $\mathrm{CDCl}_{3}(2100 \mu \mathrm{L})$ was mixed and stirred for 10 minutes until everything was dissolved. 
To each reaction, A-F, $250 \mu \mathrm{L}$ of catalyst stock solution was added, which means each reaction gets: $\mathrm{Pd}\left(\mathrm{PPh}_{3}\right)_{2} \mathrm{Cl}_{2}(145 \mu \mathrm{g}, 0.207 \mu \mathrm{mol}), \mathrm{CuI}(278 \mu \mathrm{g}, 1.46 \mu \mathrm{mol})$, benzoquinone $(312 \mu \mathrm{g}, 2.89 \mu \mathrm{mol})$, DIPA $(40 \mu \mathrm{L}, 285 \mu \mathrm{mol})$ and $\mathrm{CDCl}_{3}(210 \mu \mathrm{L})$.

All reactions A-F were stirred at room temperature. After 24 hours, another catalyst stock solution was prepared, and $250 \mu \mathrm{L}\left(\mathrm{Pd}\left(\mathrm{PPh}_{3}\right)_{2} \mathrm{Cl}_{2}(145 \mu \mathrm{g}, 0.207 \mu \mathrm{mol}), \mathrm{CuI}(278 \mu \mathrm{g}, 1.46 \mu \mathrm{mol})\right.$, benzoquinone $(312 \mu \mathrm{g}, 2.89 \mu \mathrm{mol})$, DIPA $(40 \mu \mathrm{L}, 285 \mu \mathrm{mol})$ and $\left.\mathrm{CDCl}_{3}(210 \mu \mathrm{L})\right)$ was added to each reaction along with $600 \mu \mathrm{L} \mathrm{CDCl}_{3}$ (in an attempt to dissolve precipitate). After an additional 48 hours, a portion of $100 \mu \mathrm{L}$ was taken from each reaction and mixed with $200 \mu \mathrm{L}$ THF $1 \%$ pyridine. The solutions were each filtered through syringe filters $(0.45 \mu \mathrm{m})$ to remove larger particles and then $99 \mu \mathrm{L}$ of each solution were injected onto an analytical GPC column.

In order to find the conversion between integral in the spectrum and actual concentration, $\boldsymbol{l}$-P $\mathbf{2}_{\text {THS }}(18.8$ $\mu \mathrm{L}, 0.016 \mu \mathrm{mol})$ and $\boldsymbol{l}$-P2 $\boldsymbol{t}_{\boldsymbol{t} \text {-Bu }}(16.7 \mu \mathrm{L}, 0.016 \mu \mathrm{mol})$ were each dissolved in THF $1 \%$ pyridine $(2.0 \mathrm{~mL})$ and filtered through syringe filters, before $99 \mu \mathrm{L}$ of each solution were injected onto the analytical GPC column.

5.2.4. Control Experiment. Stock solutions from $c-P 12$ formation run 1 and $c-P 6$ formation run 1 were used.

$\left[\boldsymbol{l}-\mathbf{P} \mathbf{2}_{\mathrm{THS}}\right]=0.851 \mathrm{mM}$.

$\left[\boldsymbol{l}-\mathbf{P} \boldsymbol{2}_{\boldsymbol{t}-\mathrm{Bu}}\right]=0.958 \mathrm{mM}$.

$\left[l-\mathrm{P} 4_{\mathrm{THS}}\right]=0.660 \mathrm{mM}$.

$\left[\boldsymbol{l}-\mathbf{P} 4_{t-\mathrm{Bu}}\right]=0.221 \mathrm{mM}$.

Then, four reactions were set up:

A) $\boldsymbol{l}$-P2 $\mathrm{THS}(24 \mu \mathrm{L}, 20 \mathrm{nmol})$ was concentrated to dryness. Then $\mathrm{CDCl}_{3}$ with $1.4 \%$ DIPA $(94 \mu \mathrm{L})$ was added and everything went in solution.

B) $\boldsymbol{l}$-P4 $\mathbf{T H S}_{\mathrm{THS}}(30 \mu \mathrm{L}, 20 \mathrm{nmol})$ was concentrated to dryness. Then $\mathrm{CDCl}_{3}$ with $1.4 \% \mathrm{DIPA}(94 \mu \mathrm{L})$ was added and everything went in solution.

C) $\boldsymbol{l}$-P2 $\mathbf{t}_{\text {-Bu }}(21 \mu \mathrm{L}, 20 \mathrm{nmol})$ was concentrated to dryness. Then $\mathrm{CDCl}_{3}$ with $1.4 \%$ DIPA (94 $\left.\mu \mathrm{L}\right)$ was added and everything went in solution.

D) $\boldsymbol{l}$-P4 $\mathbf{t}_{\boldsymbol{t} \text {-Bu }}(90 \mu \mathrm{L}, 20 \mathrm{nmol})$ was concentrated to dryness. Then $\mathrm{CDCl}_{3}$ with $1.4 \%$ DIPA (94 $\left.\mu \mathrm{L}\right)$ was added and everything went in solution.

A catalyst stock solution was then prepared: $\mathrm{Pd}\left(\mathrm{PPh}_{3}\right)_{2} \mathrm{Cl}_{2}(1.40 \mathrm{mg}, 1.99 \mu \mathrm{mol}), \mathrm{CuI}(2.64 \mathrm{mg}, 13.9$ $\mu \mathrm{mol})$, benzoquinone $(3.58 \mathrm{mg}, 33.1 \mu \mathrm{mol})$, DIPA $(400 \mu \mathrm{L}, 2.85 \mathrm{mmol})$ and $\mathrm{CDCl}_{3}(2100 \mu \mathrm{L})$ was mixed and stirred for 10 minutes until everything was dissolved.

To each reaction, $\mathrm{A}-\mathrm{D}, 31 \mu \mathrm{L}$ of catalyst stock solution was added, which means each reaction gets: $\mathrm{Pd}\left(\mathrm{PPh}_{3}\right)_{2} \mathrm{Cl}_{2}(17 \mu \mathrm{g}, 25 \mathrm{nmol}), \mathrm{CuI}(33 \mu \mathrm{g}, 172 \mu \mathrm{mol})$, benzoquinone (44 $\left.\mu \mathrm{g}, 410 \mathrm{nmol}\right)$, DIPA $(5 \mu \mathrm{L}$, $35 \mu \mathrm{mol})$ and $\mathrm{CDCl}_{3}(26 \mu \mathrm{L})$. 
All reactions A-D were stirred at room temperature. After 68 hours, the reactions were stopped by adding $2.0 \mathrm{~mL}$ THF $1 \%$ pyridine to each of the solutions. The solutions were each filtered through syringe filters $(0.45 \mu \mathrm{m})$ to remove larger particles and then $99 \mu \mathrm{L}$ of each solution were injected onto an analytical GPC column.

In order to find the conversion between integral in the spectrum and actual concentration, $\boldsymbol{l}-\mathbf{P} \mathbf{2}_{\mathbf{T H S}}(12$ $\mu \mathrm{L} \mu \mathrm{mol}), \boldsymbol{l}$-P2 $\mathbf{t}_{\text {-Bu }}(11 \mu \mathrm{L}), \boldsymbol{l}$-P4 $\mathbf{T}_{\mathrm{THS}}(15 \mu \mathrm{L})$ and $\boldsymbol{l}$-P4 $\mathbf{4}_{\boldsymbol{t} \text {-Bu }}(35 \mu \mathrm{L})$ were each dissolved in THF $1 \%$ pyridine $(1.0 \mathrm{~mL})$ and filtered through syringe filters, before $50 \mu \mathrm{L}$ of each solution were injected onto the analytical GPC column.

\subsection{Data analysis}

Figure S56 shows part of the UV-vis absorption spectra of selected tert-butyl oligomers plotted as molar absorption coefficient per porphyrin unit. At $466 \mathrm{~nm}$, the absorbance of $\boldsymbol{l}$-P2 and $\boldsymbol{c}$-P6 $\mathbf{T 6}$ is the same, and at $470 \mathrm{~nm}$ the absorbance of $\boldsymbol{l}$-P4 and $\boldsymbol{c}$-P12 is the same.

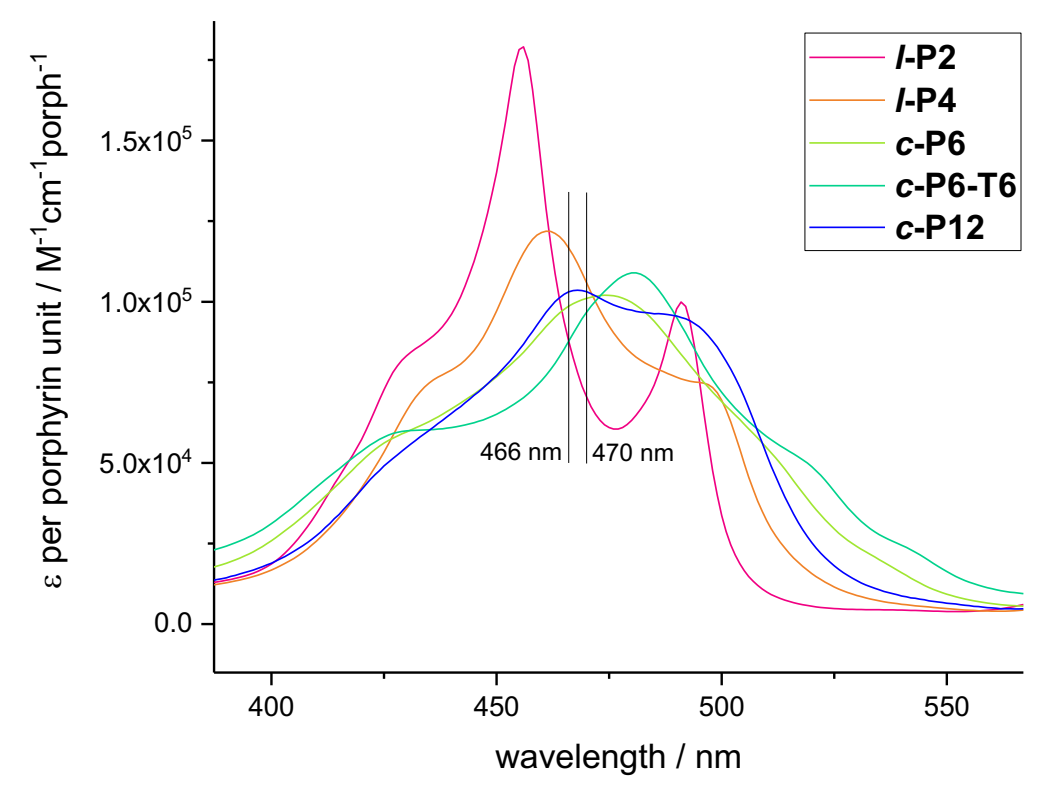

Figure S56. UV-vis spectra of tert-butyl linear and cyclic oligomers reported as the molar extinction coefficient per porphyrin unit. THF $1 \%$ pyridine, $298 \mathrm{~K}$.

The peaks in the UV-vis absorption traces obtained from the analytical GPC of the reaction mixtures were fitted and integrated, and the analytical yield was determined as the percentage of the integral of the corresponding amount of injected starting material (l-P2 or $\boldsymbol{l}$-P4). For reactions starting with $\boldsymbol{l}$-P2, we used the absorption at $466 \mathrm{~nm}$, and for reactions starting with $\boldsymbol{l}$-P4, we used $470 \mathrm{~nm}$. The calibration curve in Section 5.1 was used to identify peaks.

Figure 12 and 13 in the main text show the result of this analysis for $\mathbf{c - P 6}$ formation run 1 and $\boldsymbol{c}$-P12 formation run 1, and Figure S57 shows the result from the control reaction, giving only polymers. Figure S58 shows the traces from $\boldsymbol{c}$-P12 formation run 2, which are very similar to $\boldsymbol{c}$-P12 formation run 1 and show similar yields. The main difference is that the reaction mixtures from $c$-P12 formation run 2 
were filtered through basic alumina, which removes a large part of the longer oligomers and potentially some belonging the integrated signals. Especially $\mathbf{l}-\mathbf{P} \mathbf{4}_{\boldsymbol{t} \text {-Bu }}+\mathbf{T 6 e}$ was filtered through an additional silica plug, which means that the yield might not be directly comparable to the other traces. The yields in the figure are determined using the starting material $\mathbf{l - P 4}$ as external standard, using the same stock solutions as were used for the experiments. The yields in brackets are determined using solutions with known concentrations of the specific products as external standards. The method of using $\boldsymbol{l}$-P4 as a standard was found to be the most reliable and has the advantage of allowing the yields of higher oligomers to be determined as well.

a

I-P2
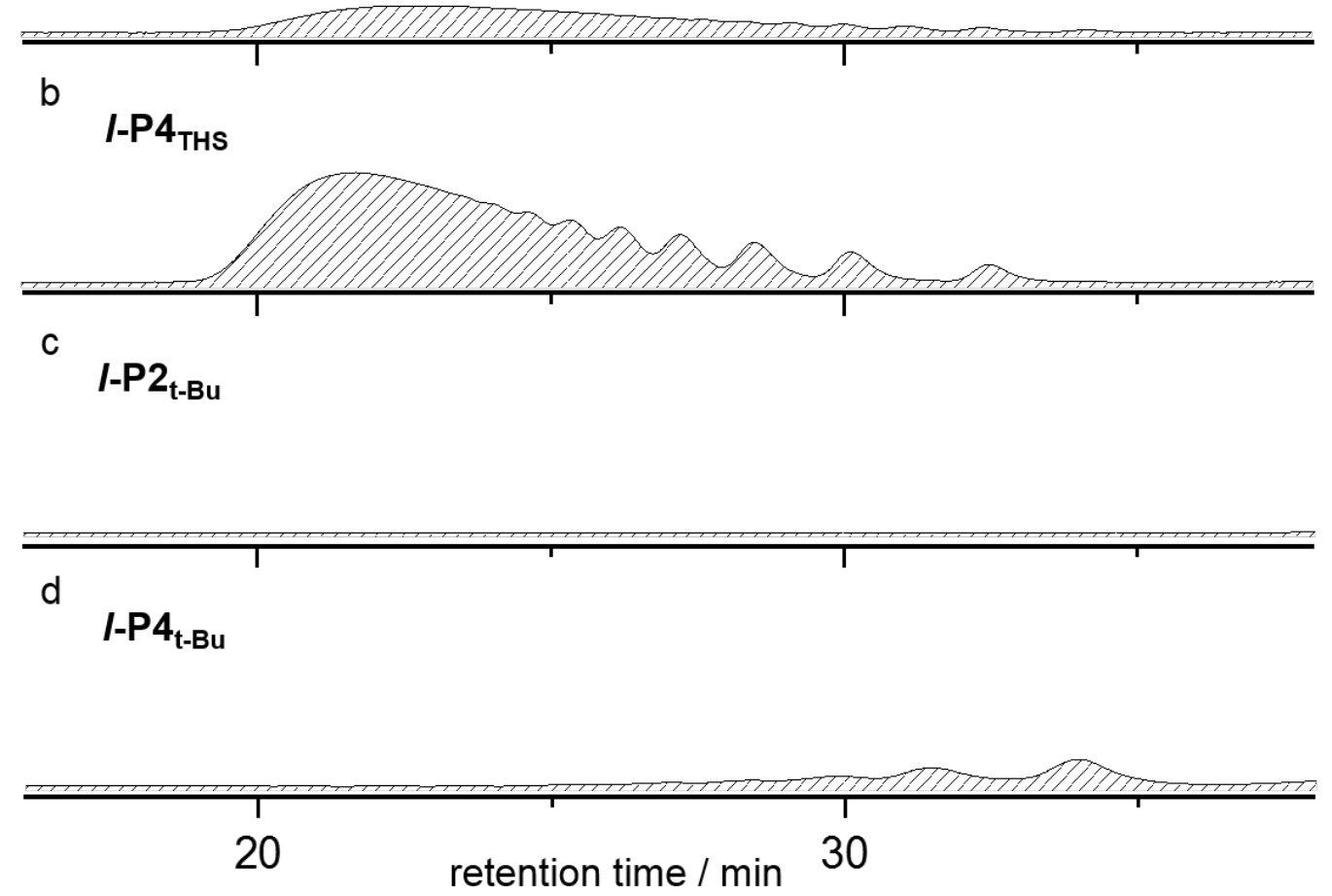

Figure S57. Analytical GPC traces for control reactions, coupling of porphyrin oligomers without any template present. The GPC traces were measured using two JIAGEL-H columns in series (3H-A then $4 \mathrm{H}-\mathrm{A})$, with THF: $1 \%$ pyridine eluent and a 1 $\mathrm{mL} / \mathrm{min}$ flow rate. Traces $a$ and $\mathrm{c}$ show detection at $466 \mathrm{~nm}$, and traces $\mathrm{b}$ and $\mathrm{d}$ show detection at $470 \mathrm{~nm}$. 
a

$I-\mathrm{P}_{\mathrm{THS}}+\mathrm{T} 6 \mathrm{e}$

\section{I-P12}

$20 \% \sqrt{-}-\mathrm{P} 12$

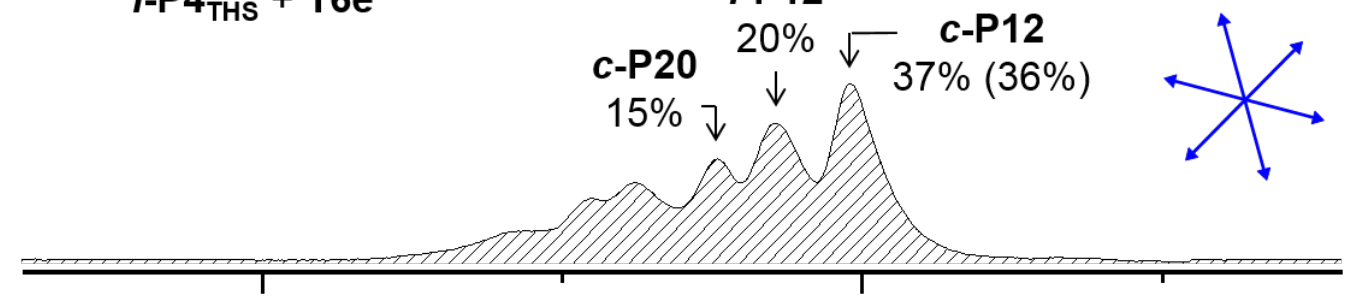

b

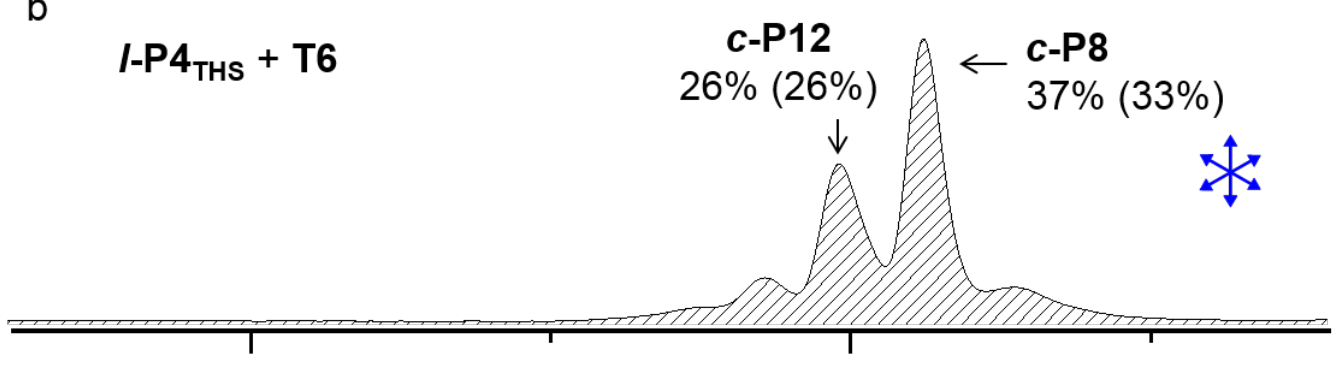

。

$I-P 4_{t-B u}+\mathrm{T} 6 \mathrm{e}$

c-P12
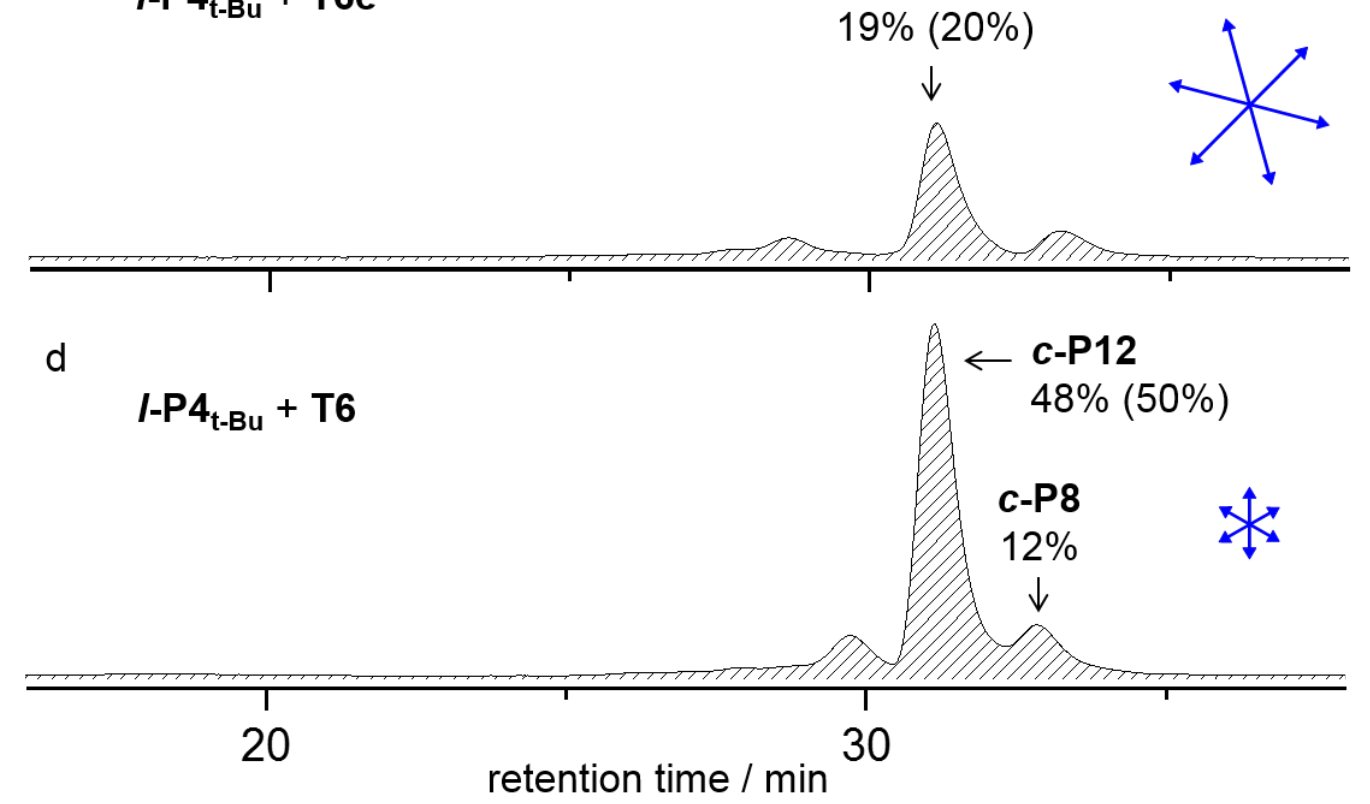

Figure S58. Analytical GPC traces for c-P12 formation run 2, coupling of I-P4 in the presence of T6 and T6e respectively. The GPC traces were measured using two JIAGEL-H columns in series (3H-A then $4 \mathrm{H}-\mathrm{A})$, with THF:1 \% pyridine eluent and a $1 \mathrm{~mL} / \mathrm{min}$ flow rate. All traces show detection at $470 \mathrm{~nm}$. The yields in brackets are determined using solutions with known concentrations of the specific products as external standards. 
Table S11. Summary of yields from stacked template directed synthesis.

\begin{tabular}{|c|c|c|c|c|}
\hline experiment & start oligomer & side chain & template & yields \\
\hline \multirow[t]{4}{*}{ PB-5-39 } & I-P4 & THS & T6e & $\begin{array}{l}\text { c-P12: } 30 \% \\
\text { I-P12: } 11 \% \\
\text { c-P20: } 10 \%\end{array}$ \\
\hline & I-P4 & THS & T6 & $\begin{array}{l}\text { c-P8: } 34 \% \\
\text { c-P12: } 18 \%\end{array}$ \\
\hline & I-P4 & $t-\mathrm{Bu}$ & T6e & $\begin{array}{l}\text { c-P12: } 21 \% \\
\text { c-P24: } 16 \%\end{array}$ \\
\hline & I-P4 & $t-\mathrm{Bu}$ & T6 & $\begin{array}{l}\text { c-P8: } 11 \% \\
\text { c-P12: } 39 \% \\
\text { c-P16: } 12 \%\end{array}$ \\
\hline \multirow[t]{4}{*}{ PB-5-25 } & I-P4 & THS & T6e & $\begin{array}{l}\text { C-P12: } 37 \%(36 \%)^{a} \\
\text { I-P12: } 20 \% \\
\text { C-P20: } 15 \%\end{array}$ \\
\hline & I-P4 & THS & T6 & $\begin{array}{l}\text { c-P8: } 37 \%(33 \%)^{a} \\
\text { c-P12: } 26 \%(26 \%)^{a}\end{array}$ \\
\hline & I-P4 & $t-\mathrm{Bu}$ & T6e & c-P12: $19 \%(20 \%)^{a}$ \\
\hline & I-P4 & $t-\mathrm{Bu}$ & T6 & $\begin{array}{l}\text { c-P8: } 12 \% \\
\text { c-P12: } 48 \%(50 \%)^{a}\end{array}$ \\
\hline \multirow[t]{6}{*}{ PB-5-43 } & I-P2 & THS & T3 & - \\
\hline & I-P2 & THS & T3N & - \\
\hline & I-P2 & THS & T6 & c-P6: $76 \%$ \\
\hline & I-P2 & $t-\mathrm{Bu}$ & T3 & - \\
\hline & I-P2 & $t-\mathrm{Bu}$ & T3N & - \\
\hline & I-P2 & $t-\mathrm{Bu}$ & T6 & c-P6: $63 \%$ \\
\hline \multirow[t]{4}{*}{ PB-5-53 } & I-P2 & THS & - & - \\
\hline & I-P4 & THS & - & - \\
\hline & I-P2 & $t-\mathrm{Bu}$ & - & - \\
\hline & I-P4 & $t-\mathrm{Bu}$ & - & - \\
\hline
\end{tabular}




\section{References}

1. Gaussian 16, Revision A.03, M. J. Frisch, G. W. Trucks, H. B. Schlegel, G. E. Scuseria, M. A. Robb, J. R. Cheeseman, G. Scalmani, V. Barone, G. A. Petersson, H. Nakatsuji, X. Li, M. Caricato, A. V. Marenich, J. Bloino, B. G. Janesko, R. Gomperts, B. Mennucci, H. P. Hratchian, J. V. Ortiz, A. F. Izmaylov, J. L. Sonnenberg, D. Williams-Young, F. Ding, F. Lipparini, F. Egidi, J. Goings, B. Peng, A. Petrone, T. Henderson, D. Ranasinghe, V. G. Zakrzewski, J. Gao, N. Rega, G. Zheng, W. Liang, M. Hada, M. Ehara, K. Toyota, R. Fukuda, J. Hasegawa, M. Ishida, T. Nakajima, Y. Honda, O. Kitao, H. Nakai, T. Vreven, K. Throssell, J. A. Montgomery, Jr., J. E. Peralta, F. Ogliaro, M. J. Bearpark, J. J. Heyd, E. N. Brothers, K. N. Kudin, V. N. Staroverov, T. A. Keith, R. Kobayashi, J. Normand, K. Raghavachari, A. P. Rendell, J. C. Burant, S. S. Iyengar, J. Tomasi, M. Cossi, J. M. Millam, M. Klene, C. Adamo, R. Cammi, J. W. Ochterski, R. L. Martin, K. Morokuma, O. Farkas, J. B. Foresman, and D. J. Fox, Gaussian, Inc., Wallingford CT, 2016.

2. Sprafke, J. K.; Kondratuk, D. V.; Wykes, M.; Thompson, A. L.; Hoffmann, M.; Drevinskas, R.; Chen, W.-H.; Yong, C. K.; Kärnbratt, J.; Bullock, J. E.; Malfois, M.; Wasielewski, M. R.; Albinsson, B.; Herz, L. M.; Zigmantas, D.; Beljonne, D.; Anderson, H. L., Belt-Shaped $\pi$-Systems: Relating Geometry to Electronic Structure in a Six-Porphyrin Nanoring. J. Am. Chem. Soc. 2011, $133,17262-17273$.

3. Tait, C. E. Neuhaus, P. Peeks, M. D. Anderson, H. L. Timmel, C. R. Transient EPR Reveals Triplet State Delocalization in a Series of Cyclic and Linear $\pi$-Conjugated Porphyrin Oligomers. J. Am. Chem. Soc. 2015, 137, 8284-8293.

4. Parkinson, P.; Knappke, C. E. I.; Kamonsutthipaijit, N.; Sirithip, K.; Matichak, J. D.; Anderson, H. L.; Herz, L. M. Ultrafast Energy Transfer in Biomimetic Multistrand Nanorings. J. Am. Chem. Soc. 2014, 136, 8217-8220.

5. Taylor, P. N.; Anderson, H. L. Cooperative Self-Assembly of Double-Strand Conjugated Porphyrin Ladders. J. Am. Chem. Soc. 1999, 121, 11538-11545.

6. Bols, P. S.; Anderson, H. L. Shadow Mask Templates for Site-Selective Metal Exchange in Magnesium Porphyrin Nanorings. Angew. Chem. Int. Ed. 2018, 57, 7874-7877.

7. Hoffmann, M.; Kärnbratt, J.; Chang, M.-H.; Herz, L. M.; Albinsson, B.; Anderson, H. L. Enhanced $\pi$-Conjugation around a Porphyrin[6] Nanoring. Angew. Chem. Int. Ed. 2008, 47, 4993-4996.

8. Rickhaus, M.; Jirasek, M.; Tejerina, L.; Gotfredsen, H.; Peeks, M. D.; Haver, R.; Jiang, H.-W.; Claridge, T. D. W.; Anderson, H. L. Global aromaticity at the nanoscale, Nat. Chem. 2020, 12, 236-241.

9. Inoue, M.; Sasaki, M.; Yashiro, T.; Yutani, K.; Okada, Y.; Kim, S.; Takahashi, H.; Fujimura, K.; Naijo, Y.; Tsuji, K.; Hirano, S.; Sagisaka, T.; Yamamoto, S.; Goto, D.; Takauji, K. Electrochromic compound, electrochromic composition, display element, and dimming element. PCT Int. Appl., 2014208775, 31 Dec 2014. 
10. Fujita, M.; Oka, H.; Ogura, K. Palladium(0)/LiCl promoted cross-coupling reaction of (4pyridyl)stannanes and aromatic bromides: Easy access to poly(4-pyridyl)-substituted aromatics. Tetrahedron Lett. 1995, 36, 5247-5250.

11. Wilcox, C. S.; Adrian, Jr., J. C.; Webb, T. H.; Zawacki, F. J. Approaches to Quantitative Supramolecular Chemistry. Hydrogen-Bond-Based Molecular Recognition Phenomena and Sigmoidal Behavior in Multicomponent Mixtures. J. Am. Chem. Soc., 1992, 114, 10189-10197.

12. Hogben, H. J.; Sprafke, J. K.; Hoffmann, M.; Pawlicki, M.; Anderson, H. L., Stepwise Effective Molarities in Porphyrin Oligomer Complexes: Preorganization Results in Exceptionally Strong Chelate Cooperativity. J. Am. Chem. Soc. 2011, 133, 20962-20969.

13. Rickhaus, M.; Vargas Jentzsch, A.; Tejerina, L.; Gruebner, I.; Jirasek, M.; Claridge, T. D. W.; Anderson, H. L. Single-Acetylene Linked Porphyrin Nanorings. J. Am. Chem. Soc. 2017, 139, $16502-16505$.

14. Thordarson, P. Determining association constants from titration experiments in supramolecular chemistry. Chem. Soc. Rev. 2011, 40, 1305-1323.

15. Benson, S.W. Statistical Factors in the Correlation of Rate Constants and Equilibrium Constants. $J$. Am. Chem. Soc. 1958, 80, 5151-5154.

16. Bailey, W. F.; Monahan, A. S. Statistical Effects and the Evaluation of Entropy Differences in Equilibrium Processes. J. Chem. Ed. 1978, 55, 489-493.

17. Ercolani, G.; Piguet, C.; Borkovec, M.; Hamacek, J. Symmetry Numbers and Statistical Factors in Self-Assembly and Multivalency. J. Phys. Chem. B 2007, 111, 12195-12203.

18. Hunter, C. A.; Anderson, H. L. What is Cooperativity? Angew. Chem. Int. Ed. 2009, 48, 74887499.

19. Haver, R.; Tejerina, L.; Jiang, H.-W.; Rickhaus, M.; Jirasek, M.; Gruebner, I.; Eggimann, H. J.; Herz, L. M.; Anderson, H. L. Tuning the Circumference of Six-Porphyrin Nanorings. J. Am. Chem. Soc. 2019, 141, 7965-7971.

20. (a) Einstein, A. Über die von der molekularkinetischen Theorie der Wärme geforderte Bewegumg von in ruhenden Flüssigkeiten suspendiert Teilchen. Ann. Physik 1905, 17, 549. (b) Edwards, J. T. Molecular Volumes and the Stokes-Einstein Equation. J. Chem. Ed. 1970, 47, 261-270. 